\title{
Evaluation of Cesium, Strontium, and Lead Sorption, Desorption, and Diffusion in Cores from Western Pahute Mesa, Nevada Test Site, Based on Macroscopic and Spectroscopic Investigations
}

\author{
prepared by \\ Charalambos Papelis and Wooyong Um \\ submitted to \\ Nevada Site Office \\ National Nuclear Security Administration \\ U.S. Department of Energy \\ Las Vegas, Nevada
}

MARCH 2003

\section{Publication No. 45187}


Reference herein to any specific commercial product, process, or service by trade name, trademark, manufacturer, or otherwise, does not necessarily constitute or imply its endorsement, recommendation, or favoring by the United States Government or any agency thereof or its contractors or subcontractors. The views and opinions of authors expressed herein do not necessarily state or reflect those of the United States Government or any agency thereof.

This report has been reproduced directly from the best available copy.

Available for sale to the public, in paper, from:

U.S. Department of Commerce

National Technical Information Service

5285 Port Royal Rd.

Springfield, VA 22161

phone: 800.553 .6847

fax: 703.605.6000

email: order@ntis.fedworld.gov

online ordering: http://www.ntis.gov/ordering.htm

Available electronically at http://www.doe.gov/bridge

Available for a processing fee to the U.S. Department of Energy and its contractors, in paper, from:

U.S. Department of Energy

Office of Scientific and Technical Information

P.O. Box 62

Oak Ridge, TN 37831-0062

phone: 423.576 .8401

fax: 423.576.5728

email: reports@adonis.osti.gov 


\title{
Evaluation of Cesium, Strontium, and Lead Sorption, Desorption, and Diffusion in Cores from Western Pahute Mesa, Nevada Test Site, Based on Macroscopic and Spectroscopic Investigations
}

\author{
Prepared by \\ Charalambos Papelis and Wooyong Um \\ Division of Hydrologic Sciences \\ Desert Research Institute \\ University and Community College System of Nevada \\ Publication No. 45187 \\ Submitted to \\ Nevada Site Office \\ National Nuclear Security Administration \\ U.S. Department of Energy \\ Las Vegas, Nevada
}

March 2003

The work upon which this report is based was supported by the U.S. Department of Energy under Contract \#DE-AC0800NV13609. Approved for public release; further dissemination unlimited. 



\section{EXECUTIVE SUMMARY}

The interaction of radionuclides and other contaminants with minerals and other aquifer materials controls the rate of migration of these contaminants in groundwater. The stronger these interactions, the more a radionuclide will be retarded. Processes such as sorption and diffusion often control the migration of inorganic compounds in aquifers. These processes are often controlled by the nature of the ions of interest, the nature of the aquifer materials, and the specific geochemical conditions. Parameters describing sorption and diffusion of radionuclides and other inorganic ions on aquifer materials are used in transport codes to predict the potential for migration of these contaminants into the accessible environment. Sorption and diffusion studies can reduce the uncertainty of radionuclide transport modeling on the Nevada Test Site (NTS) and other nuclear testing areas.

Equilibrium sorption, desorption, and core diffusion experiments were conducted with five different core samples from Western Pahute Mesa (WPM) on the NTS. These cores included samples PM-1 4823, PM-2 4177, UE18R 2228, UE20c 2855, and UE20c 2908. For three of the samples, PM-1 4823, UE18R 2228, and UE20c 2855, a distinction was made between matrix and fracture sub-samples. The samples were characterized based on mineralogy, specific surface area, morphology, density, and porosity. Sample UE18R 2228, a densely welded tuff, was the only sample that had substantially lower porosity and specific surface area compared to the rest. All samples were mainly composed of feldspars and quartz.

Based on sorption data with different solid and metal concentrations, linear sorption isotherms were derived for sorption at $\mathrm{pH} 8.3$, representing a common NTS groundwater $\mathrm{pH}$. Following sorption, desorption experiments were conducted to determine the reversibility of the sorption reactions. Lead was the most reactive metal ion and exhibited strong $\mathrm{pH}$-dependent behavior. Typical $K_{\mathrm{d}} \mathrm{S}$ for $\mathrm{Pb}$ sorption were $1 \times 10^{-3}$ to $5 \times 10^{-3} \mathrm{~m}^{3} / \mathrm{g}$. The sorption of Cs was much less $\mathrm{pH}$-dependent and was overall substantially reduced compared to $\mathrm{Pb}$. Typical $K_{\mathrm{d}} \mathrm{s}$ for $\mathrm{Cs}$ were approximately one order of magnitude less than $\mathrm{Pb} K_{\mathrm{d}} \mathrm{S}\left(1\right.$ to $\left.3 \times 10^{-4} \mathrm{~m}^{3} / \mathrm{g}\right)$. Strontium sorption was almost negligible for all solids, especially at lower concentrations. The minimal $\mathrm{Sr}$ sorption was caused, at least partly, by the substantial amount of Sr already present in the cores. Under these conditions, therefore, $S r$ would be very mobile. In all cases, $K_{\mathrm{d}} \mathrm{s}$ obtained from desorption experiments were higher than the $K_{\mathrm{d}} \mathrm{S}$ obtained from sorption experiments, typically by a factor of 2 to 10 .

Diffusion experiments with the entire core were conducted with a nonreactive tracer, bromide, before experiments with the reactive tracers, $\mathrm{Pb}, \mathrm{Cs}$, and $\mathrm{Sr}$. Based on the bromide diffusion experiments, effective diffusivities and tortuosities were estimated. The effective diffusivities appeared to be directly correlated to sample porosity. The lowest tortuosity, 8.94, was observed for sample PM-1 4823 Matrix, while the highest tortuosity, 4526, was observed for the low-porosity, densely welded tuff sample. Diffusion experiments with the reactive tracers $\mathrm{Pb}$, $\mathrm{Cs}$, and $\mathrm{Sr}$ were performed simultaneously with all cores. These experiments were interpreted by the time-lag method and resulted in estimation of overall apparent diffusivities. Based on the diffusion experiments, Sr retardation was very limited, in some cases barely above 1 . The retardation factors for Cs were substantially higher and ranged from approximately 10 to 30 . The retardation factors that were calculated from the $K_{\mathrm{d}} \mathrm{s}$ derived from the equilibrium experiments with powders were one to two orders of magnitude higher. No retardation factors for $\mathrm{Pb}$ could be calculated from the core diffusion experiments, because no Pb breakthrough was observed in any of the samples. 
The elemental surface composition, determined by x-ray photoelectron spectroscopy (XPS), was consistent with the known sample mineralogy. The binding energies for $\mathrm{Cs}, \mathrm{Pb}$, and $\mathrm{Sr}$ were consistent with the expected coordination environment of these metals under these conditions. The surface coverage of adsorbents by $\mathrm{Cs}, \mathrm{Pb}$, and $\mathrm{Sr}$, independently determined by XPS measurements following the sorption and diffusion experiments, were compared to estimates from macroscopic uptake experiments. The XPS measurements of surface coverage agreed well with the estimates from sorption experiments, except for the UE18R 2228 sample. Lead surface coverage ranged from 9 to 21 percent of a monolayer, thereby accounting for the high retardation factor.

These experiments clearly show the difference in degree of interaction between different metal ions with different aquifer materials. The spectroscopic experiments allowed distinction between different possible sorption mechanisms and helped explained observations from macroscopic sorption experiments. Finally, this work showed the significance of aquifer material properties on the observed radionuclide transport behavior and the importance of a combination of studies to reduce transport modeling uncertainties.

\section{ACKNOWLEDGEMENTS}

This work could not have been completed without the dedicated and careful experimental work of Rebekah Harris, Christine Riland, Greg Schmett, and Loyd West. Support for this work was provided by the U.S. Department of Energy under Contract \#DE-AC08-00NV13609. The continued support of Robert Bangerter is greatly appreciated. The comments of Tim Rose, Carol Bruton, Mavrik Zavarin, Janet Wille, and Dave Finnegan improved the report and are gratefully acknowledged. 


\section{TABLE OF CONTENTS}

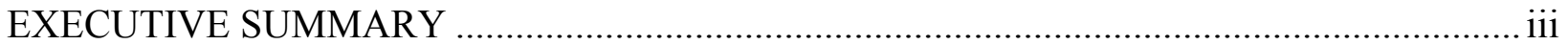

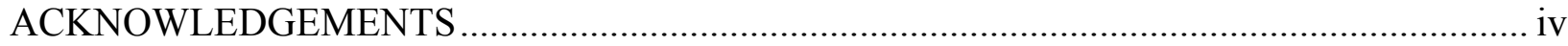

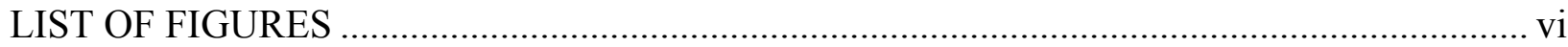

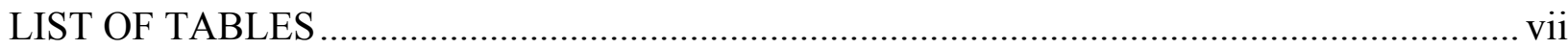

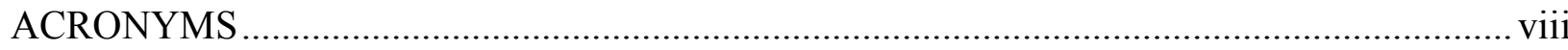

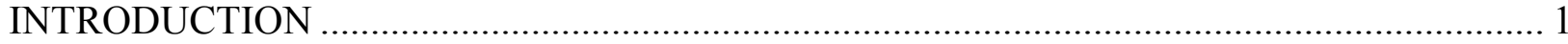

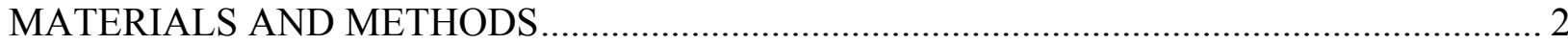

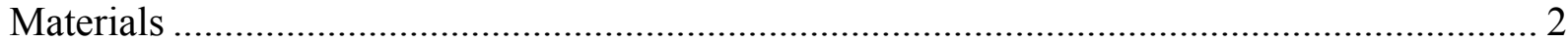

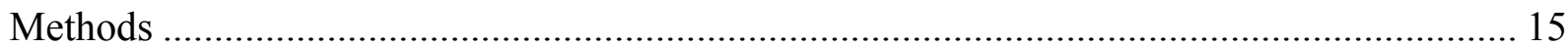

Batch Sorption/Desorption Equilibrium Experiments ....................................................... 15

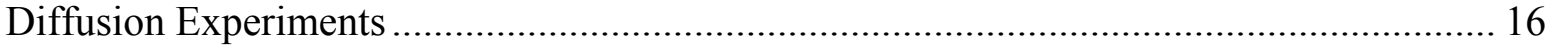

X-ray Photoelectron Spectroscopy (XPS),..................................................................... 19

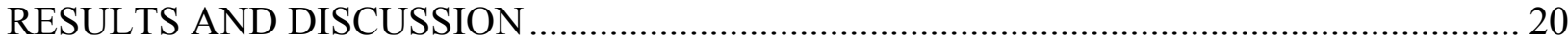

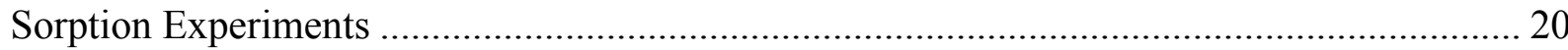

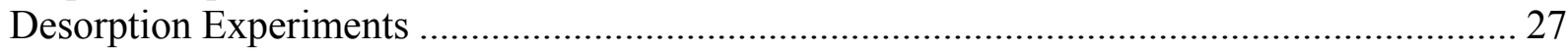

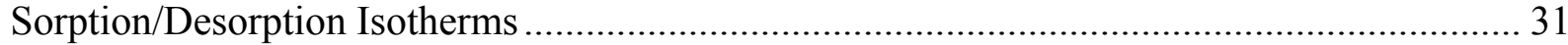

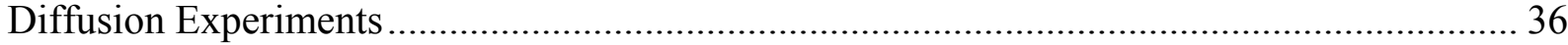

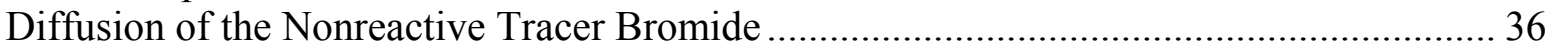

Diffusion of the Reactive Tracers Cesium, Lead, and Strontium ....................................... 38

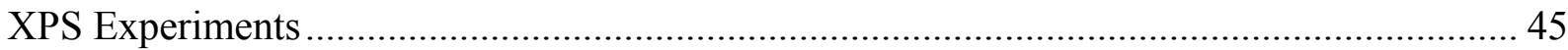

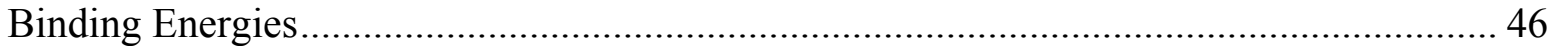

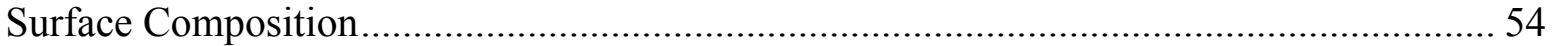

Estimation of Sorbent Surface Coverage by Cesium, Lead, and Strontium ......................... 58

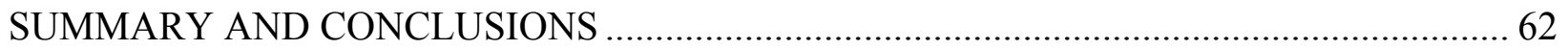

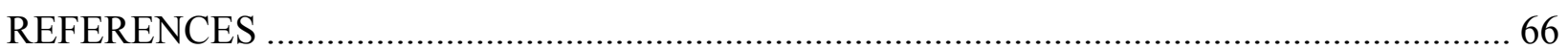




\section{LIST OF FIGURES}

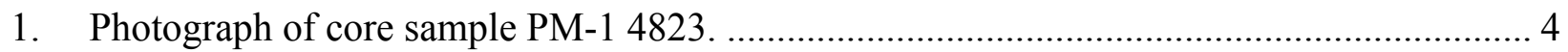

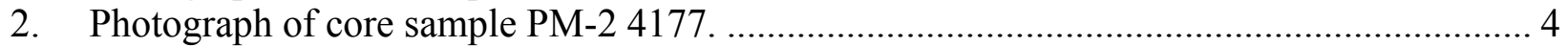

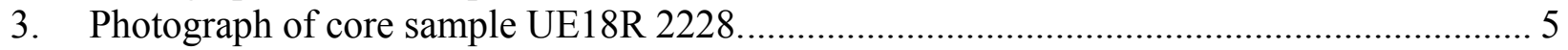

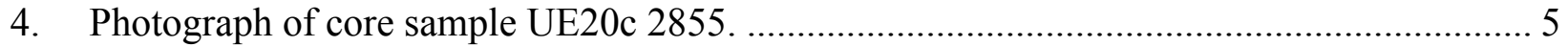

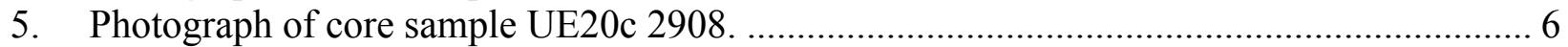

6. Scanning electron micrographs and EDX spectrum of sample PM-1 4823 (Matrix);

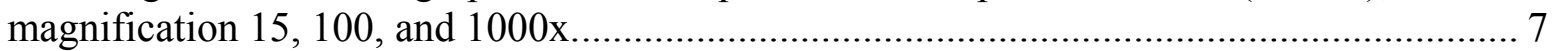

7. Scanning electron micrographs and EDX spectrum of sample PM-1 4823 (Fracture);

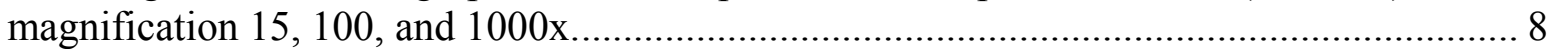

8. Scanning electron micrographs and EDX spectrum of sample PM-2 4177; magnification 15 and 100x.......................................................................................... 9

9. Scanning electron micrographs and EDX spectrum of sample UE18R 2228 (Matrix);

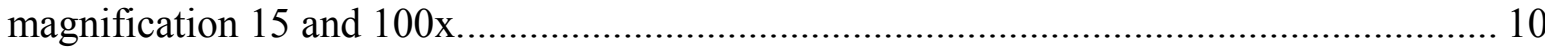

10. Scanning electron micrographs and EDX spectrum of sample UE18R 2228 (Fracture);

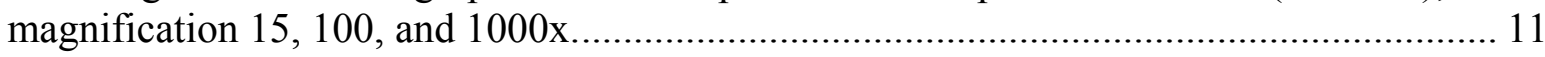

11. Scanning electron micrographs and EDX spectrum of sample UE20c 2855 (Matrix);

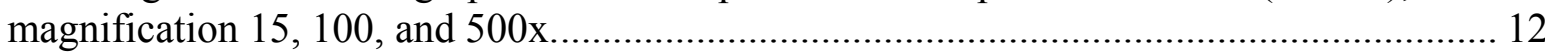

12. Scanning electron micrographs and EDX spectrum of sample UE20c 2855 (Fracture);

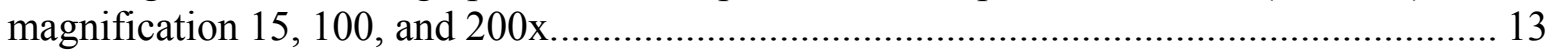

13. Scanning electron micrographs and EDX spectrum of sample UE20c 2908;

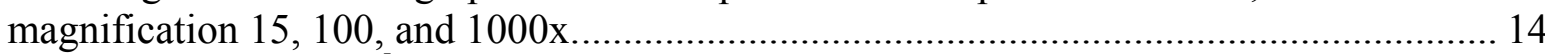

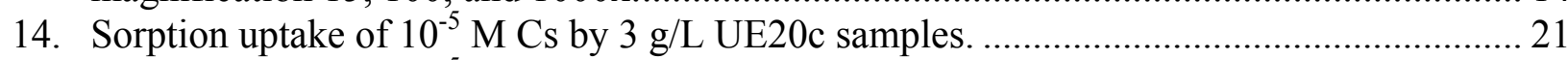

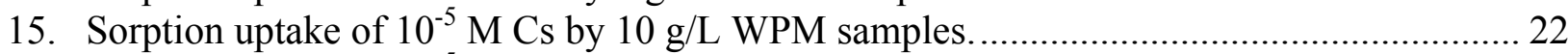

16. Sorption uptake of $10^{-5} \mathrm{M}$ Cs by $10 \mathrm{~g} / \mathrm{L}$ matrix and fracture samples................................... 22

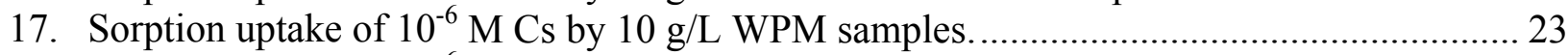

18. Sorption uptake of $10^{-6} \mathrm{M}$ Cs by $10 \mathrm{~g} / \mathrm{L}$ matrix and fracture samples.................................. 24

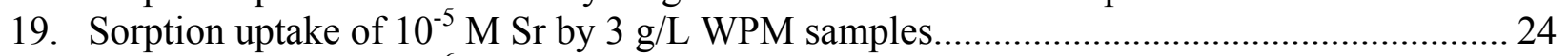

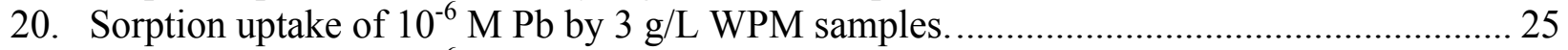

21. Sorption uptake of $10^{-6} \mathrm{M} \mathrm{Pb}$ by $3 \mathrm{~g} / \mathrm{L}$ matrix and fracture samples.................................... 26

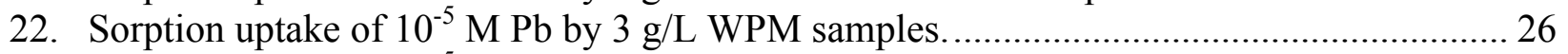

23. Sorption uptake of $10^{-5} \mathrm{M} \mathrm{Pb}$ by $3 \mathrm{~g} / \mathrm{L}$ matrix and fracture samples.................................. 27

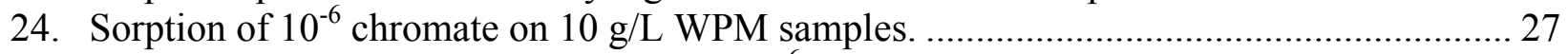

25. Percent Cs release following sorption of $10^{-6} \mathrm{M}$ Cs on $10 \mathrm{~g} / \mathrm{L}$ WPM samples..................... 28

26. Percent $\mathrm{Cs}$ release following sorption of $10^{-6} \mathrm{M} \mathrm{Cs}$ on $10 \mathrm{~g} / \mathrm{L}$ matrix and fracture samples. 29

27. Percent Cs release following sorption of $10^{-5} \mathrm{M}$ Cs on $10 \mathrm{~g} / \mathrm{L}$ WPM samples.

28. Percent $\mathrm{Cs}$ release following sorption of $10^{-5} \mathrm{M} \mathrm{Cs}$ on $10 \mathrm{~g} / \mathrm{L}$ matrix and fracture samples. 30

29. Percent $\mathrm{Pb}$ release following sorption of $10^{-5} \mathrm{M} \mathrm{Pb}$ on $3 \mathrm{~g} / \mathrm{L}$ WPM samples.

30. Percent $\mathrm{Pb}$ release following sorption of $10^{-5} \mathrm{M} \mathrm{Pb}$ on $3 \mathrm{~g} / \mathrm{L}$ matrix and fracture samples. 31

31. Linear sorption and desorption Cs isotherms for WPM samples.

32. Linear sorption and desorption Cs isotherms for UE18R 2228 matrix and fracture samples. 33

33. Linear sorption and desorption Cs isotherms for WPM samples. 
34. Linear sorption and desorption $\mathrm{Pb}$ isotherms for WPM samples.

35. Linear sorption and desorption Pb isotherms for UE18R 2228 matrix and fracture samples. 34

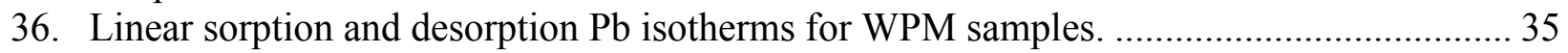

37. Bromide diffusion in WPM cores; duration of experiment: 60 days............................... 36

38. Bromide diffusion in WPM cores; duration of experiment: 140 days.............................. 37

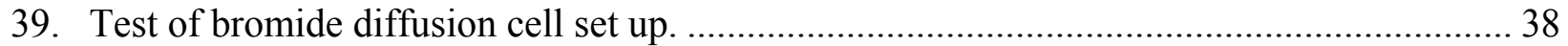

40. Flux of $\mathrm{Sr}, \mathrm{Cs}$, and $\mathrm{Pb}$ through UE20c 2908 matrix core as a function of time. ................. 40

41. Flux of $\mathrm{Sr}, \mathrm{Cs}$, and $\mathrm{Pb}$ through UE20c 2855 matrix core as a function of time. ................. 40

42. Flux of $\mathrm{Sr}, \mathrm{Cs}$, and $\mathrm{Pb}$ through PM-1 4823 and UE18R 2228 matrix core as a function of time.

43. Flux of $\mathrm{Sr}, \mathrm{Cs}$, and $\mathrm{Pb}$ through PM-1 4823 and UE18R 2228 matrix core as a function of time.

44. Flux of $\mathrm{Sr}, \mathrm{Cs}$, and $\mathrm{Pb}$ through PM-1 4823 and UE18R 2228 fracture core as a function of time.

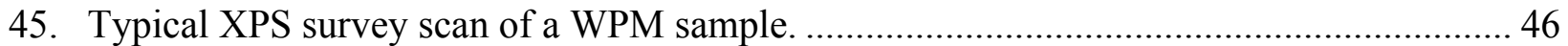

46. Typical Al 2p x-ray photoelectron spectrum in a WPM sample. ..................................... 49

47. Typical Si 2p x-ray photoelectron spectrum in a WPM sample. ....................................... 49

48. Typical O 1s x-ray photoelectron spectrum in a WPM sample........................................ 50

49. Typical $\mathrm{Na} 1 \mathrm{~s} x$-ray photoelectron spectrum in a WPM sample. .................................... 51

50. Typical K 2p x-ray photoelectron spectrum in a WPM sample......................................5 51

51. Typical Ca 2p x-ray photoelectron spectrum in a WPM sample...................................... 52

52. Typical Fe 2p x-ray photoelectron spectrum in a WPM sample. ...................................... 53

53. Typical Sr 3d x-ray photoelectron spectrum in a WPM sample...................................... 53

54. Typical Cs 3d x-ray photoelectron spectrum in a WPM sample. .................................... 54

55. Typical $\mathrm{Pb} 4 \mathrm{f} \mathrm{x}$-ray photoelectron spectrum in a WPM sample...................................... 55

\section{LIST OF TABLES}

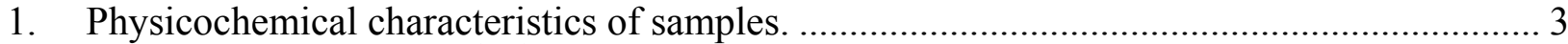

2. Specific surface area $\left(\mathrm{m}^{2} \mathrm{~g}^{-1}\right)$ measurements for the WPM material.................................... 3

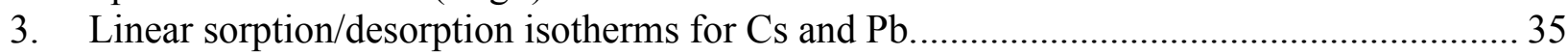

4. Diffusion coefficients of $\mathrm{Br}$ and calculated tortuosity ................................................. 38

5. Diffusion coefficients of $\mathrm{Sr}$ and calculated transport parameters .................................. 39

6. Diffusion coefficients of $\mathrm{Cs}$ and calculated transport parameters ................................. 43

7. Diffusion coefficients of $\mathrm{Pb}$ and calculated transport parameters ................................... 44

8. Chemical shifts and binding energies $(\mathrm{eV})$ of major elements in core and powder

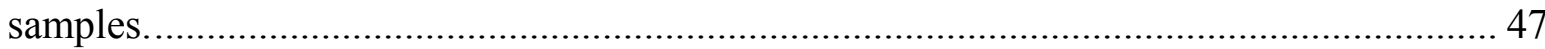

9. Atomic composition of core and powder samples................................................ 56

10. Comparison of percent monolayer coverage of WPM powders as determined by total lead uptake and XPS.

11. Comparison of percent monolayer coverage of WPM powders as determined by total cesium uptake and XPS.

12. Comparison of percent monolayer coverage of UE18R 2228 powders as determined by total strontium uptake and XPS.

13. Percent monolayer coverage of WPM cores by $\mathrm{Pb}, \mathrm{Cs}$, and $\mathrm{Sr}$, as determined by XPS. ..... 61 


\section{ACRONYMS}

$\begin{array}{ll}\text { AA } & \text { atomic adsorption } \\ \text { BE } & \text { binding energy } \\ \text { DOE } & \text { U.S. Department of Energy } \\ \text { EDX } & \text { energy dispersion x-ray } \\ \text { LANL } & \text { Los Alamos National Laboratory } \\ \text { NTS } & \text { Nevada Test Site } \\ \text { SEM } & \text { scanning electron microscope } \\ \text { WPM } & \text { Western Pahute Mesa } \\ \text { XPS } & \text { x-ray photoelectron spectroscopy } \\ \text { XRD } & \text { x-ray diffraction }\end{array}$




\section{INTRODUCTION}

The potential release of radionuclides and toxic metals from the U.S. Department of Energy's Nevada Test Site (NTS) may pose environmental problems to adjacent areas. Because several hundreds of nuclear weapon tests were conducted near or below the groundwater table on the NTS, radionuclides and heavy metals released might be transported by groundwater flow through porous materials or fractures. Although diffusion seems to play a minor role in relatively fast solute transport in fractured aquifers, there are indications that matrix diffusion is an essential mechanism both in retarding the migration and reducing the concentration of dissolved radionuclides and metal contaminants (Neretnieks, 1980; Hölttä et al., 1996).

Matrix diffusion in fractured media and dual-porosity porous materials occurs as a result of concentration gradients between mobile water in the fractures or interparticle pores and immobile water in the matrix of fractured rock or intraparticle pores (Hoag et al., 1997). Because intraparticle and dead-end pores are known to exist in most rock materials even in dense crystalline rock such as granite, the migration of nonreactive solutes can be retarded by dilution due to matrix diffusion of solutes into the stagnant water in dead-end pores (Neretnieks, 1980; Hoag and Price, 1997). For reactive solutes, sorption reactions may take place in both the surfaces of fractures and the surfaces of intraparticle pores in the matrix following diffusion into the immobile water, resulting in an increase of retardation.

Sorption is also an important physicochemical process at mineral-water interfaces controlling the transport of contaminants in the subsurface environment. Because a stronger sorption affinity for aquifer materials results in increased retardation, it is important to understand the sorption behavior of individual radionuclides or toxic metals on specific aquifer materials to better predict contaminant transport. In addition, the desorption behavior of radionuclides and other contaminants is significant in considering the reversibility of sorption. Because of its simplicity, equilibrium distribution coefficients $\left(\mathrm{K}_{\mathrm{d}}\right)$ are widely used to model ion partitioning at mineral-water interfaces. The assumption of reversible sorption is often valid in the case of organic contaminants, but it is not always true for inorganic contaminants, such as radionuclides, where sorption may not be completely reversible. Understanding the sorption/desorption behavior of radionuclides and metals is required to determine the reversibility of sorption and the mobility of contaminants of concern on the NTS.

In this study, sorption/desorption and diffusion experiments were conducted with Western Pahute Mesa (WPM) aquifer materials. Cations including lead (Pb), strontium (Sr), and cesium (Cs) and the anions chromate and bromide were used. Strontium and Cs were used because the radioisotopes of these cations are very common in nuclear test sites. Lead was expected to bind stronger than $\mathrm{Cs}$ or $\mathrm{Sr}$ on these surfaces. Radionuclides such as plutonium are thought to bind even stronger than $\mathrm{Pb}$; Pb sorption, therefore, could be used as a conservative estimate for the migration of plutonium or other strongly binding cations. Chromate was used as a surrogate for the weakly binding anionic radionuclide pertechnetate and bromide was used as a conservative tracer. Some of WPM materials were further subdivided into fracture surface and matrix sub-samples. Secondary mineral coatings with Fe or Mn oxides were visible in the fracture surfaces and they were used to test if mineral coatings at the fracture surfaces controlled the effects of sorption/desorption and diffusion on the fate and transport of radionuclides or inorganic metal contaminants. Because the fracture surfaces had been in contact with flowing groundwater, surface coatings must have resulted from weathering or alteration of the aquifer materials, or precipitation or recrystallization from the groundwater solution (Skagius and 
Neretnieks, 1986). Sorption/desorption reactions, diffusivities of metals, and reactive surface characterization in both fracture surfaces and matrix were estimated by macroscopic sorption/desorption and diffusion cell experiments and x-ray photoelectron spectroscopy (XPS).

Different sorption mechanisms of reactive solutes at the surface of both fracture and matrix were identified using XPS. These mechanisms included either surface precipitation or surface complexation/ion exchange. XPS is a surface sensitive technique that is used to examine the composition of the outmost layers of mineral surfaces (Hochella, 1988; Biino and Gröning, 1998). Several introductory papers to the XPS technique and applications are available (Jean and Bancroft, 1985; Hochella, 1988, 1990; Paterson and Swaffield, 1994; Papelis, 1995). Because XPS can measure only the top surface layers of the adsorbents, surface precipitates resulting in an increase of average adsorbed layer thickness on the external surface of the particles could be differentiated from the uniform coverage of the entire particle surface by intraparticle diffusion followed by adsorption (Papelis, 1995). Based on differences in surface coverage of particle surfaces by reactive solutes, XPS was expected to allow differentiation between different sorption mechanisms (e.g., sorption controlled by intraparticle diffusion and surface precipitation) of $\mathrm{Pb}, \mathrm{Sr}$, and $\mathrm{Cs}$ sorption on fracture surfaces and matrix.

Combining macroscopic sorption and diffusive behavior with spectroscopic information that can be used to distinguish between different sorption mechanisms provides valuable complementary information for predicting the fate and transport of radionuclides and heavy metals in the saturated zone at the NTS. The ultimate goal of these sorption/desorption, diffusion, and spectroscopic studies was to decrease the uncertainty of modeling radionuclide migration in the NTS.

\section{MATERIALS AND METHODS}

\section{Materials}

A total of five core samples from WPM at the NTS were used in this study. These cores included samples PM-1 4823, PM-2 4177, UE18R 2228, UE20c 2855, and UE20c 2908. Samples PM-1 4823, UE18R 2228, and UE20c 2855 included visible fracture surfaces with coatings, so an attempt was made to separate the part of the core that includes the fracture surface from the rest of the core, using a rock saw, resulting in "fracture" and "matrix" samples for the three samples PM-1 4823, UE18R 2228, and UE20c 2855. A total of eight samples were therefore produced, PM-1 4823 Matrix, PM-1 4823 Fracture, PM-2 4177, UE18R 2228 Matrix, UE18R 2228 Fracture, UE20c 2855 Matrix, UE20c 2855 Fracture, and UE20c 2908. Core samples were crushed, ground, and separated into different sizes using sieves. The physicochemical characteristics of the samples are shown in Table 1.

The mineralogy of the sorbents was previously determined by quantitative x-ray diffraction (XRD) at the Los Alamos National Laboratory (LANL). Dark colored coatings were visible at fracture surfaces and identified as Fe or Mn oxide coatings by energy dispersive X-ray (EDX) and XPS. Based on the EDX and XPS results, variable amounts of Fe and Mn were present in the different samples. The specific surface area and the pore size distribution of different size fractions were estimated using a Micromeritics ASAP 2010 surface area analyzer and the BET-nitrogen adsorption method (Brunauer et al., 1938). Two samples (UE 18R 2228

Fracture and Matrix) had substantially lower surface area compared to the rest of the samples. In general, although the specific surface area tended to decrease with increasing particle size, the surface area dependence on particle size was relatively minor, suggesting the presence of 
accessible internal surface area. The specific surface areas of particles with different sizes are shown in Table 2. The surface morphology of core samples was investigated by scanning electron microscopy (SEM) using a JEOL JSM-840A SEM and elemental composition was determined using an EDX attachment. Pictures of the cores are shown in Figures 1 through 5 and scanning electron micrographs and EDX spectra are shown in Figures 6 through 13.

Table 1. Physicochemical characteristics of samples.

\begin{tabular}{|c|c|c|c|}
\hline Core Samples & Porosity (\%) & XRD Results & General Description \\
\hline UE18R 2228 Matrix & 3.65 & $\begin{array}{l}\text { quartz }(28 \%) ; \text { feldspar }(66 \%) ; \\
\text { smectite }(1 \%) \text {; cristobalite }(2 \%) \text {; } \\
\text { mica( } 3 \%) ; \text { hematite }(1 \%)\end{array}$ & $\begin{array}{l}\text { densely welded tuff; Timber Mt. } \\
\text { aquifer }\end{array}$ \\
\hline UE18R 2228 Fracture & 2.0 & same as above & same as above \\
\hline UE20C 2908 & 28.8 & $\begin{array}{l}\text { quartz( } 37 \%) \text {; feldspar(57\%); } \\
\text { smectite }(2 \%)\end{array}$ & $\begin{array}{l}\text { devitrified moderately welded tuff; } \\
\text { Topopah spring aquifer }\end{array}$ \\
\hline UE20C 2855 Matrix & 15.0 & $\begin{array}{l}\text { quartz(34\%); feldspar( } 65 \%) ; \\
\text { smectite }(1 \%) ; \operatorname{mica}(1 \%) ; \\
\text { hematite(1\%) }\end{array}$ & same as above \\
\hline UE20C 2855 Fracture & 14.8 & same as above & same as above \\
\hline PM-1 4823 Matrix & 26.3 & $\begin{array}{l}\text { quartz(39\%); feldspar(55\%); } \\
\text { smectite(5\%); kaolinite(1\%) }\end{array}$ & $\begin{array}{l}\text { Quartzofeldspathic altered non- } \\
\text { welded tuff; Bullfrog tuff }\end{array}$ \\
\hline PM-1 4823 Fracture & 28.0 & same as above & same as above \\
\hline PM-2 4177 & 13.0 & $\begin{array}{l}\text { quartz }(30 \%) \text {; feldspar( } 50 \%) \text {; } \\
\text { smectite }(2 \%) \text {; kaolinite }(3 \%) \text {; } \\
\text { mica }(7 \%) ; \text { hematite }(3 \%) \text {; } \\
\text { calcite }(5 \%)\end{array}$ & devitrified lava \\
\hline
\end{tabular}

Table 2. Specific surface area $\left(\mathrm{m}^{2} \mathrm{~g}^{-1}\right)$ measurements for the WPM material.

\begin{tabular}{lllcl}
\hline Core Samples & $<44 \mu \mathrm{m}$ & $44 \mu \mathrm{m}$ to $149 \mu \mathrm{m}$ & $149 \mu \mathrm{m}$ to $500 \mu \mathrm{m}$ & $500 \mu \mathrm{m}$ to $1 \mathrm{~cm}$ \\
\hline UE18R 2228 Fracture & 1.848 & 0.9996 & 0.9669 & 0.9388 \\
UE18R 2228 Matrix & 1.822 & 1.147 & 0.8089 & 0.5007 \\
UE20C 2908 & 5.548 & 5.246 & 5.220 & 4.959 \\
UE20C 2855 Matrix & 4.704 & 3.759 & 3.450 & 3.988 \\
UE20C 2855 Fracture & 3.612 & 3.259 & 3.659 & 3.195 \\
PM-1 4823 Matrix & 6.725 & 5.652 & 5.761 & 5.543 \\
PM-1 4823 Fracture & 5.882 & 4.987 & 4.697 & 4.534 \\
PM-2 4177 & 4.961 & 4.707 & 3.727 & 3.432 \\
\hline
\end{tabular}




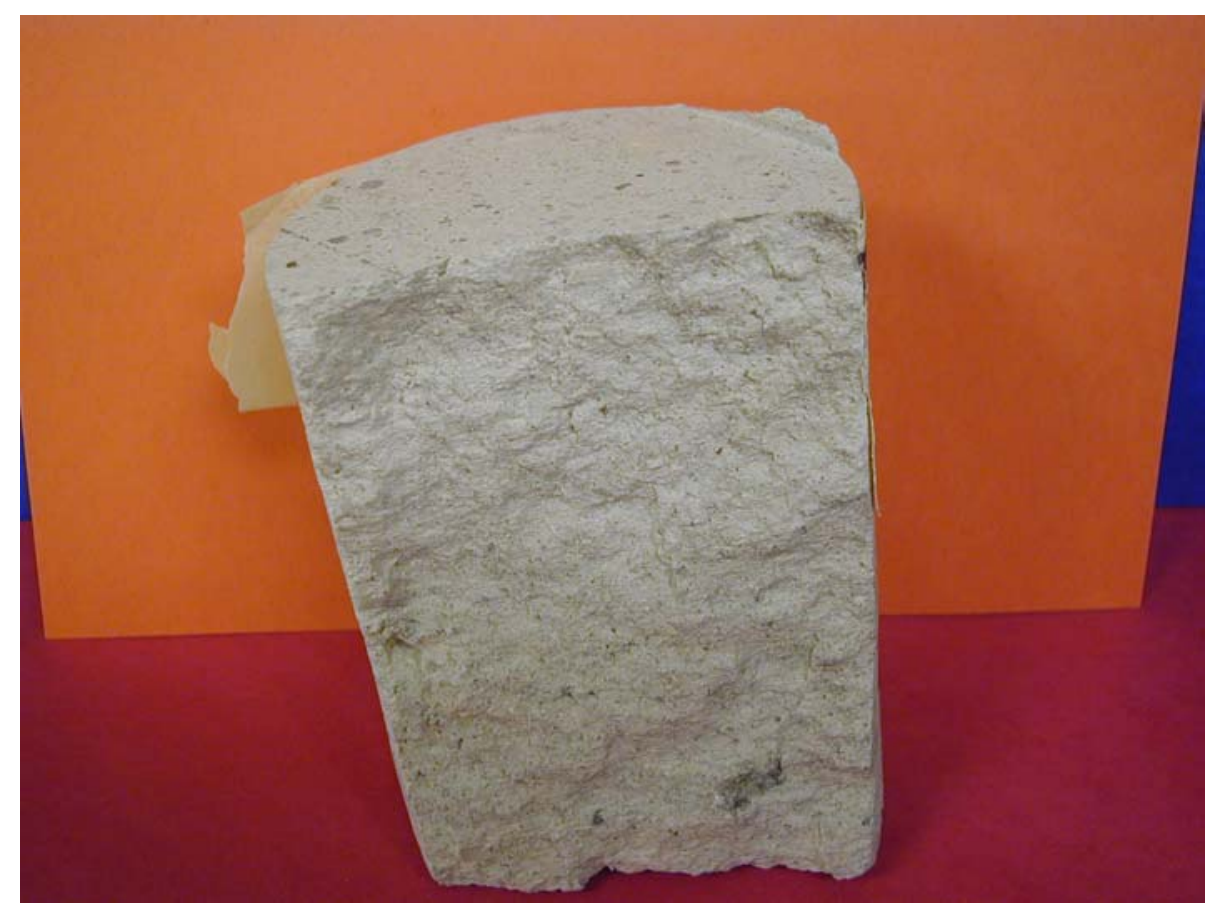

Figure 1. Photograph of core sample PM-1 4823.

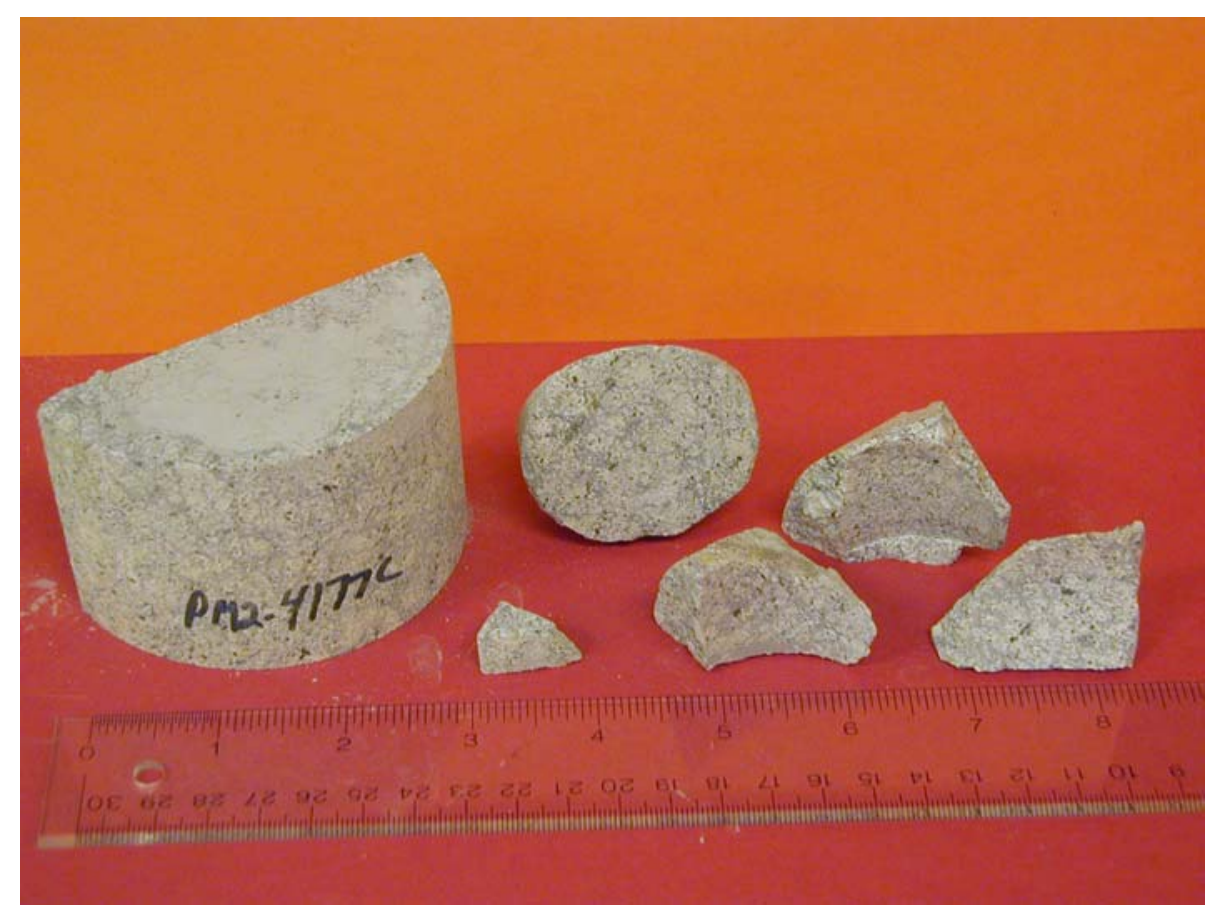

Figure 2. Photograph of core sample PM-2 4177. 


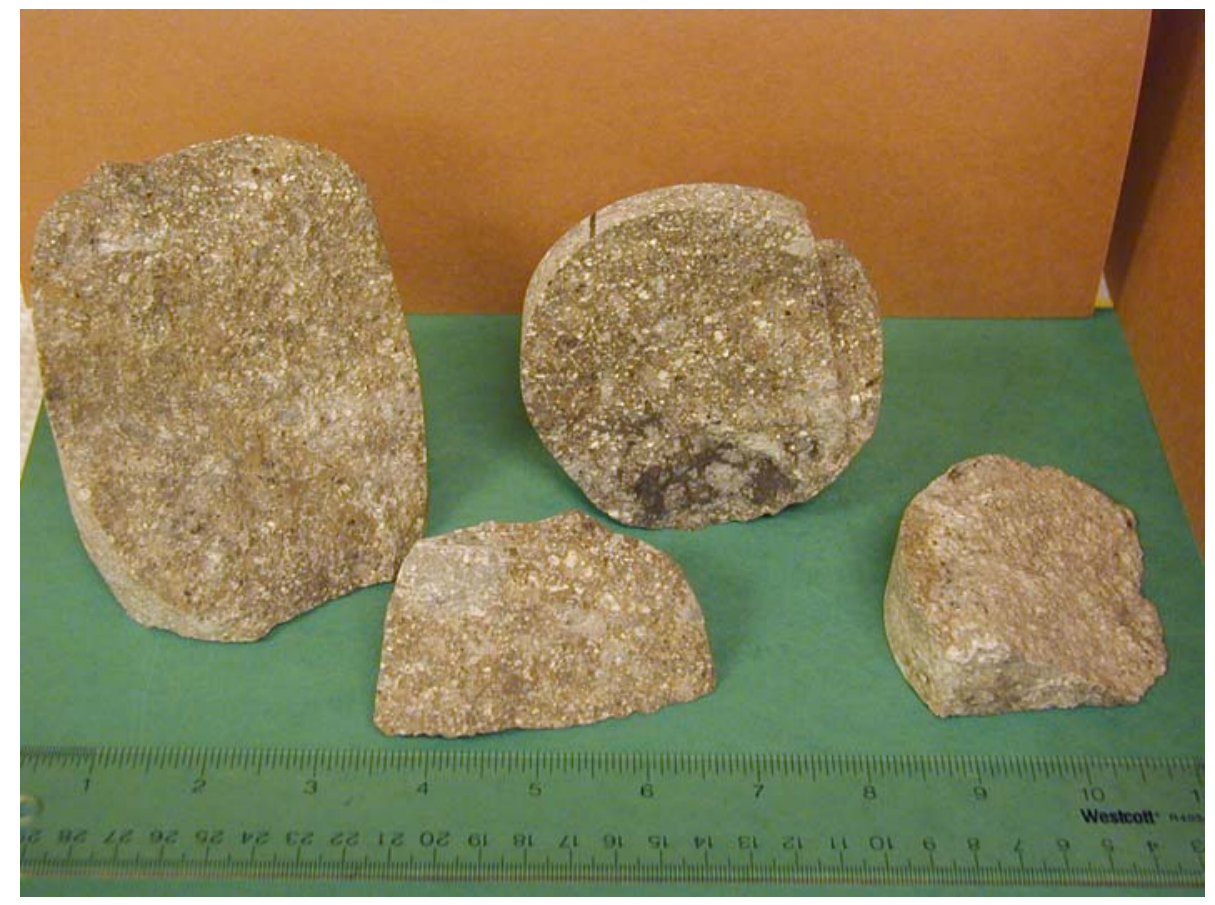

Figure 3. Photograph of core sample UE18R 2228.

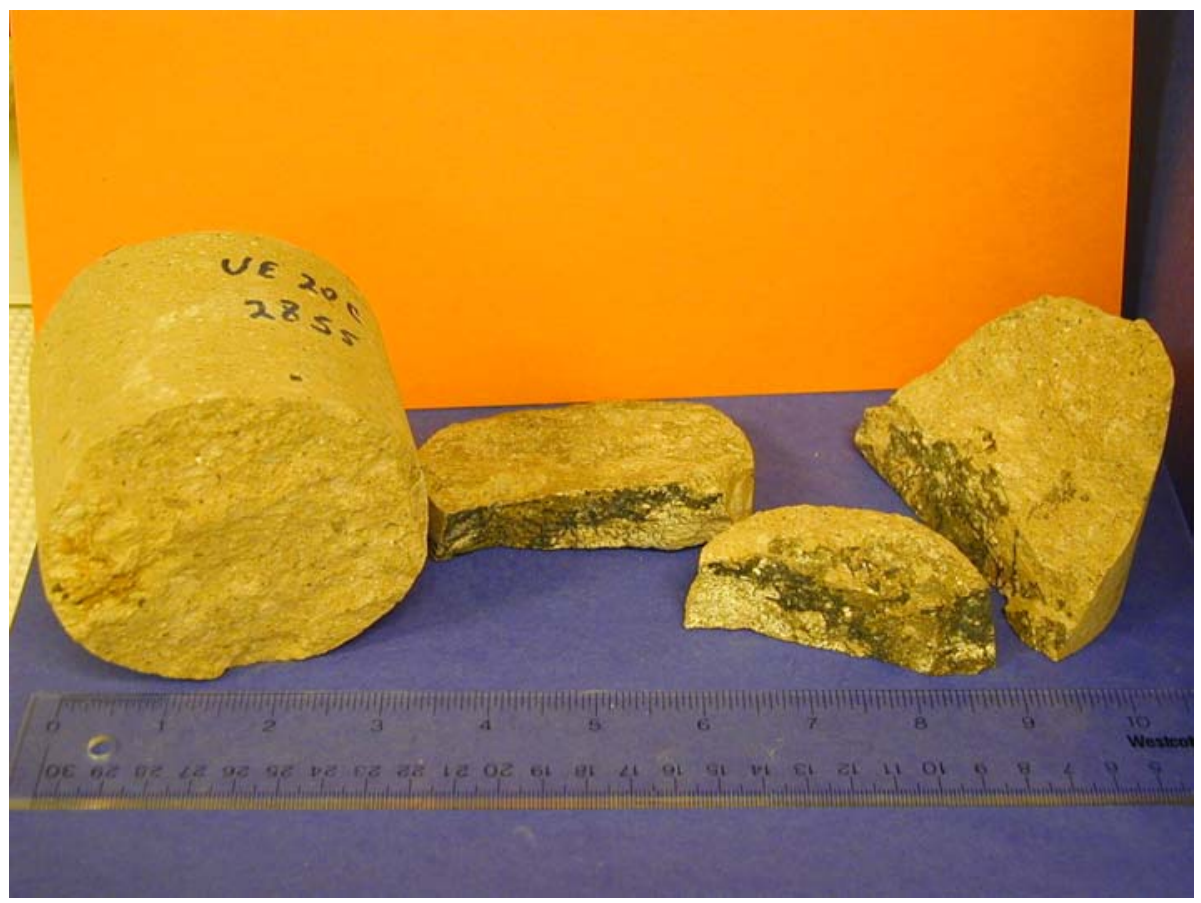

Figure 4. Photograph of core sample UE20c 2855. 


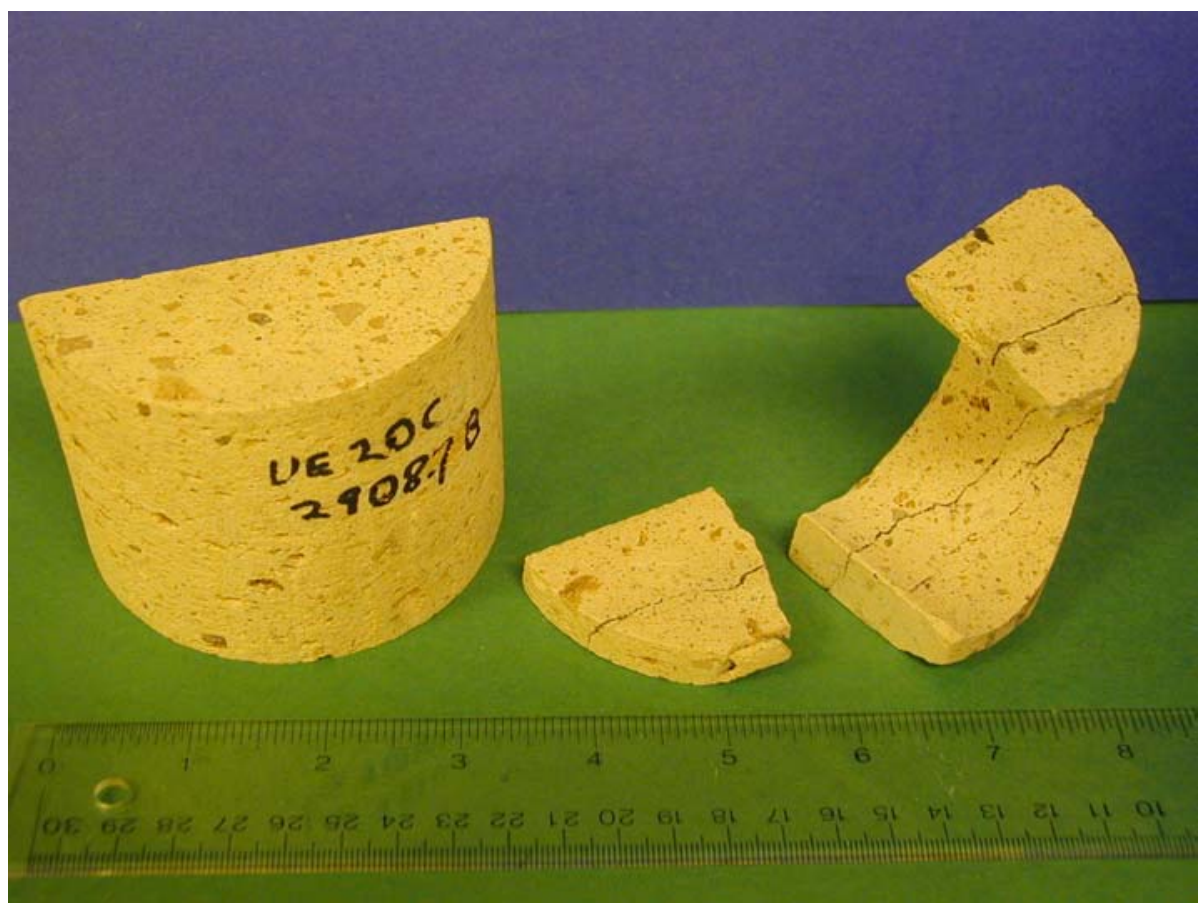

Figure 5. Photograph of core sample UE20c 2908. 

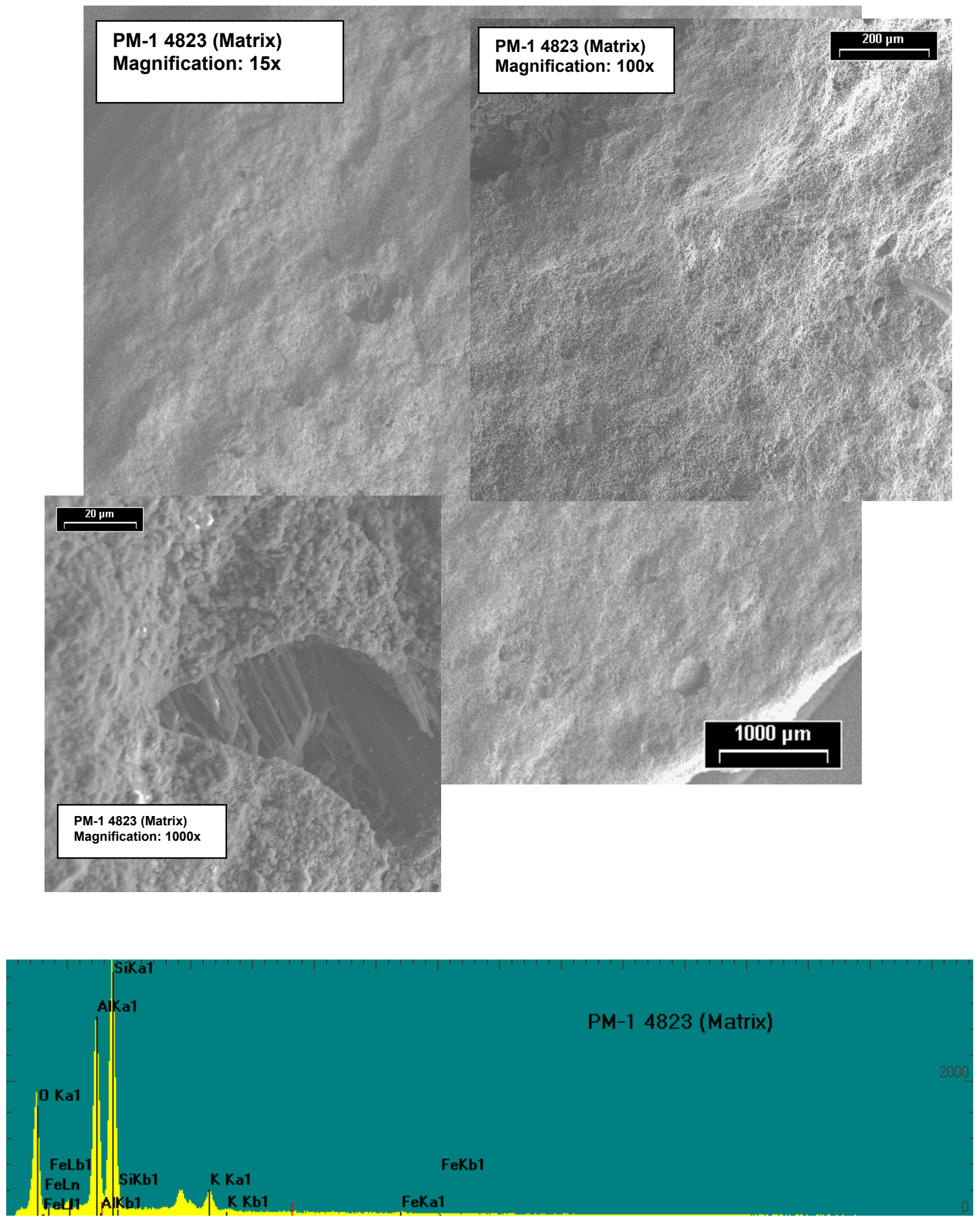

Figure 6. Scanning electron micrographs and EDX spectrum of sample PM-1 4823 (Matrix); magnification 15, 100, and 1000x. 


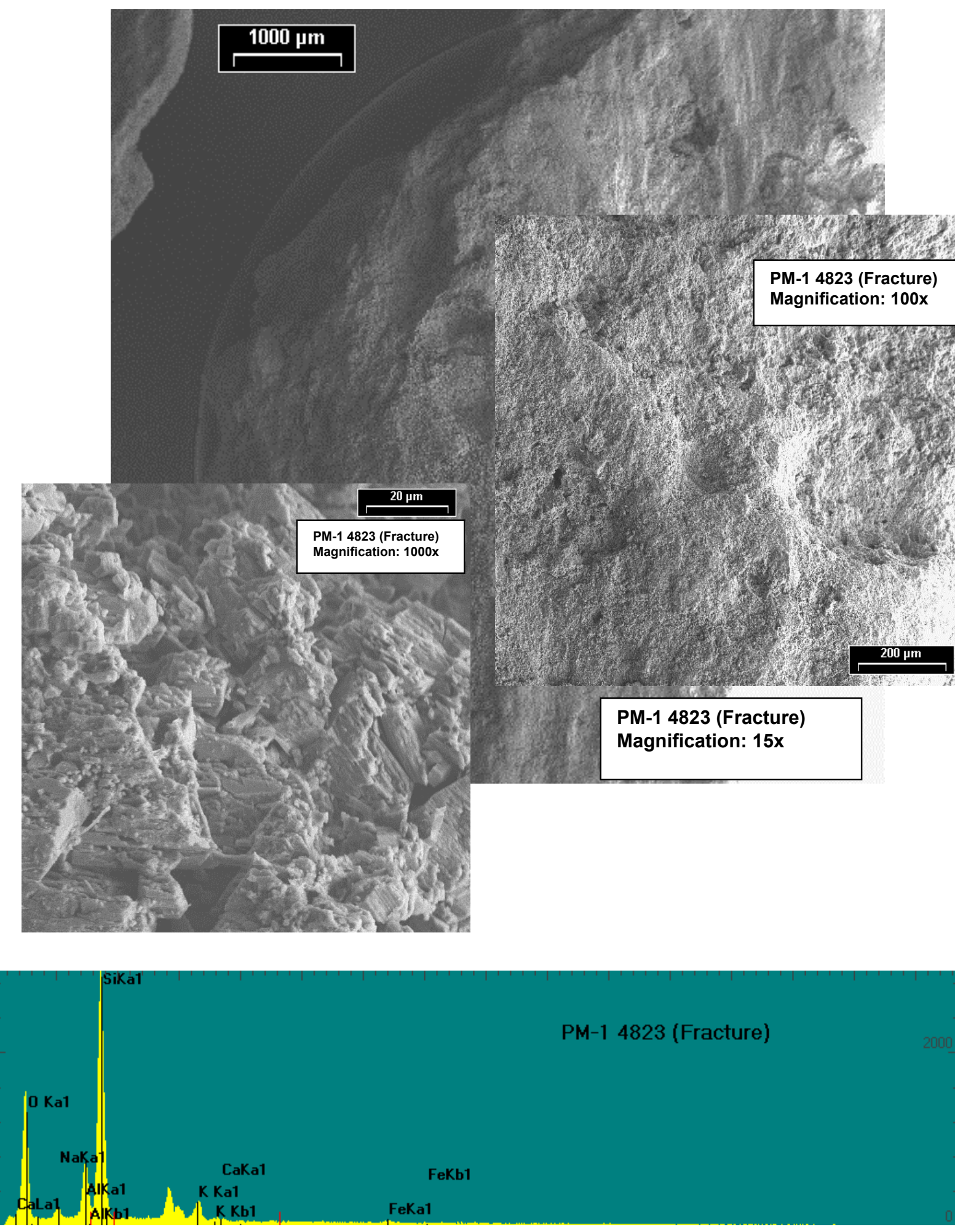

Figure 7. Scanning electron micrographs and EDX spectrum of sample PM-1 4823 (Fracture); magnification 15, 100, and 1000x. 

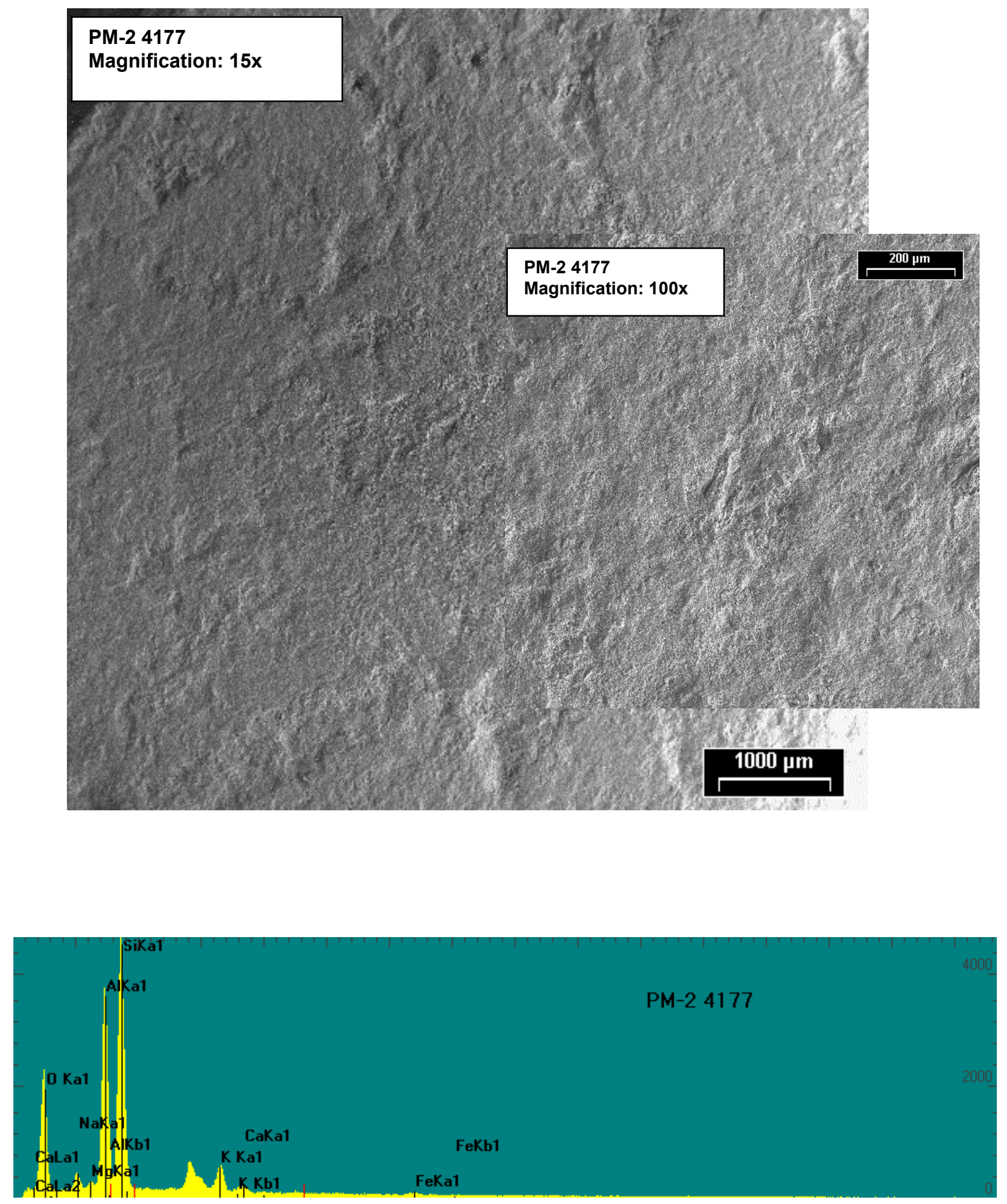

Figure 8. Scanning electron micrographs and EDX spectrum of sample PM-2 4177; magnification 15 and $100 x$. 

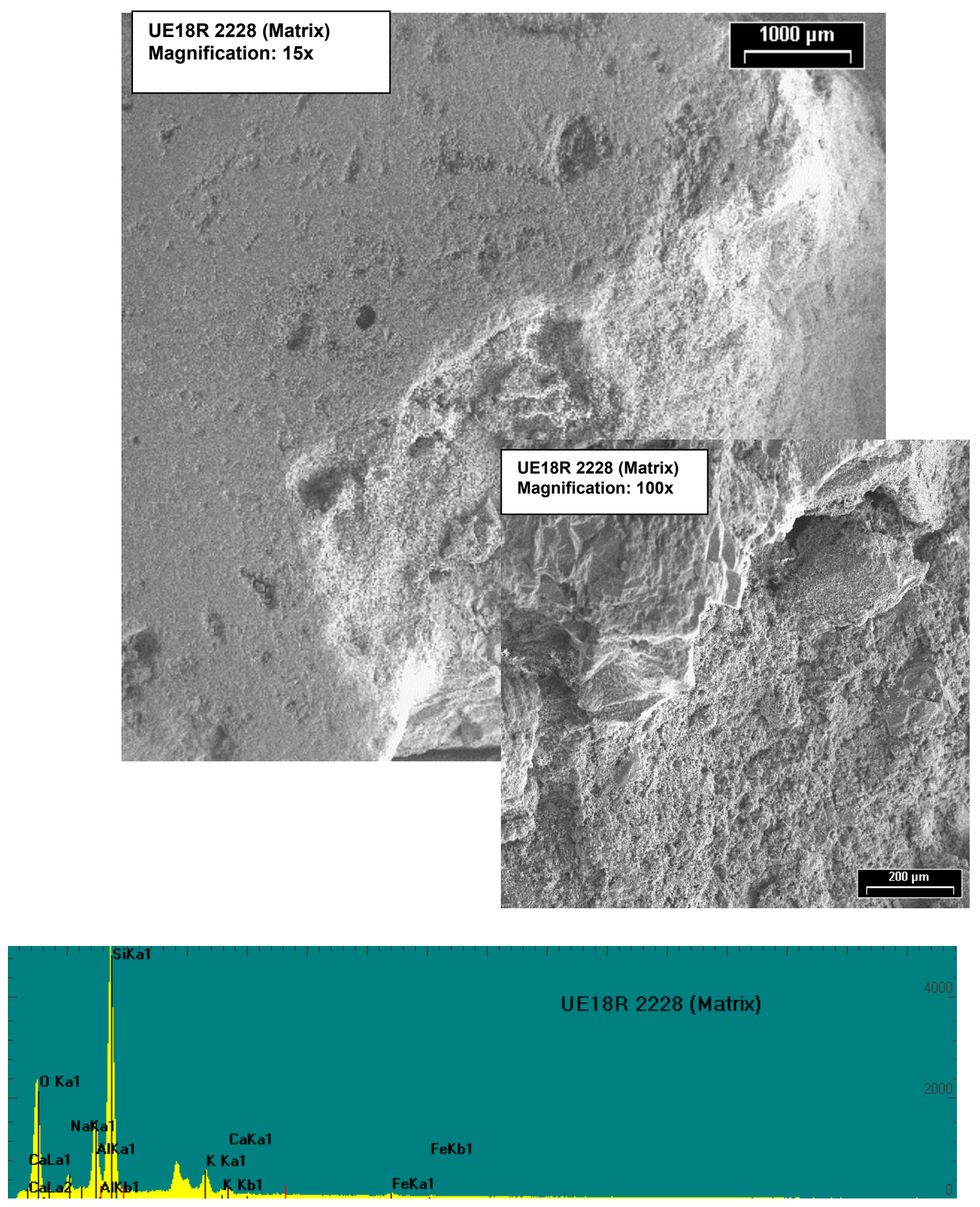

Figure 9. Scanning electron micrographs and EDX spectrum of sample UE18R 2228 (Matrix); magnification 15 and 100x. 

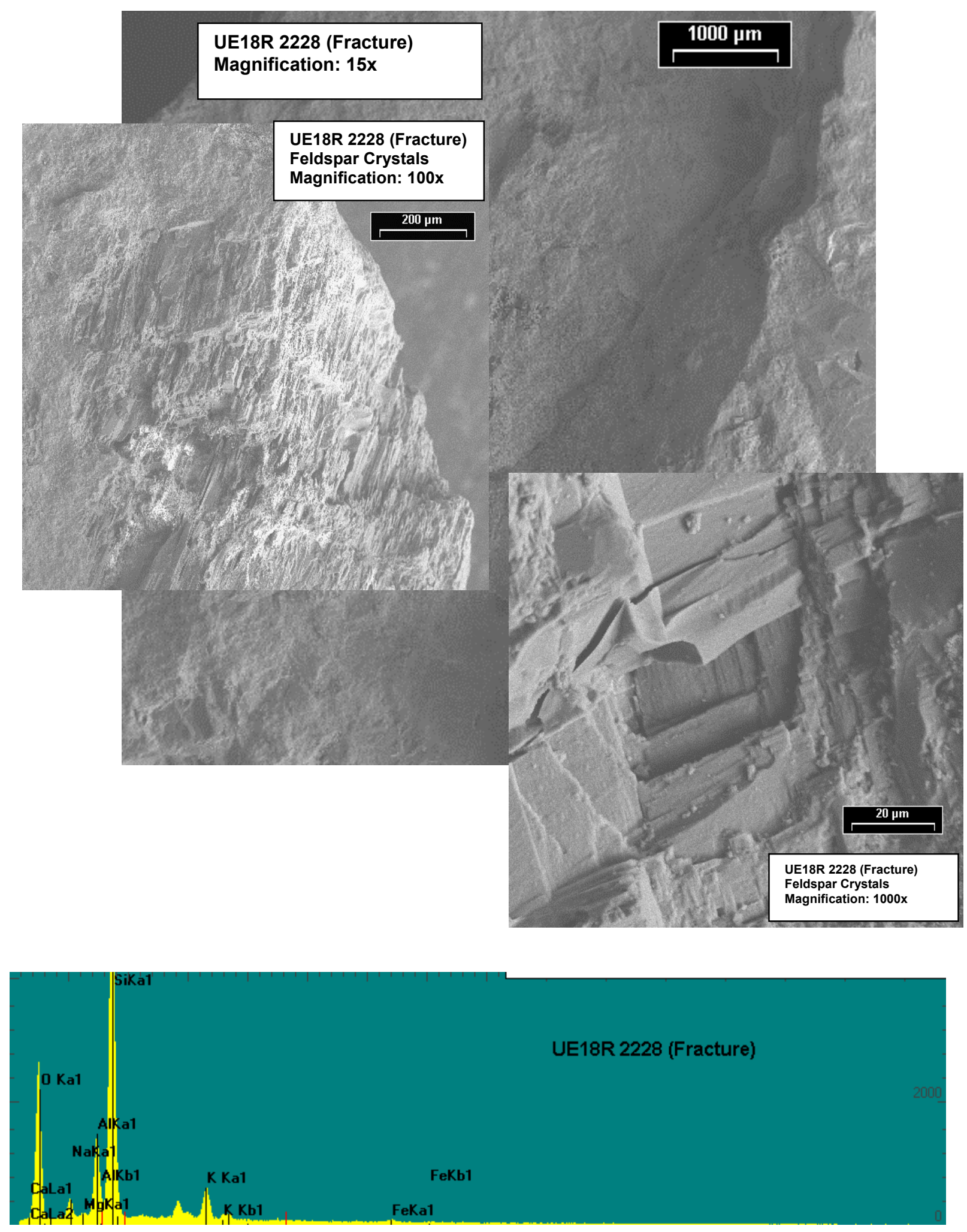

Figure 10. Scanning electron micrographs and EDX spectrum of sample UE18R 2228 (Fracture); magnification 15, 100, and 1000x. 

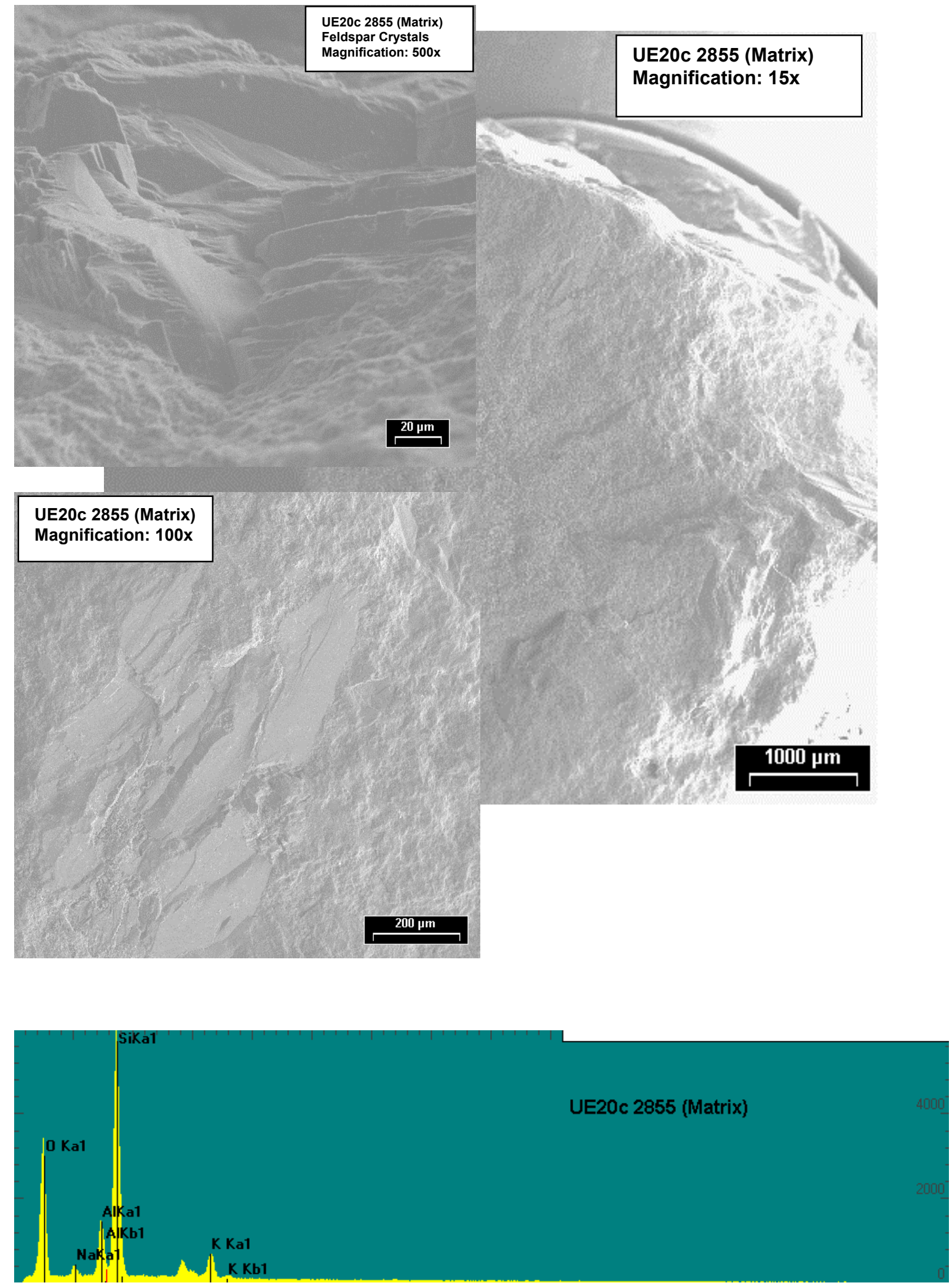

Figure 11. Scanning electron micrographs and EDX spectrum of sample UE20c 2855 (Matrix); magnification 15,100 , and 500x. 
UE20c 2855 (Fracture)

Magnification: 100x

$1000 \mu \mathrm{m}$

UE20c 2855 (Fracture)

Magnification: 15x

UE20c 2855 (Fracture)

Feldspar and Manganese Phases

Magnification: 200x

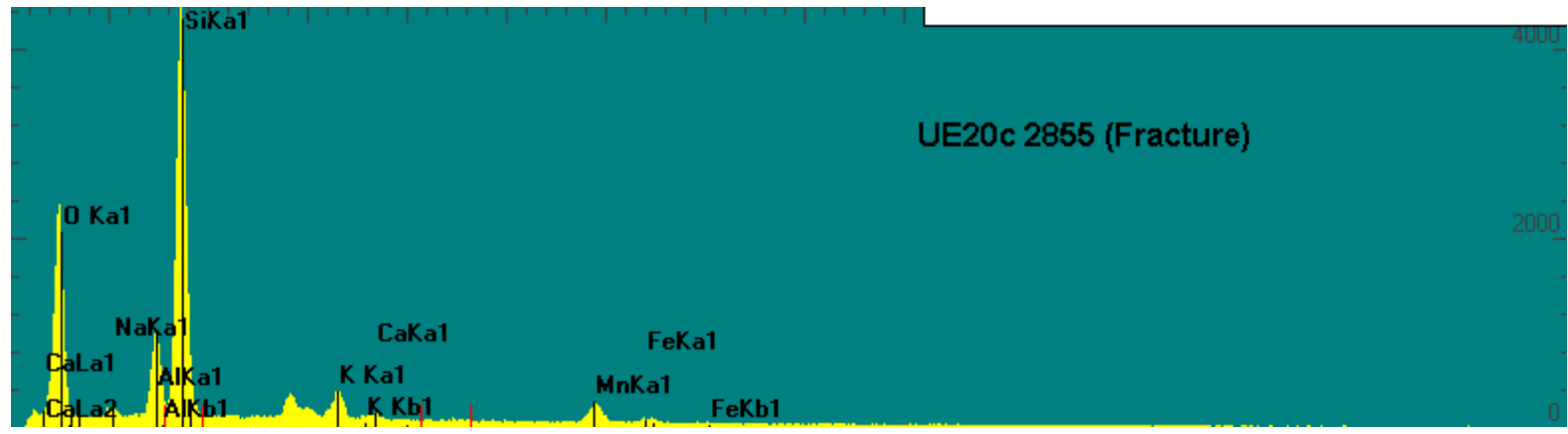

Figure 12. Scanning electron micrographs and EDX spectrum of sample UE20c 2855 (Fracture); magnification 15,100 , and 200x. 

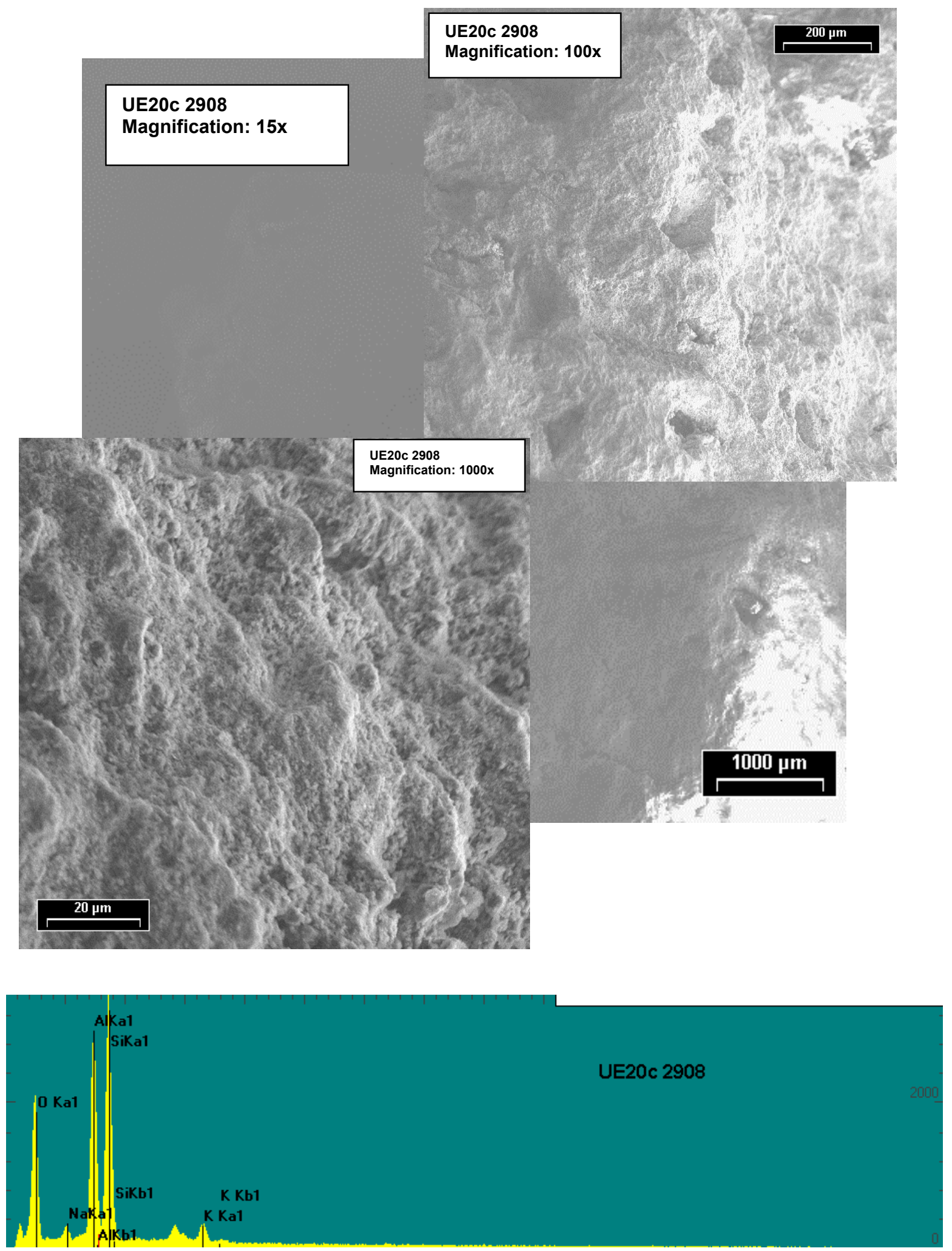

Figure 13. Scanning electron micrographs and EDX spectrum of sample UE20c 2908; magnification 15, 100 , and 1000x. 
Particles with diameters between 44 and $149 \mu \mathrm{m}$ were used for batch equilibrium sorption/desorption experiments. Diffusion slabs were cut from the WPM cores and the properties of the diffusion slabs, such as dimension and porosity, were measured before diffusion experiments. Most of the diffusion slabs had similar dimensions of $2 \mathrm{~cm} \times 2 \mathrm{~cm} \times 0.5 \mathrm{~cm}$ (length $\mathrm{x}$ height $\mathrm{x}$ width). Each diffusion slab was pretreated with $0.1 \mathrm{~N}$ hydrochloric acid $(\mathrm{HCl})$ and 0.1 $\mathrm{M}$ sodium nitrate $\left(\mathrm{NaNO}_{3}\right)$ solution to remove the organic coating present on the surface and easily exchangeable metal ions in the sample. After washing several times with NANOpure ${ }^{\mathrm{TM}}$ water, leaching by $\mathrm{NaNO}_{3}(0.1 \mathrm{M})$ solution was repeated until the final leached metal concentration was negligible. The bulk density of each sample slab was measured by the dried mass of the slab divided by the volume of the slab (measured by water displacement). The porosity was determined by a water saturation method (Skagius and Neretnieks, 1986). The measured porosity is also shown in Table 1. Two samples (UE18R 2228 Matrix and Fracture) had much lower porosity, 2.0 and 3.65 percent, respectively, compared to the other samples. These low values were considered a result of the physical properties of two samples, because UE18R 2228 was a densely welded tuff. The low-porosity values are in agreement with the low specific surface areas of this sample. The porosity values of other samples were well in agreement with previous measurement of average porosity (20 to 25 percent) for the zeolitized tuffs from Rainier Mesa at the NTS (Sloop, 1998).

All experiments were conducted using reagent-grade chemicals. NANOpure ${ }^{\mathrm{TM}}$ water (high purity water of at least $18 \mathrm{M} \Omega \mathrm{cm}^{-1}$ resistivity) was used for all solutions. Lead, $\mathrm{Sr}, \mathrm{Cs}$, chromate $\left(\mathrm{CrO}_{4}{ }^{2-}\right)$, and bromide ( $\mathrm{Br}^{-}$were prepared as aqueous lead nitrate $\left(\mathrm{Pb}\left(\mathrm{NO}_{3}\right)_{2}\right)$, strontium nitrate $\left(\mathrm{Sr}\left(\mathrm{NO}_{3}\right)_{2}\right)$, cesium nitrate $\left(\mathrm{CsNO}_{3}\right)$, potassium chromate $\left(\mathrm{K}_{2} \mathrm{CrO}_{4}\right)$, and sodium bromide $(\mathrm{NaBr})$ solutions. Because all experiments were conducted with chromate, chromium in the +6 oxidation state, as opposed to chromium metal in the +3 oxidation state, in the rest of the document the symbol $\mathrm{Cr}^{\mathrm{VI}}$ will be used to indicate the chromate anion.

\section{Methods}

\section{Batch Sorption/Desorption Equilibrium Experiments}

Batch sorption experiments were conducted in 12-mL polypropylene test tubes by mixing WPM powders with the metal ion of interest. A synthetic groundwater solution was prepared based on the groundwater analysis from well U-20 at the NTS. The calculated $\mathrm{pH}$ and ionic strength were 8.3 and $0.003 \mathrm{M}$, respectively. Nitric acid $\left(\mathrm{HNO}_{3}\right)$ and sodium hydroxide $(\mathrm{NaOH})$ were used to adjust the solution $\mathrm{pH}$. Two metal concentrations $\left(10^{-6}\right.$ and $\left.10^{-5} \mathrm{M}\right)$ and solid concentrations ( 3 and $10 \mathrm{~g} \mathrm{~L}^{-1}$ ) were used in the sorption/desorption experiments. Sorption of metal ions on the polypropylene test tubes was also checked and was found to be negligible. In general, 8 to 10 test tubes were set up for sorption experiments under otherwise identical conditions, except for $\mathrm{pH}$. A blank solution sample, without solid, was included in the set as a standard for the metal concentration. The samples were equilibrated by end-over-end rotation at $8 \mathrm{rpm}$ for 48 hours. End-over-end rotation was used to accelerate equilibration times. The low agitation of the sample by the device used has not been shown to contribute to particle abrasion during the equilibration time used. In addition, preliminary kinetic experiments suggested that 48 hours was adequate time to achieve equilibration in this system. After equilibration, the samples were centrifuged at 9,000 rpm for 30 minutes to separate the solution from the solid. The final $\mathrm{pH}$ was measured and a 2-mL aliquot was removed from the supernatant. The metal concentration was measured by atomic absorption spectroscopy (AA) using a Perkin-Elmer 4110 ZL spectrometer with graphite furnace and Zeeman background correction. The fractional 
sorption uptake (expressed as a percentage of the initial total metal concentration) was determined by the difference between the total (initial) and the final metal concentration in the supernatant. All reported results are averages of duplicate samples. Typical relative standard deviations for the duplicate samples were on the order of 5 percent.

Desorption experiments were conducted following the sorption experiments. Several test tubes were prepared, under the same conditions, including $\mathrm{pH}(\approx 8.0)$, to be analyzed as a function of time. After sorption equilibrium was reached, the supernatant was centrifuged and decanted carefully. The metal concentration in the solution was measured and the sorbed metal concentration on the solid was determined as usual. The desorption solution, a synthetic groundwater solution without the metal of interest, was introduced into each test tube. Test tubes were mixed again by end-over-end rotation. Each test tube was centrifuged after a certain time period and the concentration of desorbed metal ion in the supernatant was measured. Synthetic groundwater solutions used for the previous sorption experiments were prepared to test the reversibility of sorption for each metal ion.

Diffusion Experiments

\section{Diffusion Theory}

Diffusion is the process by which dissolved ions or molecular species in solution move from a higher concentration area to a lower concentration area (Fetter, 1994). The diffusion of dissolved species in an aqueous solution is described by Fick's first law:

$$
J=-D_{m o l} \nabla C
$$

where $J$ is the diffusional flux $\left(\mathrm{M} \mathrm{L}^{-2} \mathrm{~T}^{-1}\right), C$ is the total solute concentration $\left(\mathrm{M} \mathrm{L}^{-3}\right)$, and $D_{m o l}$ is the molecular diffusion coefficient $\left(\mathrm{L}^{2} \mathrm{~T}^{-1}\right)$ describing diffusion of a solute in a bulk aqueous solution. The molecular diffusion coefficient for each electrolyte can be calculated using the Nernst-Haskell equation (Reid et al., 1977):

$$
D_{m o l}=\frac{R T}{F^{2}} \frac{1 / n_{+}+1 / n_{-}}{1 / \lambda_{+}+1 / \lambda_{-}}
$$

where $D_{m o l}$ is the molecular diffusion coefficient $\left(\mathrm{L}^{2} \mathrm{~T}^{-1}\right), T=$ temperature $(\mathrm{K}), R=$ gas constant $\left(8.314 \mathrm{~J} \mathrm{~mol}^{-1} \mathrm{~K}^{-1}\right), F=$ Faraday constant $\left(96485 \mathrm{C} \mathrm{mol}^{-1}\right), n_{+}, n_{-}=$valences of cation and anion, respectively (dimensionless), and $\lambda_{+}, \lambda_{-}=$ionic conductivity at infinite dilution for cation and anion $\left(\mathrm{L}^{2} \mathrm{~S} \mathrm{~mol}^{-1}\right)$.

In porous media, diffusion is affected by geometric parameters such as porosity $(\theta)$ and tortuosity $(\chi)$, because the ions must follow longer pathways as they travel through pores rather than a straight line (Berner, 1971; Fetter, 1994). Tortuosity is the actual sinuous flowpath, $l$, over a theoretical straight-line distance, $\mathrm{x}$ (i.e., $\chi=l / \mathrm{x}$ ). In terms of porosity and tortuosity, diffusive flux in one-dimensional $\mathrm{x}$-direction becomes

$$
\begin{gathered}
J_{x}=-\frac{D_{m o l}}{\chi} \frac{\partial C}{\partial x} \\
=-\frac{D_{m o l} \theta}{\chi} \frac{\partial C_{l}}{\partial x}
\end{gathered}
$$


where $C$ is the total solute concentration (mass of solute per volume of soil) and $C_{l}$ is the dissolved solute concentration defined as mass of solute per volume of soil solution $\left(C=C_{l} \theta\right)$. For the change of concentration with time, Fick's second law is used:

$$
\begin{gathered}
\frac{\partial C}{\partial t}=-\frac{\partial J_{x}}{\partial x} \\
=\frac{D_{m o l} \theta}{\chi}\left[\frac{\partial^{2} C_{l}}{\partial x^{2}}+\left(\frac{1}{\theta} \frac{\partial \theta}{\partial x}-\frac{1}{\chi} \frac{\partial \chi}{\partial x}\right) \frac{\partial C_{l}}{\partial x}\right]
\end{gathered}
$$

Since $\frac{\partial \theta}{\partial x}$ and $\frac{\partial \chi}{\partial x}$ are very small for small distances, the second term within the brackets in Equation (4) can be neglected resulting in the simplified equation:

$$
\frac{\partial C}{\partial t}=\frac{D_{m o l} \theta}{\chi} \frac{\partial^{2} C_{l}}{\partial x^{2}}
$$

For a nonreactive solute, $C=C_{l} \theta$ and Equation (5) becomes:

$$
\frac{\partial C_{l}}{\partial t}=D_{e f f} \frac{\partial^{2} C_{l}}{\partial x^{2}}
$$

where $D_{\text {eff }}\left(=\frac{D_{m o l}}{\chi}\right)$ is the effective diffusion coefficient, which is a diffusion coefficient

representing the diffusion of a nonreactive solute in a porous medium. Because of the retardation by geometric parameters, $D_{\text {eff }}$ should be less than $D_{\text {mol }}$. For a reactive solute, because of the interaction of solutes with solid materials such as ion exchange and sorption, a partition factor $\left(\mathrm{K}_{\mathrm{d}}\right)$ or retardation factor $(\mathrm{R})$ should be considered for the diffusion of a sorbing solute. Since $C=C_{s} \rho_{b}+C_{l} \theta$ (where $C_{\mathrm{s}}$ is the adsorbed solute concentration and $\rho_{b}$ is the bulk density) and assuming a linear isotherm $\left(C_{s}=K_{\mathrm{d}} C_{l}\right)$, for a reactive solute, Equation (6) becomes:

$$
\frac{\partial C_{l}}{\partial t}=\frac{D_{m o l} \theta}{\chi\left(\theta+\rho_{b} K_{d}\right)} \frac{\partial^{2} C_{l}}{\partial x^{2}}=\frac{D_{e f f}}{R} \frac{\partial^{2} C_{l}}{\partial x^{2}}=D_{a p p} \frac{\partial^{2} C_{l}}{\partial x^{2}}
$$

where $K_{\mathrm{d}}$ is the distribution coefficient, $R$ is the retardation factor $\left(R=1+\frac{\rho_{b} K_{d}}{\theta}\right)$, and $D_{\text {app }}$ is the apparent diffusion coefficient describing the diffusion of a reactive solute in a porous medium and given by:

\section{Diffusion Cell Experiments}

$$
D_{a p p}=\frac{D_{e f f}}{R} \text { and } D_{e f f}=\frac{D_{m o l}}{\chi}
$$

The experimental method used here is based on the classical through-diffusion cell design (Skagius and Neretnieks, 1986; Moridis, 1998). An acrylic diffusion cell, which consists of a tracer and a measurement cell, was prepared for diffusion experiments. The volume of both tracer and measurement cells was $100 \mathrm{~mL}$. The diffusion slab $(2 \mathrm{~cm}$ x $2 \mathrm{~cm}$ x $0.5 \mathrm{~cm})$ was placed in the center of the divider plate and sealed with a silicone sealant. An acrylic plate cover was 
used to reduce evaporative losses. Before the diffusion experiments started, each diffusion cell was tested for leaks and the diffusion slab in the cell was saturated for at least seven days with the same synthetic groundwater solution as that used for the experiments.

After full saturation, solutions in both tracer and measurement cells were decanted carefully. Several times leaching and rinsing with groundwater solution and NANOpure ${ }^{\mathrm{TM}}$ water were conducted until negligible metal concentrations of interests were detected in both tracer and measurement cell. Measurement cells were filled with $0.003 \mathrm{M}$ synthetic groundwater solution, resulting in $\mathrm{pH}$ of about 8.3. Each tracer cell was filled with the same solution and $\mathrm{Br}^{-}$. After completing the $\mathrm{Br}^{-}$diffusion measurement, solutions in both tracer and measurement cells were discarded and diffusion cells were washed with NANOpure ${ }^{\mathrm{TM}}$ water several times. The same groundwater solution used for the $\mathrm{Br}^{-}$diffusion experiments was prepared in both tracer and measurement cells. The reactive solute of interest was placed only into the tracer cell. Magnetic stirrers were used to keep solutions in both tracer and measurement cells fully mixed.

Samples were collected from both measurement and tracer cells. The same amount $(100 \mu \mathrm{L})$ of solution was periodically collected from both measurement and tracer diffusion cells to keep the same volume in both sides of the cells. Concentrations of metals were determined by AA. For the Br measurement, an ion-selective electrode was placed in each cell to measure the concentration of Br directly in the cells. Duplicate samples were collected and the mean value was used. The tracer cell was replaced with new solution having the same concentration as the initial metal solution at 24-hour intervals to keep the concentration of the tracer cell constant during the duration of the diffusion. The concentration of diffused solute through the crosssectional area of the diffusion slab was measured from the measurement cell and plotted as a function of time. Simultaneously, a sample was collected from the tracer cell and the concentration was measured to check for constant concentration in the tracer cell. Some of the diffusion cells were also prepared to measure the concentration decrease in the tracer cell as a function of time without replacing the solution of the tracer cell. Diffusion coefficients of solutes were determined using the time-lag method.

Time-lag Method

The time-lag method was originally used to obtain the diffusion coefficient, the permeability constant, and the solubility of a gas flowing through a porous membrane (Crank, 1975; Shackelford, 1991). The total amount of a diffusing substance through a porous slab with a constant concentration in the tracer cell, $C_{1}$ at $\mathrm{x}=0$ and a very small concentration in the measurement cell, $C_{2}\left(C_{2}<<C_{1}\right)$ at $\mathrm{x}=X$ is (Crank, 1975; Skagius and Neretnieks, 1986):

$$
\frac{Q}{X C_{1}}=\frac{D_{e f f} t}{X^{2}}-\frac{\alpha}{6}-\frac{2 \alpha}{\pi^{2}} \sum_{n=1}^{\infty} \frac{(-1)^{n}}{n^{2}} \exp \left(-\frac{D_{e f f} n^{2} \pi^{2} t}{X^{2} \alpha}\right)
$$

where $Q$ is the total amount of diffusing solute through the sample slab per time $\left(\mathrm{M} \mathrm{L}^{-2}\right), X$ is the thickness of a sample slab $(\mathrm{L}), C_{1}$ is the concentration at the tracer cell $\left(C_{1}>>C_{2}\right)\left(\mathrm{M} \mathrm{L} \mathrm{L}^{-3}\right), C_{2}$ is the concentration at the measurement cell $\left(\mathrm{M} \mathrm{L}^{-3}\right)$, and $D_{\text {eff }}$ is the effective diffusion coefficient for a nonreactive solute $\left(\mathrm{L}^{2} \mathrm{~T}^{-1}\right)$. The effective diffusion coefficient is replaced by $D_{a p p}$, the apparent diffusion coefficient, for a reactive solute, $t$ is time (T), and $\alpha$ is the rock capacity factor $\left(=\theta_{t o t}+K_{\mathrm{d}} \rho_{b}\right)$

As time ( $\mathrm{t}$ ) approaches infinity or after enough time has passed, the exponential term in Equation (9) becomes negligible and Equation (9) is reduced to the linear equation: 


$$
Q=\frac{C_{1} D_{e f f}}{X} t-\frac{C_{1} X \alpha}{6}
$$

with slope $\frac{\mathrm{C}_{1} \mathrm{D}_{\text {eff }}}{\mathrm{X}}$ and intercept on the time axis, $\frac{X^{2} \alpha}{6 D_{\text {eff }}}$. The slope and the intercept on the time

axis of the linear equation provide the diffusion coefficient and rock capacity factor, respectively.

X-ray Photoelectron Spectroscopy (XPS)

Background

This section is intended as a brief introduction to $\mathrm{x}$-ray photoelectron spectroscopy (XPS). A thorough introduction to this important technique is, obviously, beyond the scope of this report. The interested reader should consult the additional references given below. A very brief introduction to XPS is given by Hochella (1990). A concise overview of the technique, its history, the basic theory behind it, and some applications are given by Kelly (1986). Briggs and Seah (1990) give a complete coverage of the technique including instrumentation, spectral interpretation, quantification, and an extended discussion of various technological applications. A fairly basic introduction to XPS with emphasis on spectral interpretation and accompanied by a discussion of applications in geology is given by Perry et al. (1990). Hochella (1988) gives a more complete overview of the technique including basic theory, spectral interpretation, instrumentation, sample preparation, and applications in geology, mineralogy, and geochemistry. Finally, a substantially more theoretical treatment of the subject is presented by Brundle and Baker (1978).

\section{Basic Theory}

$\mathrm{X}$-ray photoelectron spectroscopy is based on the photoelectric effect. When materials are bombarded with X-rays energetic enough to eject electrons from inner- or valence shells, the difference between the incoming photon energy and electron binding energy (BE) is converted to kinetic energy of the escaping photoelectron. Binding energies (BEs) for different elements and orbitals can be determined either experimentally or from single-atom models. XPS is a surfacesensitive technique because it is based on detection of photoelectrons, which have, essentially, undergone no inelastic collisions. This can only happen if the atoms from which electrons are ejected are located near the surface. The depth of analysis is therefore typically between 10 and $50 \AA \AA$.

\section{Spectral Interpretation and Chemical Shifts}

Because every element has a unique atomic structure and the low-energy x-rays used can only excite a few atomic levels from each element, elements can be identified unambiguously in most cases. A wide-energy-range "survey" scan can be used to identify the elements present in the sample but it is not used for quantification of elemental composition because it lacks resolution; narrow scans are used for this purpose. Contaminants in the air and residual gases in the vacuum chamber, give rise to a $\mathrm{C} 1 \mathrm{~s}$ peak, referred to as the "adventitious carbon" peak.

A chemical shift is defined as the difference in BE between a particular line and the BE for the same line in a reference compound. The chemical shift is a function of the environment of 
an atom. By means of chemical shifts one can often distinguish between two different oxidation states of an element in a given sample or between different coordination environments.

\section{Charge Referencing}

When insulators are being analyzed, the sample is necessarily insulated from the spectrometer and the surface is charged positively as photoelectrons are ejected from the sample. This surface charging results in observed BE shifts typically between 5 and $10 \mathrm{eV}$. To obtain accurate BEs for insulators, the magnitude of charge shifting must be estimated. This procedure is called charge referencing and is usually accomplished by either the adventitious carbon, the gold dot, or the argon implantation method. The adventitious carbon method uses the presence of adventitious carbon on practically every sample and assigns a $\mathrm{BE}$ to the $\mathrm{C} 1 \mathrm{~s}$ line. Because reported values for the adventitious $\mathrm{C}$ 1s line range from 284.6 to $285.2 \mathrm{eV}$, the values determined with this method may be off by as much as $0.6 \mathrm{eV}$.

\section{Chemical Quantification}

With XPS, one can obtain at least semi-quantitative estimates of the relative abundance of the elements present on the surface of a sample. To obtain reliable quantitative information, narrow scans of the regions corresponding to the peaks of interest must be collected using small energy steps. Quantification, however, from wide (survey) scans has also been attempted (Turner, 1992). If only the ratio of two elements is needed, as is often the case in surface analysis, the relative abundance of the two elements can be estimated from the photoionization cross sections and the intensities of the two peaks. The photoionization cross section gives the probability that a photon will be absorbed by an electron in a specific orbital. Theoretical photoionization cross sections were tabulated by Scofield (1976). Quantification, therefore, only requires measurement of the intensities of the two peaks and knowledge of the corresponding cross sections. An alternative approach, however, which may give better results, is to use empirical cross sections derived from well-defined crystalline materials, where the elements whose ratio must be determined in the unknown are present.

\section{RESULTS AND DISCUSSION}

\section{Sorption Experiments}

The sorption uptake of $\mathrm{Cs}, \mathrm{Sr}, \mathrm{Pb}$, and $\mathrm{Cr}$ by various crushed core samples in synthetic groundwater solutions, under varying $\mathrm{pH}$ conditions, was evaluated. Two different metal and solid concentrations were used to study the sorption affinity of metals for solid samples. The sorption uptake of Cs by UE20c samples is shown in Figure 14. Because of the low solid concentration $\left(3 \mathrm{~g} \mathrm{~L}^{-1}\right)$ and high initial metal concentration $\left(10^{-5} \mathrm{M}\right)$, sorption was low for all samples. Although the UE20c 2855 Fracture and UE20c 2908 samples showed pH-independent and slightly higher sorption affinity compared to the others, there were many uncertainties. The sorption uptake of $\mathrm{Cs}$ by other solid samples was low and in some cases statistically indistinguishable from zero and not plotted to avoid clutter. 


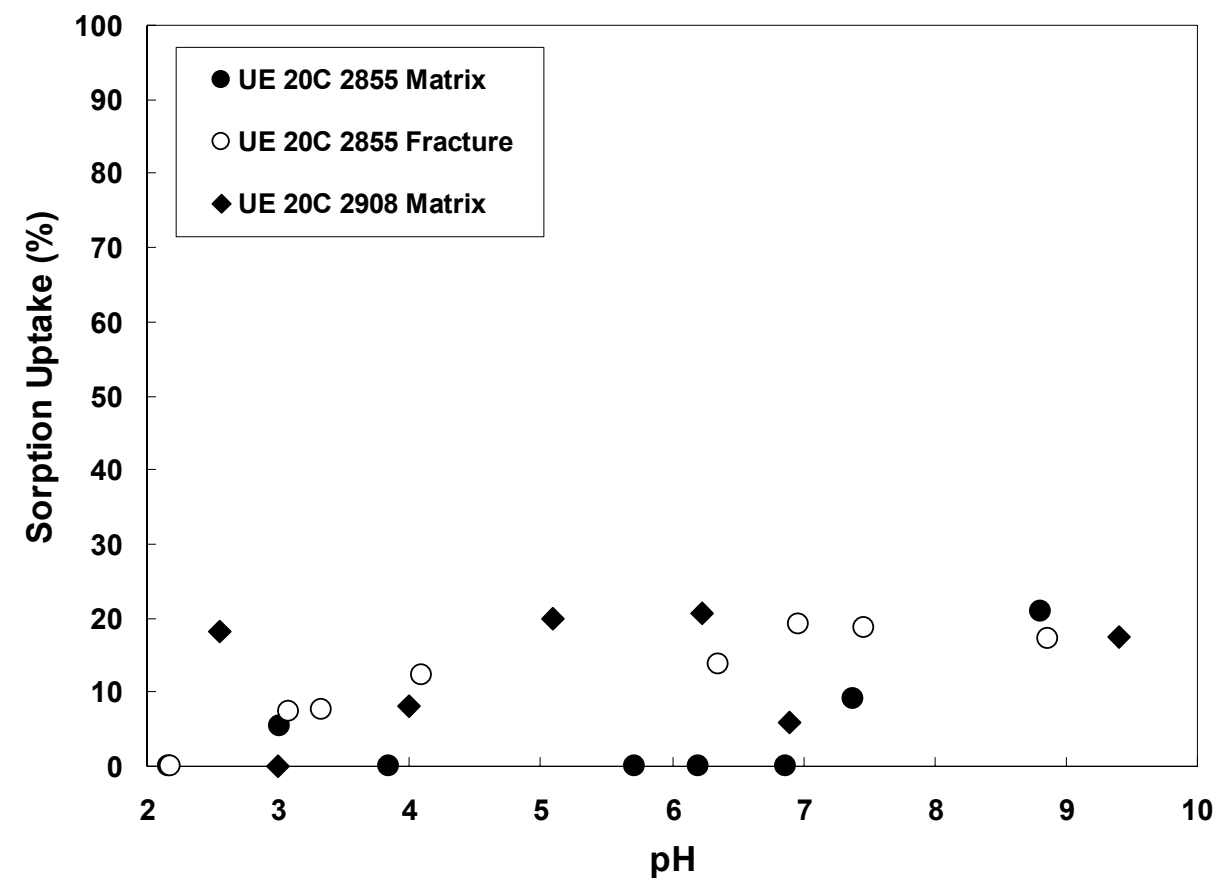

Figure 14. Sorption uptake of $10^{-5} \mathrm{M}$ Cs by $3 \mathrm{~g} \mathrm{~L}^{-1} \mathrm{UE} 20 \mathrm{c}$ samples.

Cesium $\left(10^{-5} \mathrm{M}\right)$ sorption on $10 \mathrm{~g} \mathrm{~L}^{-1}$ solid is shown in Figure 15. UE20c 2908 and PM-2 4177 showed higher sorption capacities for Cs. The sorption uptake of Cs by other samples was similar and slightly $\mathrm{pH}$-dependent, consistent with the small percentage of surface hydroxyl sorption sites existing in the samples. These $\mathrm{pH}$-dependent sorption sites are associated with iron or silicon oxides, such as quartz, feldspars, kaolinite, and hematite, present in these samples. The $\mathrm{pH}$-dependent edge sites of smectite clays may also contribute to the observed sorption behavior. It should be noted that Cs sorption on cation exchange sites, such as sites on mica or the cation exchange sites of smectite clays, would result in $\mathrm{pH}$-independent sorption behavior (Papelis and Hayes, 1996). Given the very low tendency of Cs to hydrolyze (Baes and Mesmer, 1986), surface precipitation can also be eliminated as a possible sorption mechanism. The observed moderate $\mathrm{pH}$ dependency of sorption, therefore, must be attributed to sorption on $\mathrm{pH}$-dependent sites.

The sorption results for the matrix and fracture samples are shown in Figure 16. Cesium sorption was not different between the two samples, indicating that even matrix samples had surface hydroxyl sites resulting from quartz, feldspars, or hematite. In comparing the results between the matrix and fracture samples, one must keep in mind that the fracture samples resulted from an attempt to cut the portion of the sample closest to the fracture surface using a rock saw. The thickness of the actual fracture surface, therefore, was in reality almost insignificant compared to the total thickness of the sample, which included the fracture surface. Because the samples used in these experiments resulted from size reduction of the corresponding sample (matrix or fracture), the actual fraction of minerals present in the fracture was expected to be relatively small compared to the minerals present in the bulk of the matrix. It is therefore not surprising that the contribution of iron and manganese oxides present in the fracture surface would be minimized in these experiments. 


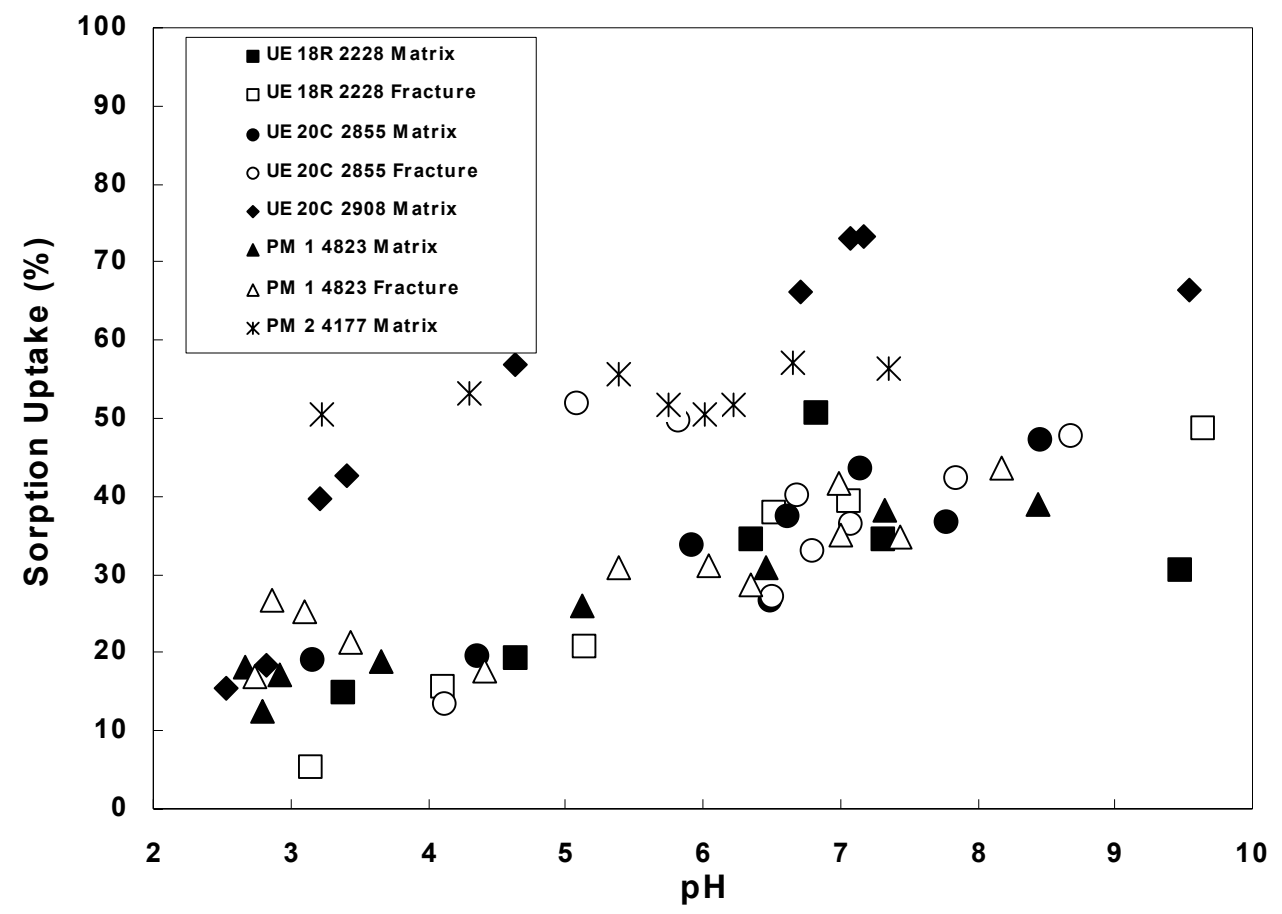

Figure 15. Sorption uptake of $10^{-5} \mathrm{M}$ Cs by $10 \mathrm{~g} \mathrm{~L}^{-1}$ WPM samples.

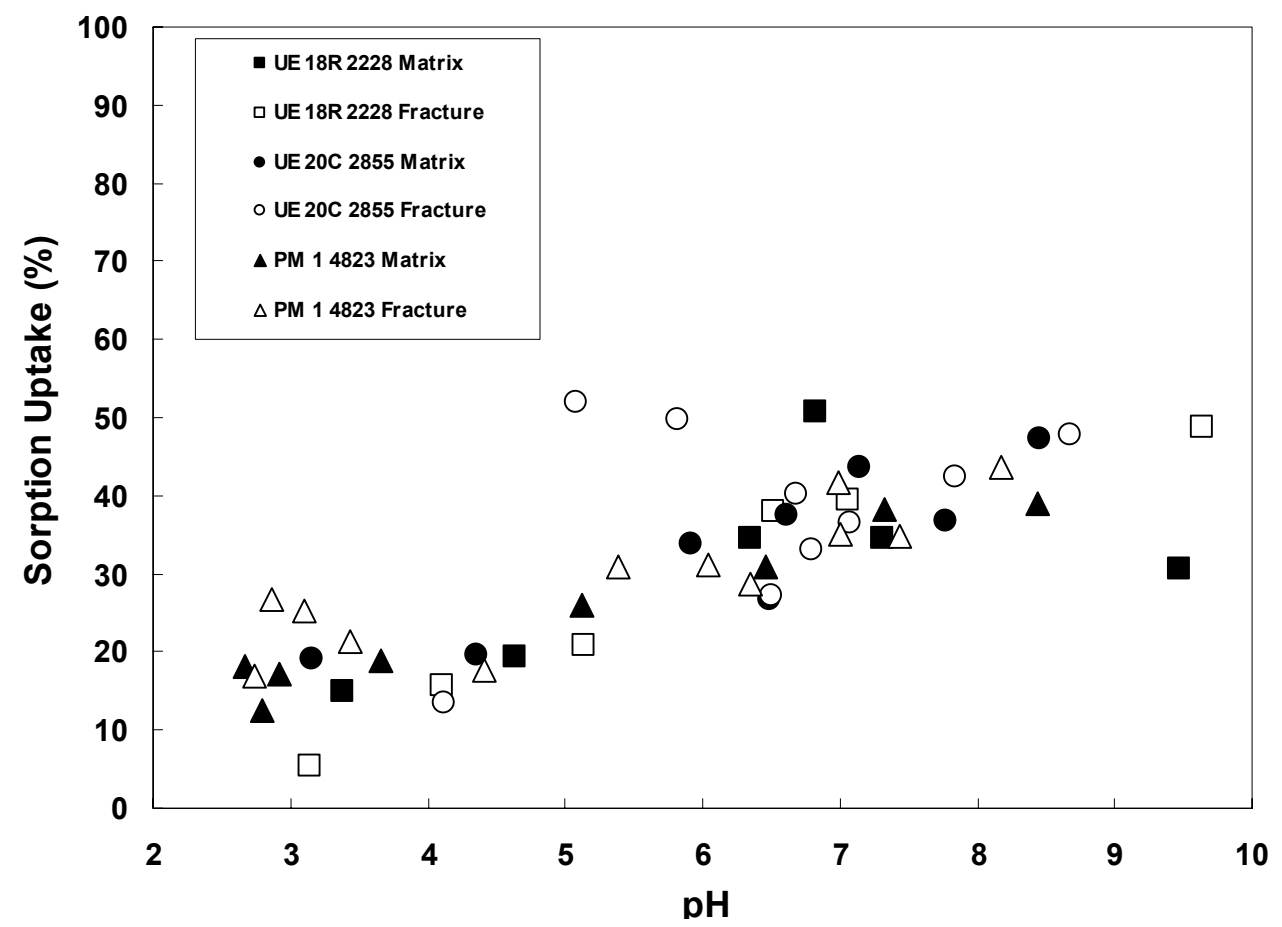

Figure 16. Sorption uptake of $10^{-5} \mathrm{M} \mathrm{Cs}$ by $10 \mathrm{~g} \mathrm{~L}^{-1}$ matrix and fracture samples. 
Cesium sorption with a metal concentration of $10^{-6} \mathrm{M}$ showed a slightly different result for the various core samples (Figure 17). Because of the one order of magnitude decrease in the initial metal concentration, there was decreased competition to occupy sorption sites and therefore Cs could react with easily accessible ion exchange sorption sites on smectites, resulting in $\mathrm{pH}$-independent sorption behavior. Higher fractional uptake, 40 to 85 percent in $10^{-6} \mathrm{M} \mathrm{Cs}$ compared to 10 to 70 percent in $10^{-5} \mathrm{M} \mathrm{Cs}$, and the reduced tendency of pH-dependent sorption behavior were contributed to the decreased initial metal concentration. Because of the high percentage of smectite and hematite in UE20c 2908, PM-1 4823, and PM-2 4177 samples, these samples showed higher Cs sorption uptake compared to UE18R 2228 and UE20c 2855. The comparison between experiments with matrix and fracture is also shown in Figure 18. There were no discernible differences between matrix and fracture, except in the PM-1 4823 samples. The PM-1 4823 Fracture showed higher sorption uptake than the PM-1 4823 Matrix, suggesting that minerals existing at fracture surfaces must be responsible for the enhanced total sorption capacity of the PM-1 4823 Fracture sample.

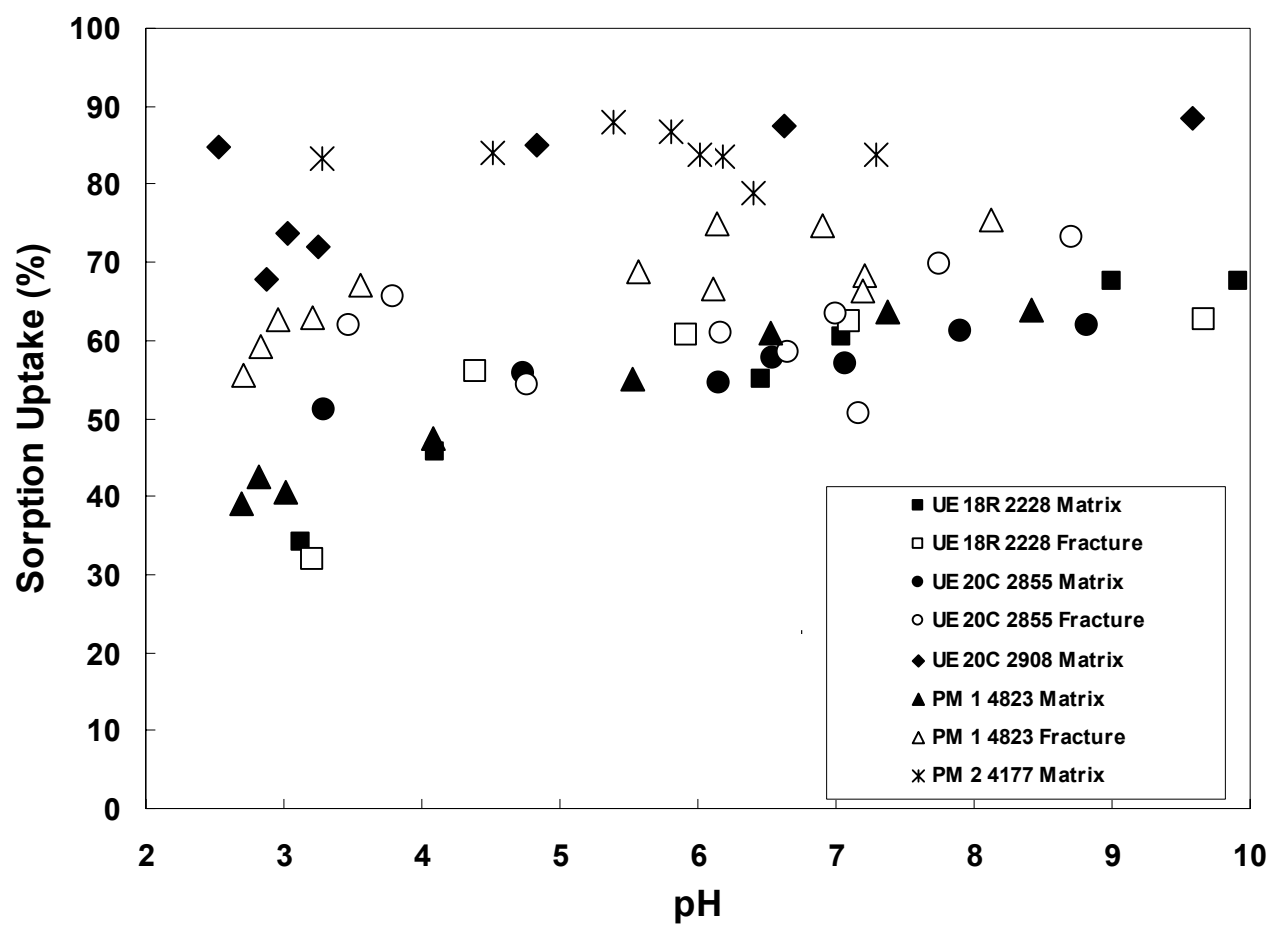

Figure 17. Sorption uptake of $10^{-6} \mathrm{M} \mathrm{Cs}$ by $10 \mathrm{~g} \mathrm{~L}^{-1}$ WPM samples.

The results of Sr sorption on $3 \mathrm{~g} \mathrm{~L}^{-1}$ solid samples are shown in Figure 19. Although some samples (UE20c 2908 and UE20c 2855 Matrix) showed approximately 10 percent of sorption uptake in the high-pH region, the Sr sorption uptake for most of the samples was negligible. The sorbents were pretreated with a high normality of $\mathrm{Ca}$ and $\mathrm{Na}$ solution in an attempt to remove the initial $\mathrm{Sr}$ existing either as part of the mineral structure or at cation exchange sites. Because of relatively high initial $\mathrm{Sr}$ concentration in the solid, even after pretreatment, $\mathrm{Sr}$ sorption experiments with $10^{-6} \mathrm{M}$ initial concentration could not be performed. The negligible $\mathrm{Sr}$ sorption uptake could be attributed to the high concentration of $\mathrm{Sr}$ in the solid. Even at higher solid concentration $\left(10 \mathrm{~g} \mathrm{~L}^{-1}\right)$ sorption experiments at the lower concentration, $10^{-6} \mathrm{M}$, could not be 
performed, because the higher solid concentration resulted in even more Sr leaching from the solid.

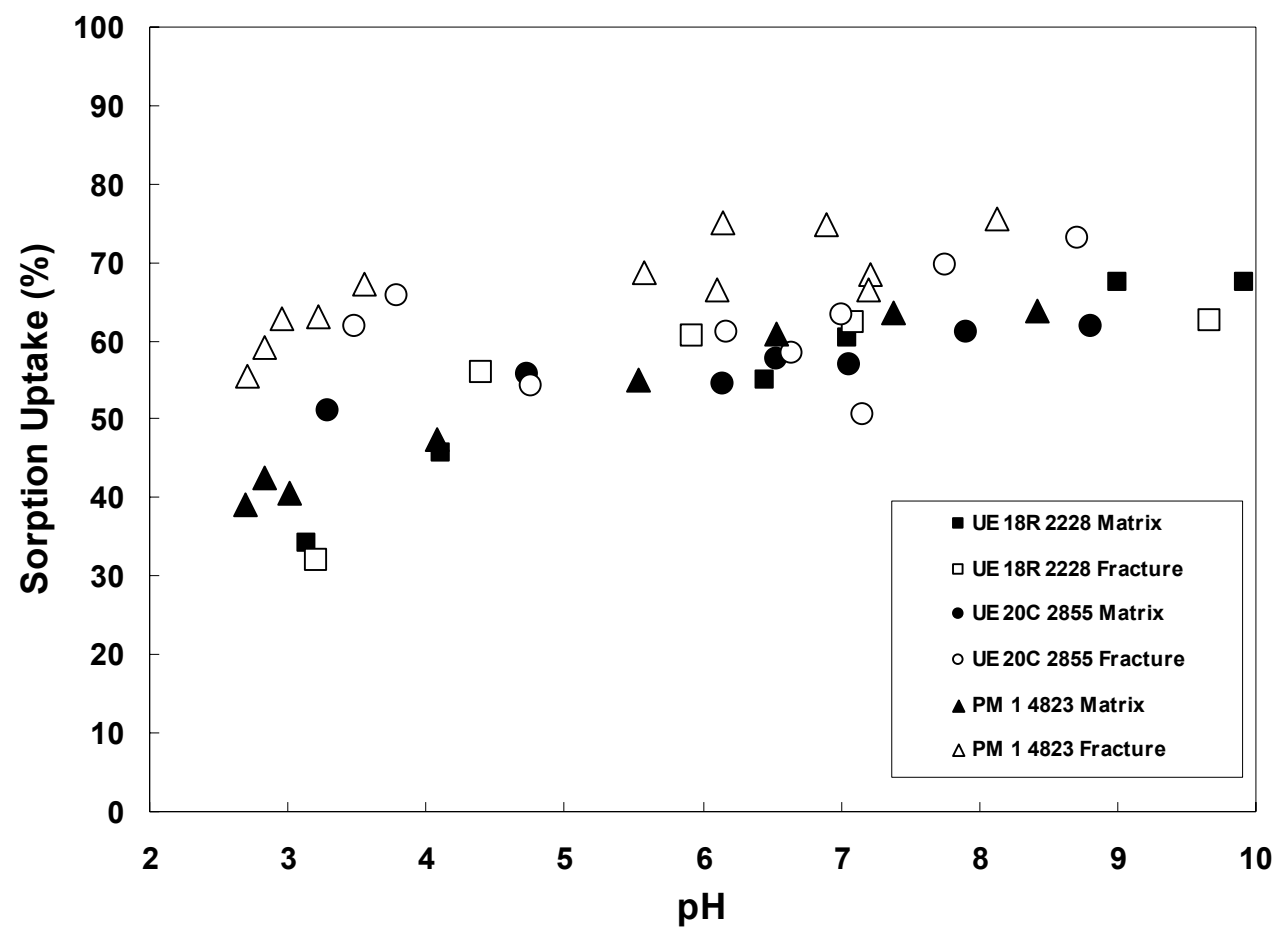

Figure 18. Sorption uptake of $10^{-6} \mathrm{M} \mathrm{Cs}$ by $10 \mathrm{~g} \mathrm{~L}^{-1}$ matrix and fracture samples.

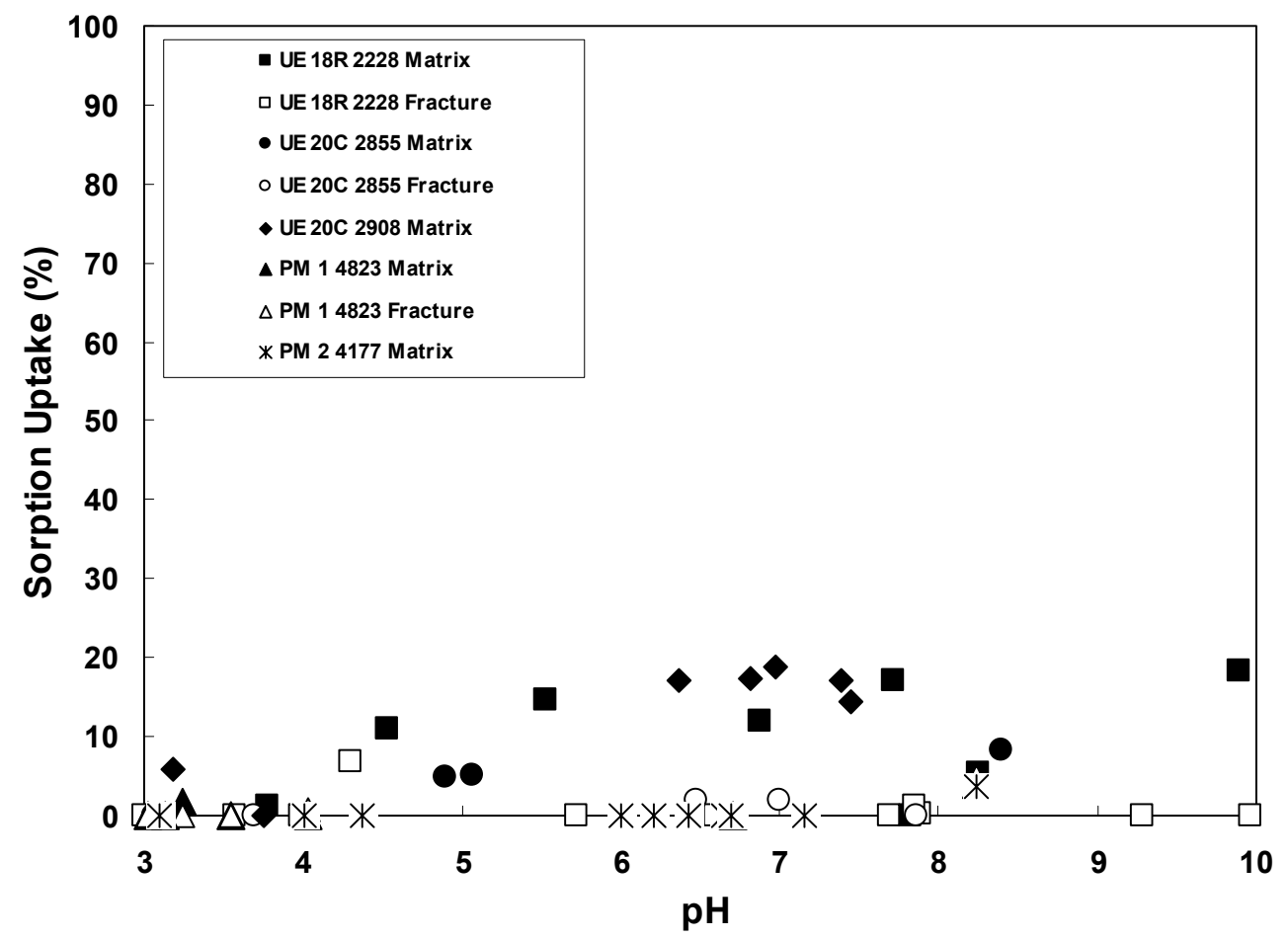

Figure 19. Sorption uptake of $10^{-5} \mathrm{M}$ Sr by $3 \mathrm{~g} \mathrm{~L}^{-1} \mathrm{WPM}$ samples. 
The sorption of $\mathrm{Pb}$ showed typical $\mathrm{pH}$-dependent sorption behavior on most solid materials. Surface hydroxyl sorption sites are negatively charged at high $\mathrm{pH}$ and the magnitude of negative surface charge increases with increasing $\mathrm{pH}$. A divalent cation, $\mathrm{Pb}$ showed higher sorption affinity for most samples at high $\mathrm{pH}$ (Figure 20). The low sorption uptake of $\mathrm{Pb}$ at low $\mathrm{pH}$ was attributed to both ion exchange and limited sorption on surface hydroxyl sorption sites. Because of high hydrolysis tendency (Baes and Mesmer, 1986) and the formation of inner-sphere complexes at high $\mathrm{pH}$ (Chisholm-Brause et al., 1989; Bargar et al., 1998; Farquhar et al., 1997), $\mathrm{Pb}$ sorption on the samples was highly $\mathrm{pH}$-dependent, suggesting that $\mathrm{Pb}$ ions would be strongly retarded by the WPM aquifer materials at the nominal $\mathrm{pH}$ of groundwater at the NTS $(\mathrm{pH}=8.3)$.

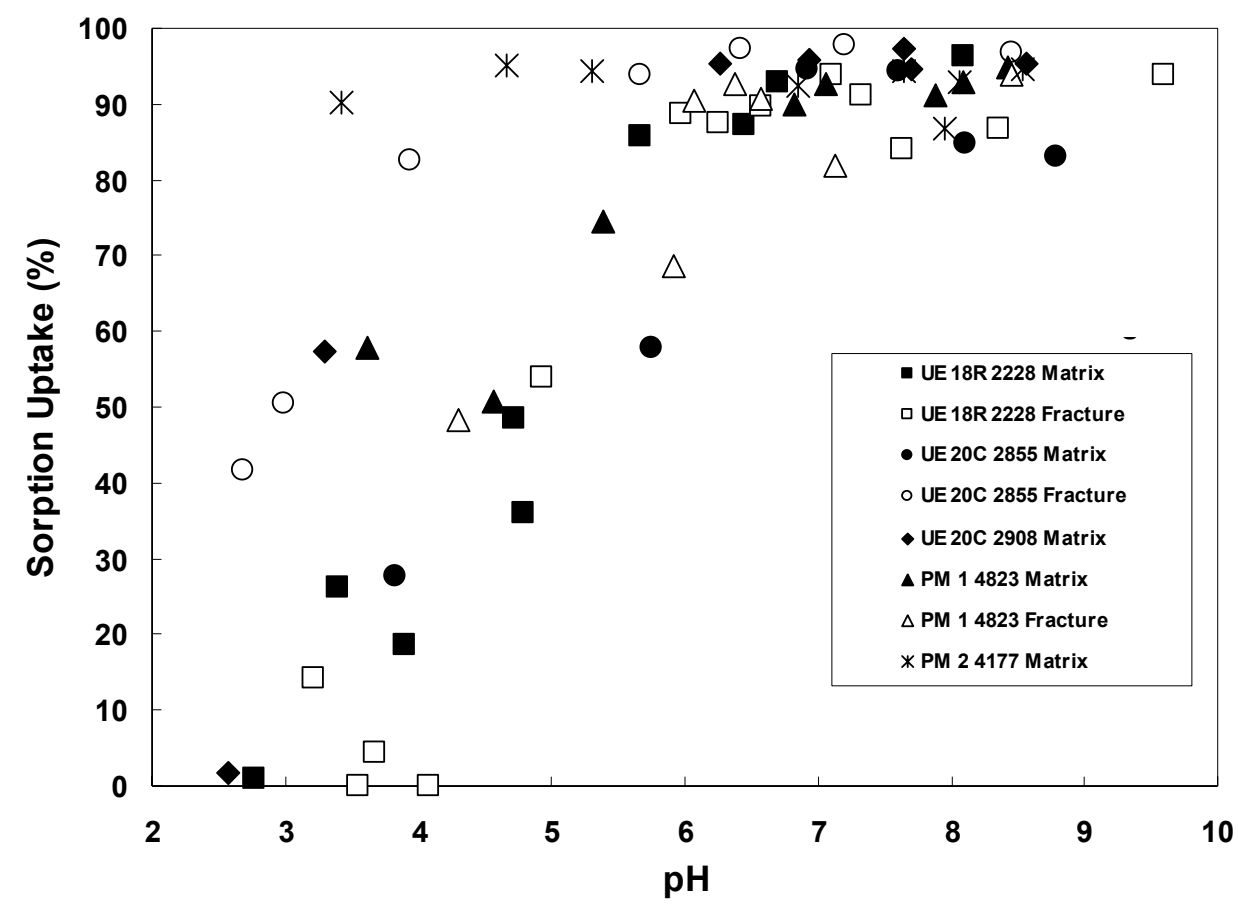

Figure 20. Sorption uptake of $10^{-6} \mathrm{M} \mathrm{Pb}$ by $3 \mathrm{~g} \mathrm{~L}^{-1} \mathrm{WPM}$ samples.

No significant differences in $\mathrm{Pb}$ sorption were observed for matrix and fracture samples, except for the UE20c 2855 samples, suggesting that the fracture sample showed slightly higher sorption capacity compared to the matrix sample (Figure 21). This difference, however, was not observed in $\mathrm{Pb}$ sorption at the higher initial concentration $\left(10^{-5} \mathrm{M}\right)$ (Figure 22). Because of increased sorption competition at high $\mathrm{Pb}$ initial concentration, $\mathrm{Pb}$ sorption uptake became more $\mathrm{pH}$-dependent and the sorption edge moved a little to higher $\mathrm{pH}$. Differences for $10^{-5} \mathrm{M} \mathrm{Pb}$ sorption on matrix and fracture were not significant, indicating no significant effects of fracture surfaces on $\mathrm{Pb}$ sorption. Because of the high sorption affinity of $\mathrm{Pb}$ for all surfaces, experiments with $10 \mathrm{~g} \mathrm{~L}^{-1}$ solid concentration were not conducted.

To test the anionic sorption capacity of WPM materials, chromate $\left(\mathrm{Cr}^{\mathrm{VI}}\right)$ was also used in batch sorption experiments. Most of the samples showed negligible sorption uptake of $\mathrm{Cr}^{\mathrm{VI}}$ at high pH (Figure 24). UE18R 2228 and UE20c 2855 Matrix samples showed weak pH-dependent sorption uptake of $\mathrm{Cr}^{\mathrm{VI}}$. Because $\mathrm{Cr}^{\mathrm{VI}}$ is negatively charged, $\mathrm{Cr}^{\mathrm{VI}}$ sorption uptake was a mirror image of $\mathrm{Pb}$ sorption. The sorption uptake of $\mathrm{Cr}^{\mathrm{VI}}$ decreased with increasing $\mathrm{pH}$. Since ionexchange sorption sites are usually negatively charged, $\mathrm{Cr}^{\mathrm{VI}}$, a negatively charged oxyanion, 


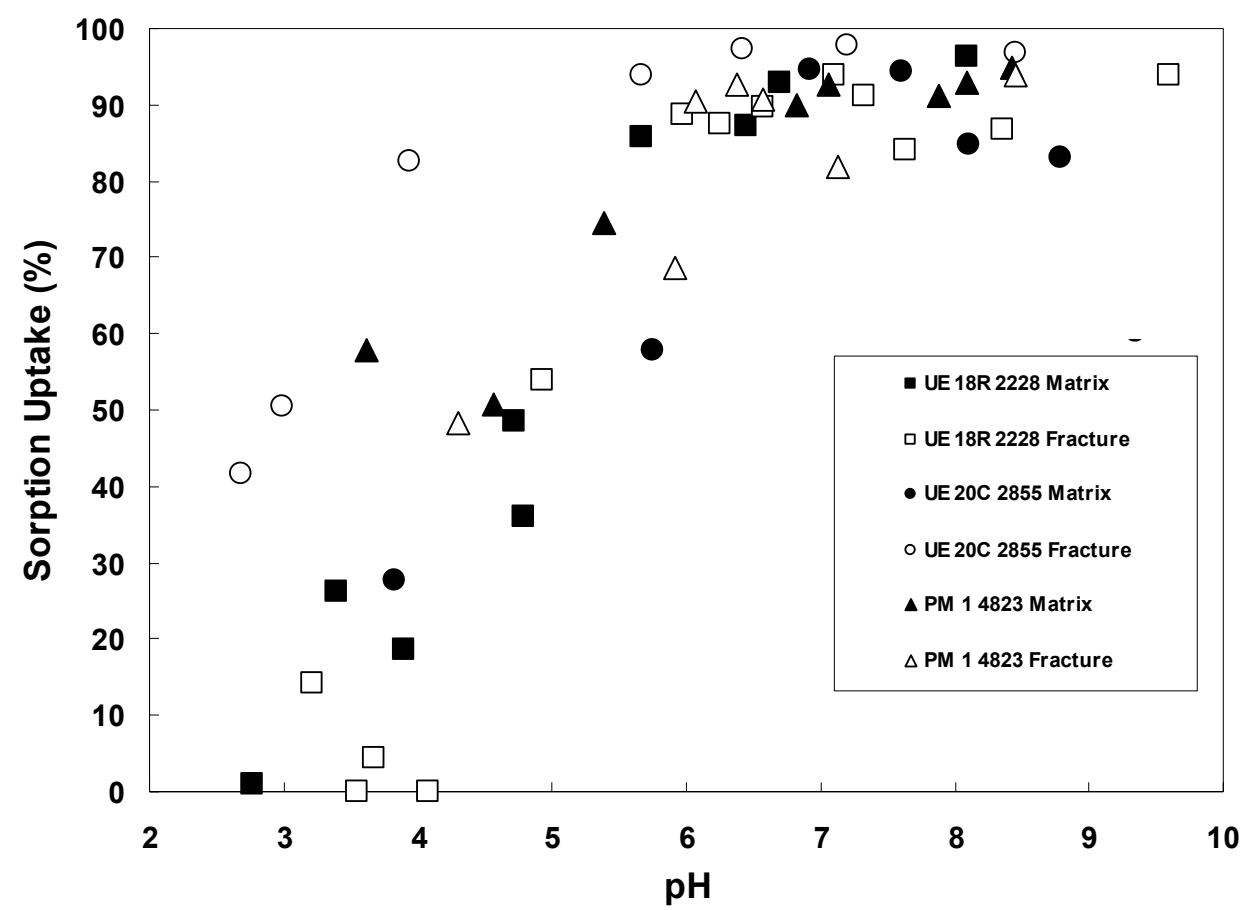

Figure 21. Sorption uptake of $10^{-6} \mathrm{M} \mathrm{Pb}$ by $3 \mathrm{~g} \mathrm{~L}^{-1}$ matrix and fracture samples.

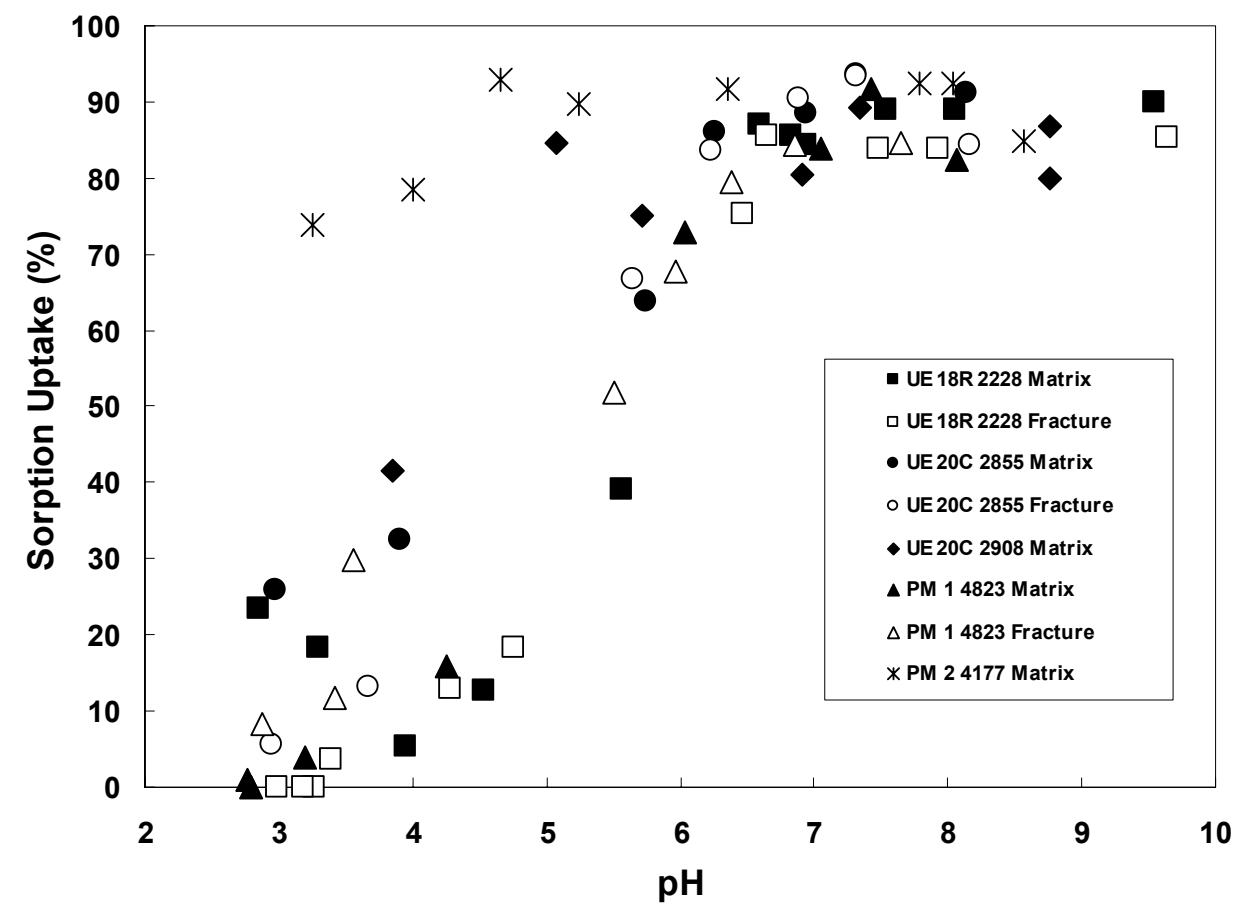

Figure 22. Sorption uptake of $10^{-5} \mathrm{M} \mathrm{Pb}$ by $3 \mathrm{~g} \mathrm{~L}^{-1} \mathrm{WPM}$ samples.

could react only with the limited number of surface hydroxyl sorption sites at low $\mathrm{pH}$. Higher fractional uptake of $\mathrm{Cr}^{\mathrm{VI}}$ was observed at low $\mathrm{pH}$. Most WPM core samples showed no $\mathrm{Cr}^{\mathrm{VI}}$ sorption at $\mathrm{pH}$ around 8.3 , suggesting that $\mathrm{Cr}$ would be highly mobile under natural condition at the NTS. 


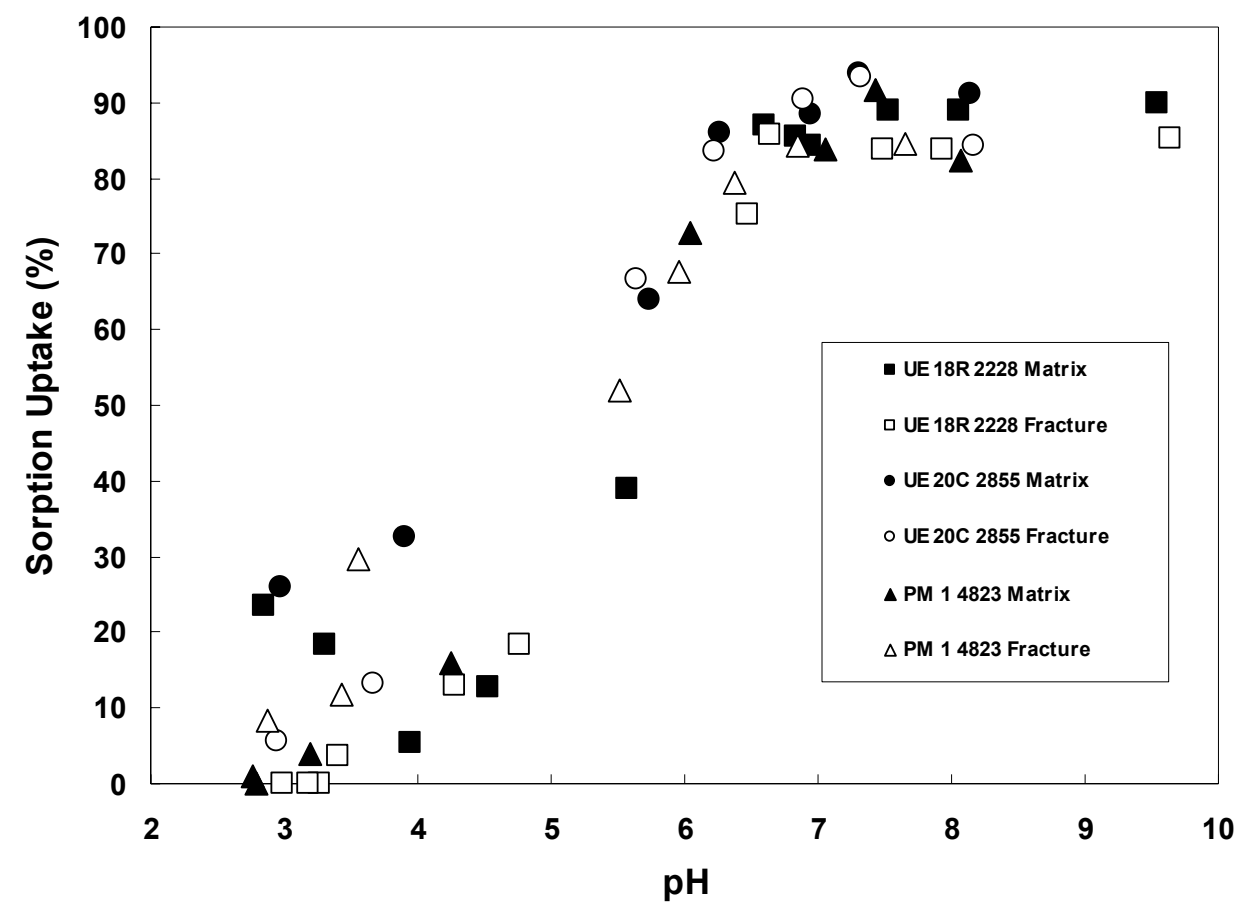

Figure 23. Sorption uptake of $10^{-5} \mathrm{M} \mathrm{Pb}$ by $3 \mathrm{~g} \mathrm{~L}^{-1}$ matrix and fracture samples.

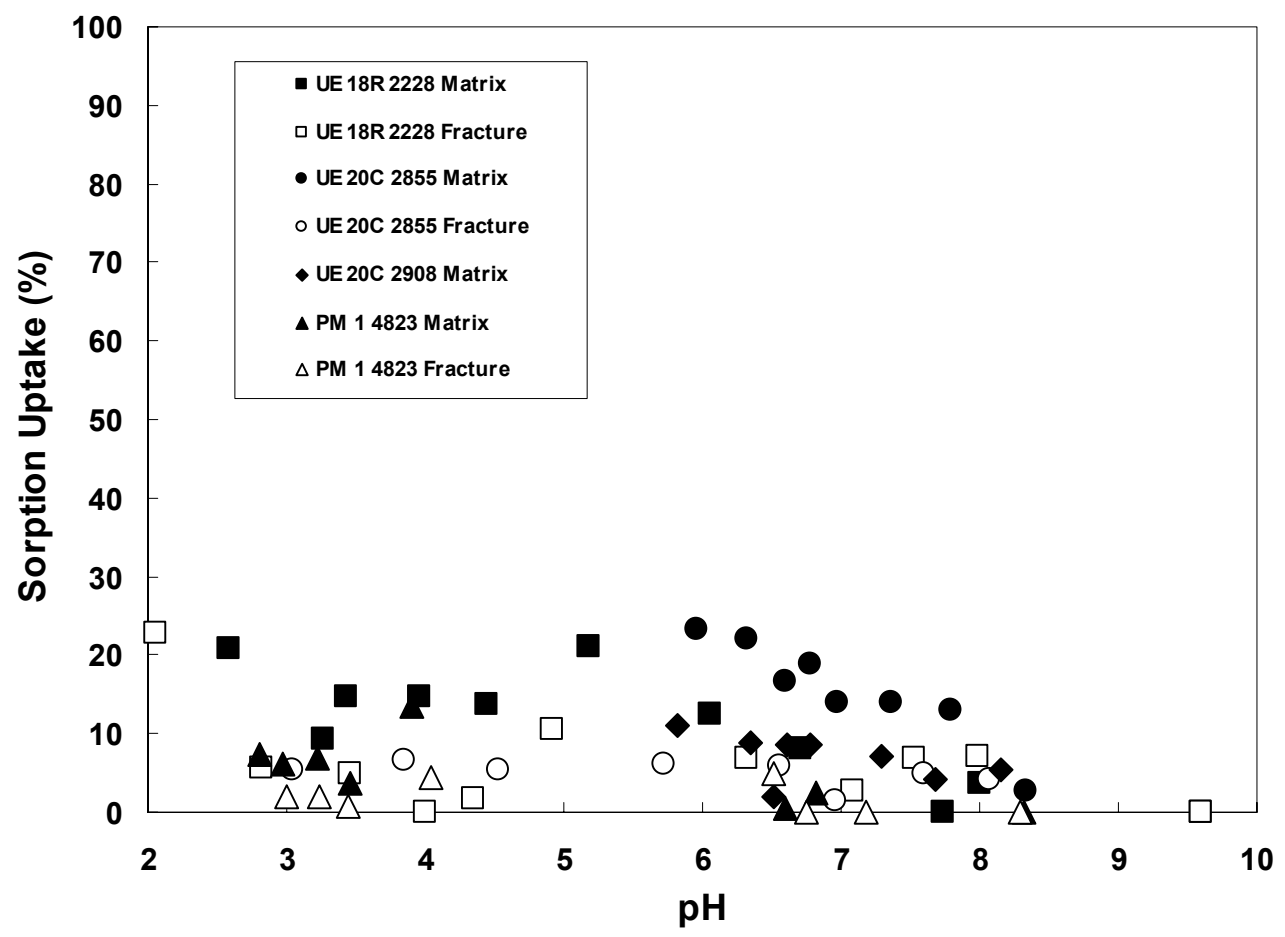

Figure 24. Sorption of $10^{-6}$ chromate on $10 \mathrm{~g} \mathrm{~L}^{-1}$ WPM samples.

\section{Desorption Experiments}

Desorption behavior of initially sorbed $\mathrm{Cs}$ and $\mathrm{Pb}$ from the WPM solids was tested by desorption experiments. Although the sorption uptake of metal ions is important, understanding the reversibility of metal ion sorption onto adsorbents is also necessary to predict the migration 
of contaminants. The release of Cs $\left(10^{-6} \mathrm{M}\right)$ from $10 \mathrm{~g} \mathrm{~L}^{-1}$ solid samples is shown in Figure 25 . The condition for initial sorption was selected to maximize sorption uptake. Most of the core samples showed 20 to 35 percent desorption after three days. UE20c 2908 and PM-2 4177 samples did not result in more than 10 percent desorption, consistent with the relatively strong sorption of Cs on these solids compared to the other solids, which was in good agreement with the previous sorption experiments (Figure 15). No significant differences in desorption release between matrix and fracture samples were found, as can be seen in Figure 26, as expected based on results from sorption experiments shown in Figure 16.

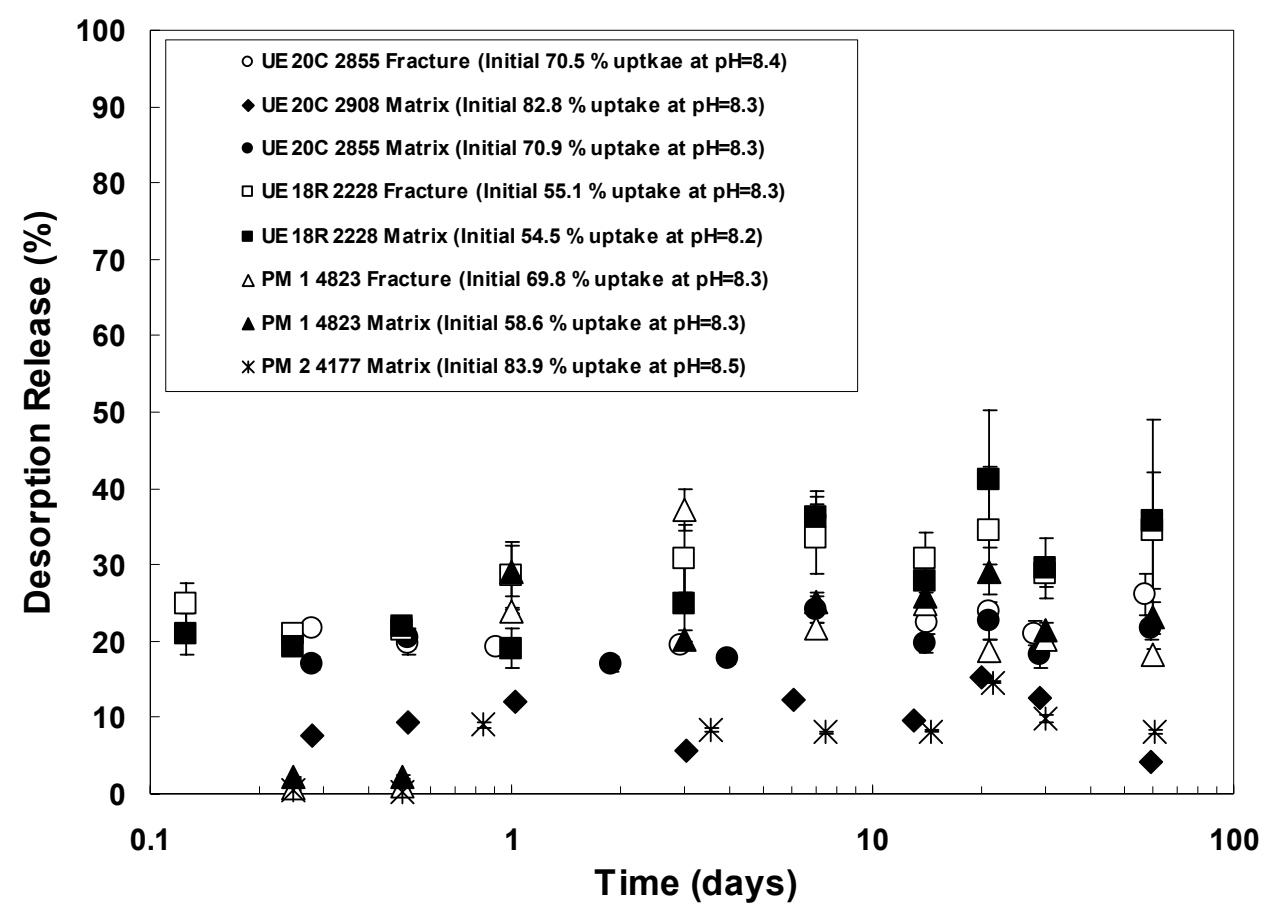

Figure 25. Percent Cs release following sorption of $10^{-6} \mathrm{M}$ Cs on $10 \mathrm{~g} \mathrm{~L}^{-1} \mathrm{WPM}$ samples.

Desorption experiments of initially high Cs concentration $\left(10^{-5} \mathrm{M}\right)$ showed slightly higher desorption releases (Figures 27 and 28) without significant differences between matrix and fracture, compared to those of $10^{-6} \mathrm{M}$ Cs. Enhanced desorption release (20 to 50 percent) at the higher initial Cs concentration $\left(10^{-5} \mathrm{M}\right)$ was considered to result from enhanced metal competition for sorption sites. Because of the competition at higher initial concentration $\left(10^{-5} \mathrm{M}\right)$, some Cs ions possibly would not bind tightly to the sorption sites, and would be released more easily when new synthetic groundwater solution was introduced to the samples. It should be emphasized that the individual points correspond to independent experiments, so that some noise in the data, because of analytical uncertainty, would be expected. For example, the Cs release result for sample UE20C 2855 matrix at 0.5 days is probably an outlier, a fact supported by the large error bar. Partial readsorption of Cs is also possible and would explain some of the observed behavior. Based on these desorption experiments, Cs showed partly reversible sorption behavior on the WPM materials.

The results of the experiments of $\mathrm{Pb}$ desorption were different from the results obtained with $\mathrm{Cs}$ (Figures 29 and 30). The average fractional release of Pb from WPM materials was 
about or less than 10 percent, suggesting that once $\mathrm{Pb}$ sorbed onto the solids, it was not easily released

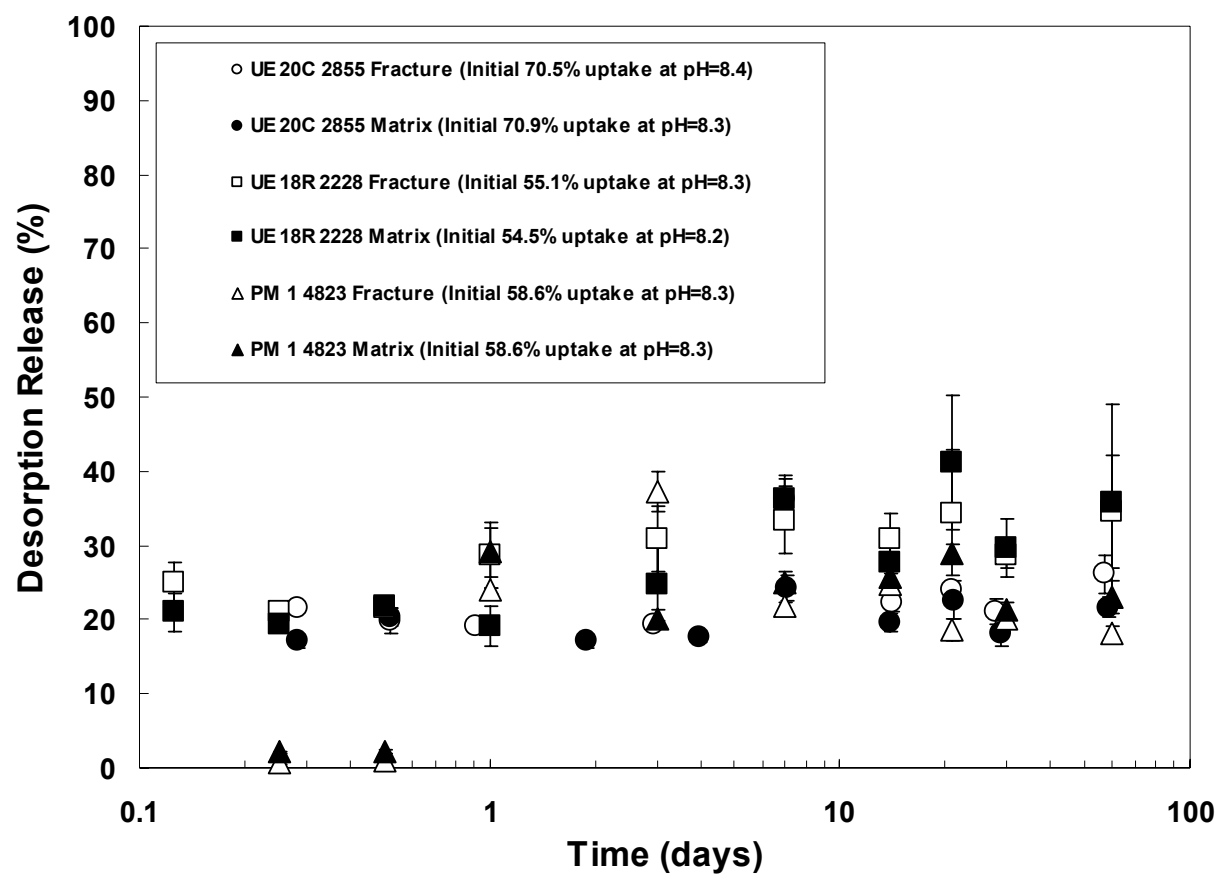

Figure 26. Percent Cs release following sorption of $10^{-6} \mathrm{M} \mathrm{Cs}$ on $10 \mathrm{~g} \mathrm{~L}^{-1}$ matrix and fracture samples.

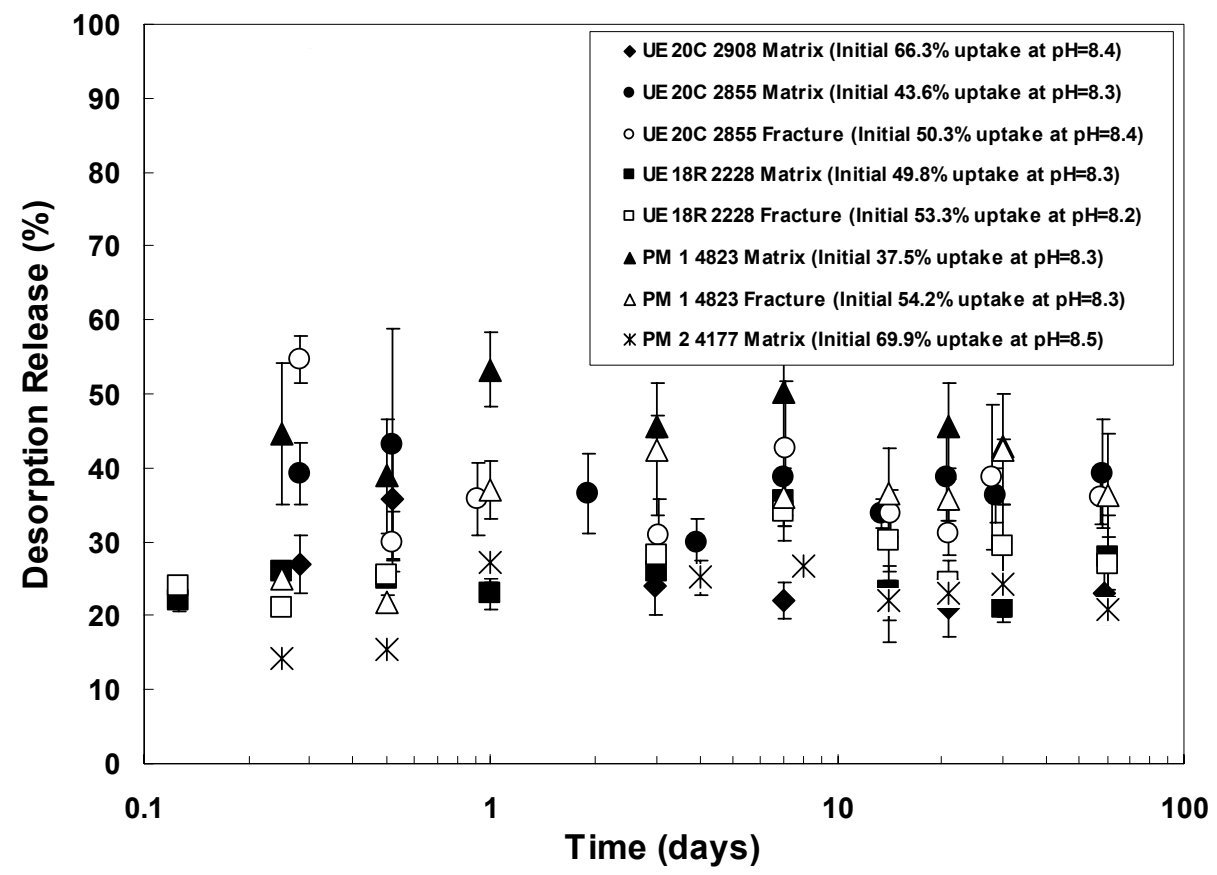

Figure 27. Percent Cs release following sorption of $10^{-5} \mathrm{M} \mathrm{Cs}$ on $10 \mathrm{~g} \mathrm{~L}^{-1} \mathrm{WPM}$ samples. 


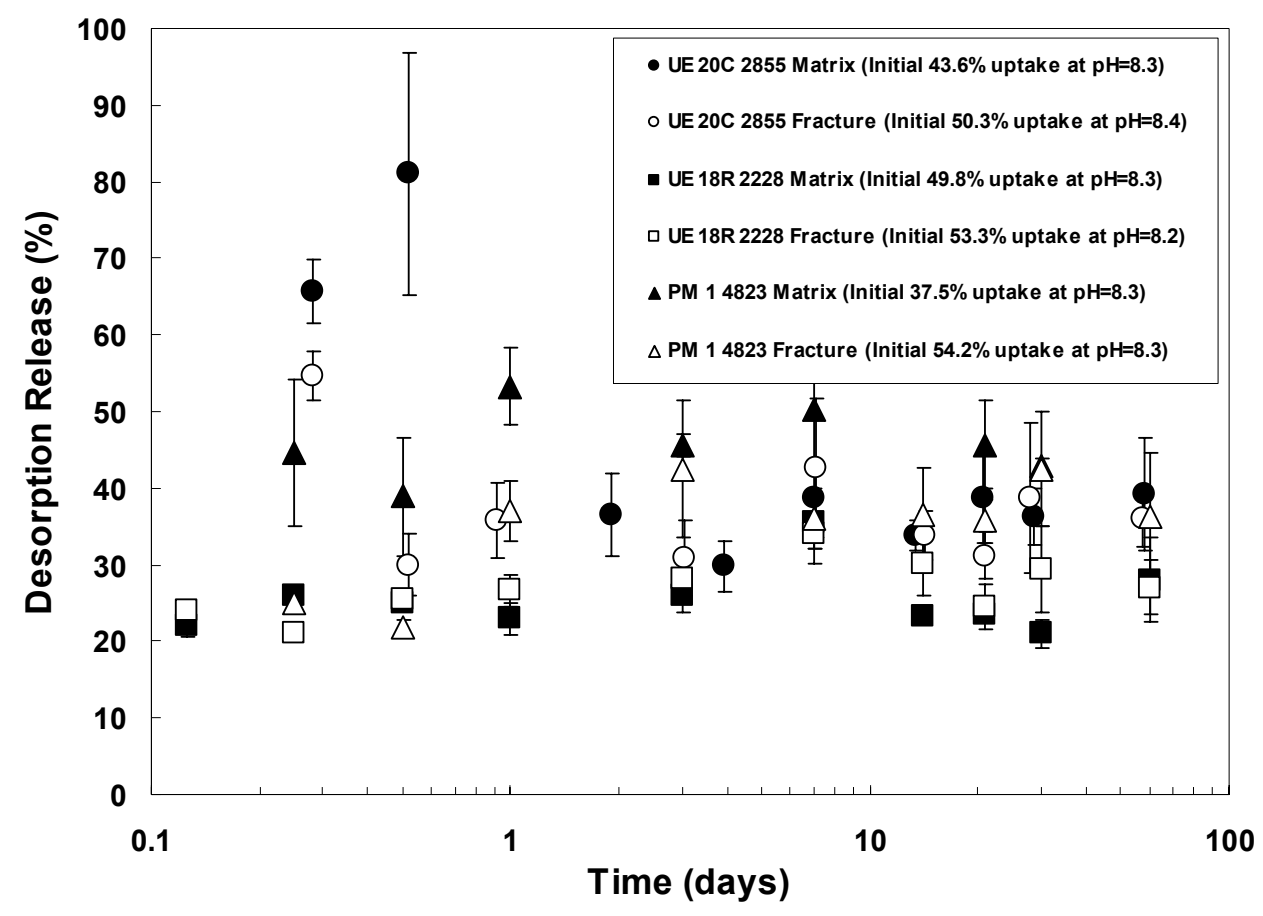

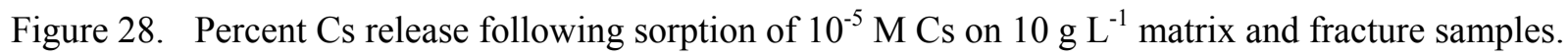

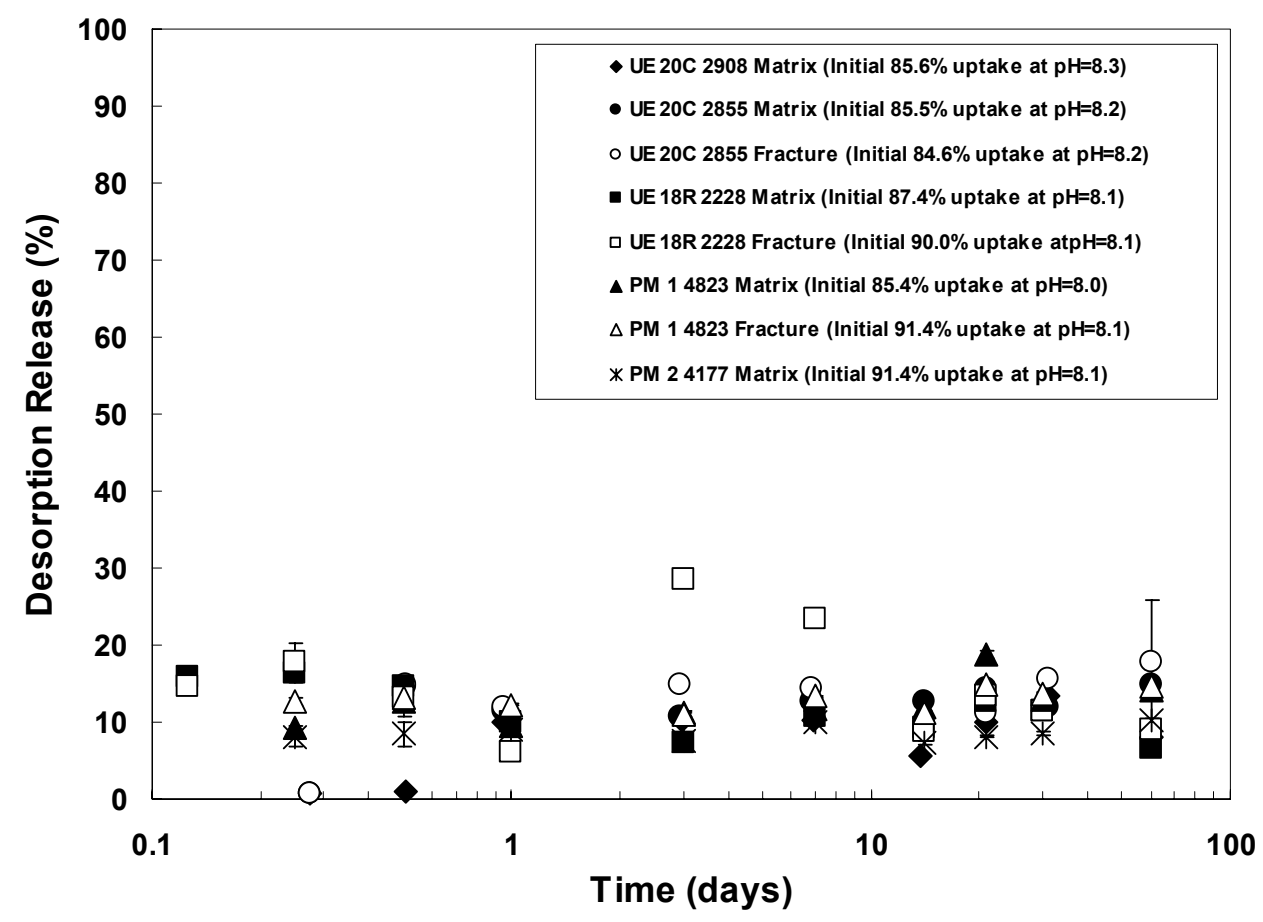

Figure 29. Percent $\mathrm{Pb}$ release following sorption of $10^{-5} \mathrm{M} \mathrm{Pb}$ on $3 \mathrm{~g} \mathrm{~L}^{-1} \mathrm{WPM}$ samples. 


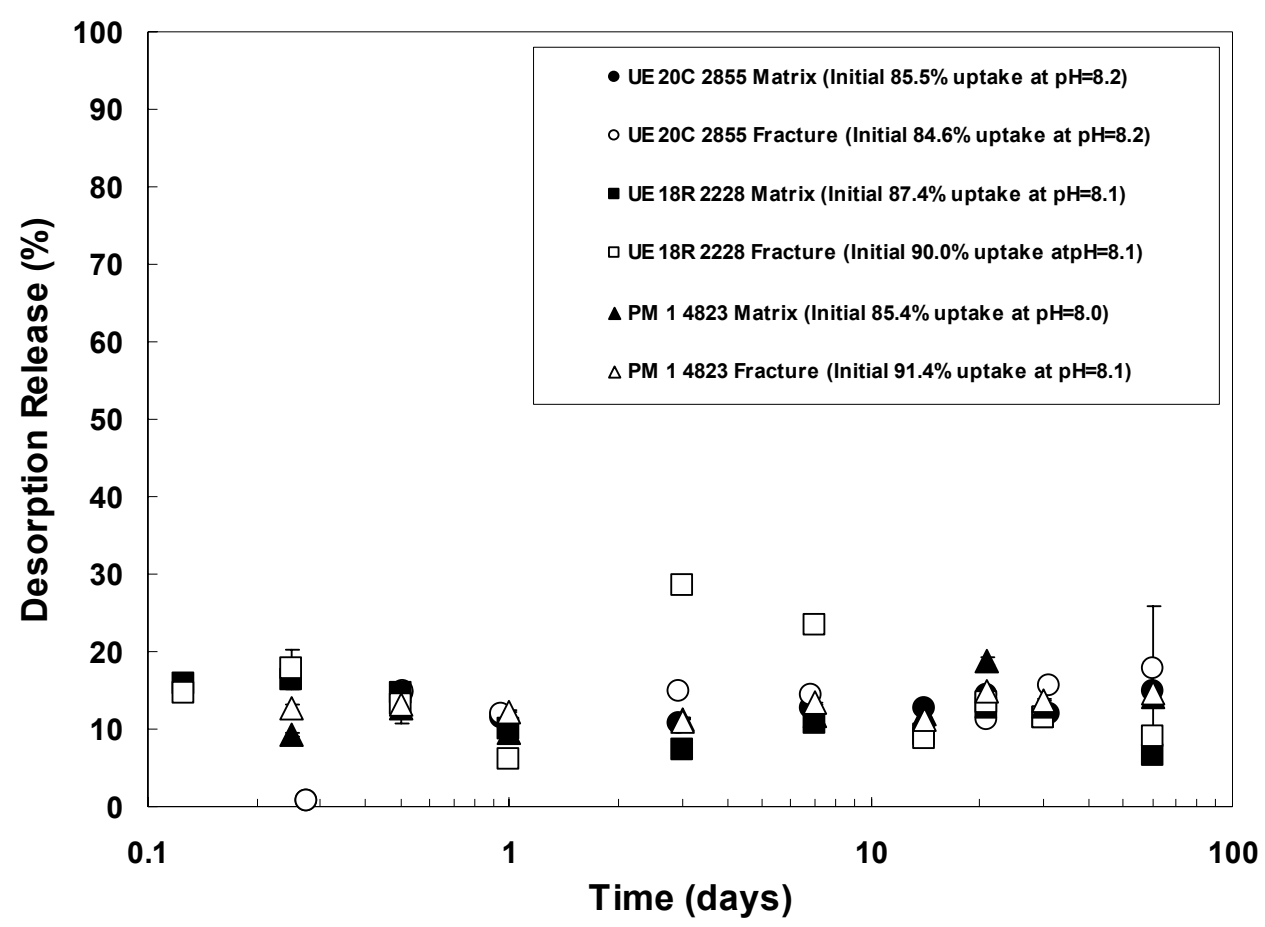

Figure 30. Percent $\mathrm{Pb}$ release following sorption of $10^{-5} \mathrm{M} \mathrm{Pb}$ on $3 \mathrm{~g} \mathrm{~L}^{-1}$ matrix and fracture samples.

under the same background electrolyte conditions as during initial sorption. The low desorption release of $\mathrm{Pb}$ was attributed to the much stronger sorption behavior of $\mathrm{Pb}$, compared to $\mathrm{Cs}$. As mentioned in the discussion of sorption experiments, because $\mathrm{Pb}$ forms inner-sphere complexes at high $\mathrm{pH}$, binding is much stronger and is more likely to be irreversible. Lead is easily sorbed on WPM materials and, therefore, $\mathrm{Pb}$ would be expected to be immobile at WPM under these geochemical conditions.

\section{Sorption/Desorption Isotherms}

The amount of solute sorbed onto the sorbents can be measured by the mass difference in the initial and the final metal solutions before and after reaction, respectively. A solute distribution coefficient between the solid and solution phases is widely used in transport model codes to predict the migration of contaminants in the subsurface environment. The equation (or its graphical representation) relating the concentration of a species adsorbed on a solid to its concentration in solution is often referred to as an isotherm (Drever, 1997). Several isotherms have been developed and used over the years; the most commonly used isotherms, however, are the linear, Freundlich, and Langmuir isotherms. Although the linear distribution coefficient, or $K_{\mathrm{d}}$, is a function of the property of solid, solute concentration, and geochemical conditions in the background solution, because of its simplicity and straightforward incorporation in transport models, $K_{\mathrm{d}} \mathrm{S}$ are still widely used in contaminant transport codes to incorporate surface chemical reactions.

Because of the frequently reversible sorption behavior of organic contaminants, linear distribution coefficients are more appropriate to predict organic contaminant sorption on aquifer materials (Curtis et al., $1986 \mathrm{a}, \mathrm{b}$ ). For inorganic contaminants, sometimes the Freundlich or Langmuir isotherms provide better prediction compared to the linear isotherm. However, for a limited range of conditions, such as low metal concentration, the non-linearity of the Freundlich 
and Langmuir isotherms is negligible so that the linear isotherm can be used without major differences between the three isotherms. Linear distribution coefficients $\left(K_{\mathrm{d}}\right)$ for sorption and desorption isotherms were determined by Equation (11)

$$
K_{\mathrm{d}}=\frac{S}{C_{e q}}
$$

where $S$ is the concentration of sorbed ions (sorbed metal ion mass per mass of sorbent, $\mathrm{M} \mathrm{M}^{-1}$ ) and $C_{e q}$ is the equilibrium metal ion concentration in solution $\left(\mathrm{M} \mathrm{L}^{-3}\right)$.

Sorption and desorption isotherms were obtained by changing metal and solid concentrations under fixed $\mathrm{pH}$ condition $(\mathrm{pH} \approx 8.3)$. Sorption isotherms were prepared after 48 hours equilibrium. Since 14 days were enough to reach the equilibrium based on the previous desorption experiments, the released metal concentration in the solution was measured after 14 days of new solution introduction. The linear distribution and isotherms of sorption and desorption with $\mathrm{Cs}$ and $\mathrm{Pb}$ are shown in Figures 31 to 36. Calculated distribution coefficients of sorption and desorption for $\mathrm{Cs}$ and $\mathrm{Pb}$ are also given in Table 3. Most samples showed high sorption $\mathrm{K}_{\mathrm{d}}$ values for Cs. Sorption $\mathrm{K}_{\mathrm{d}}$ values of $\mathrm{Cs}$ in fracture samples were found to be a little bit higher compared to that of the matrix samples. Sorption $\mathrm{K}_{\mathrm{d}}$ of $\mathrm{Pb}$ was usually higher than $\mathrm{Cs}$, consistent with the higher sorption affinity of $\mathrm{Pb}$ for most core samples compared to $\mathrm{Cs}$.

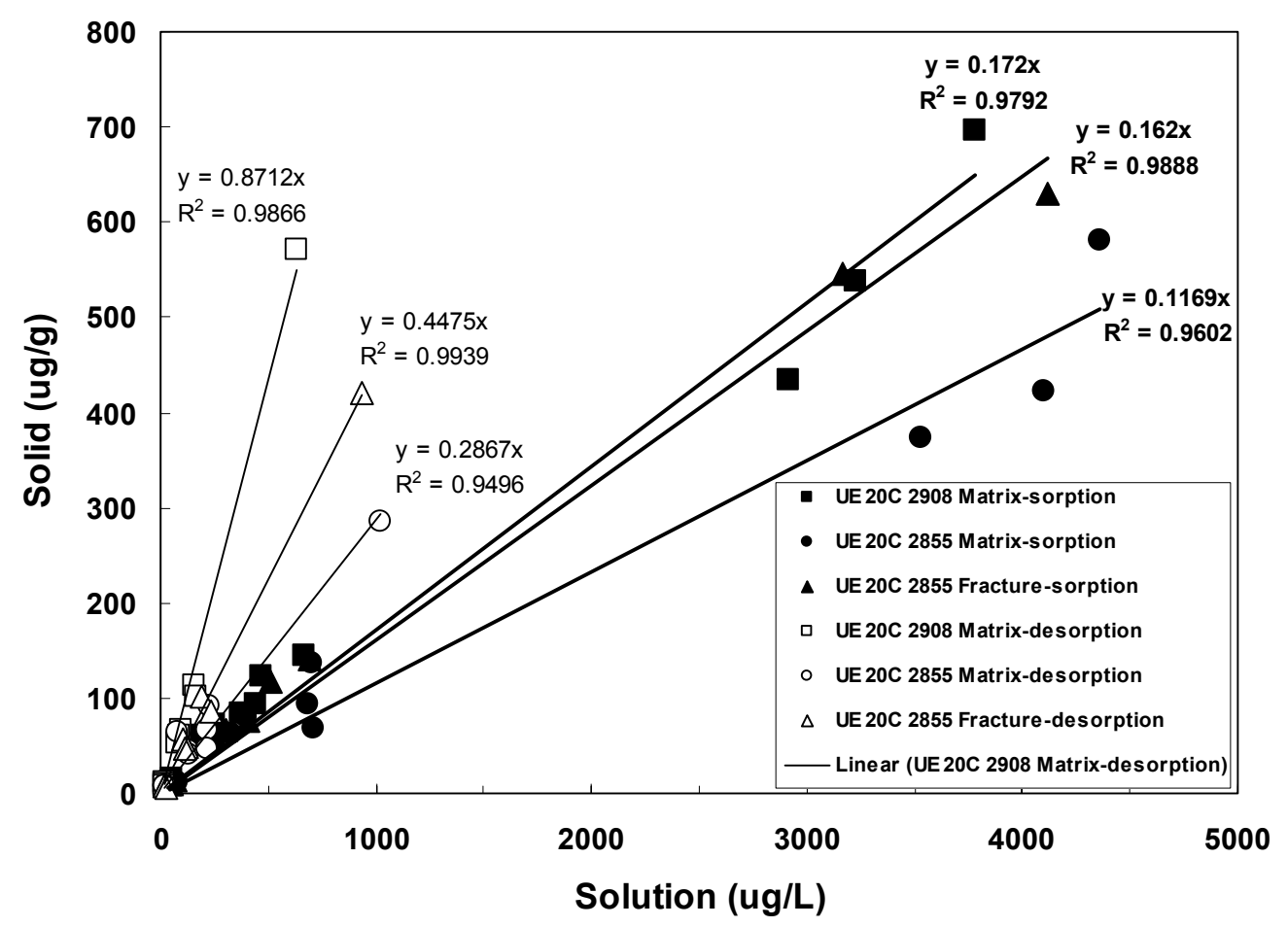

Figure 31. Linear sorption and desorption Cs isotherms for WPM samples. 


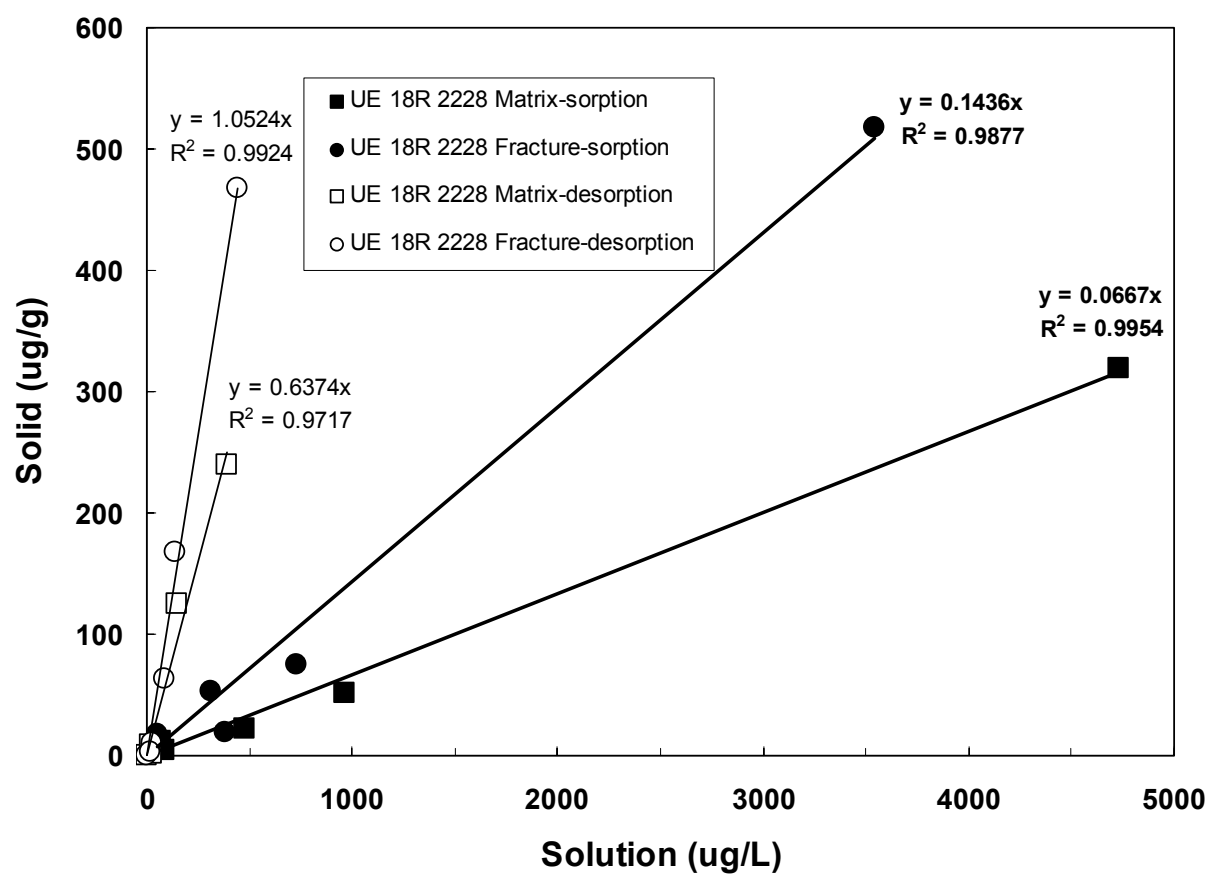

Figure 32. Linear sorption and desorption Cs isotherms for UE18R 2228 matrix and fracture samples.

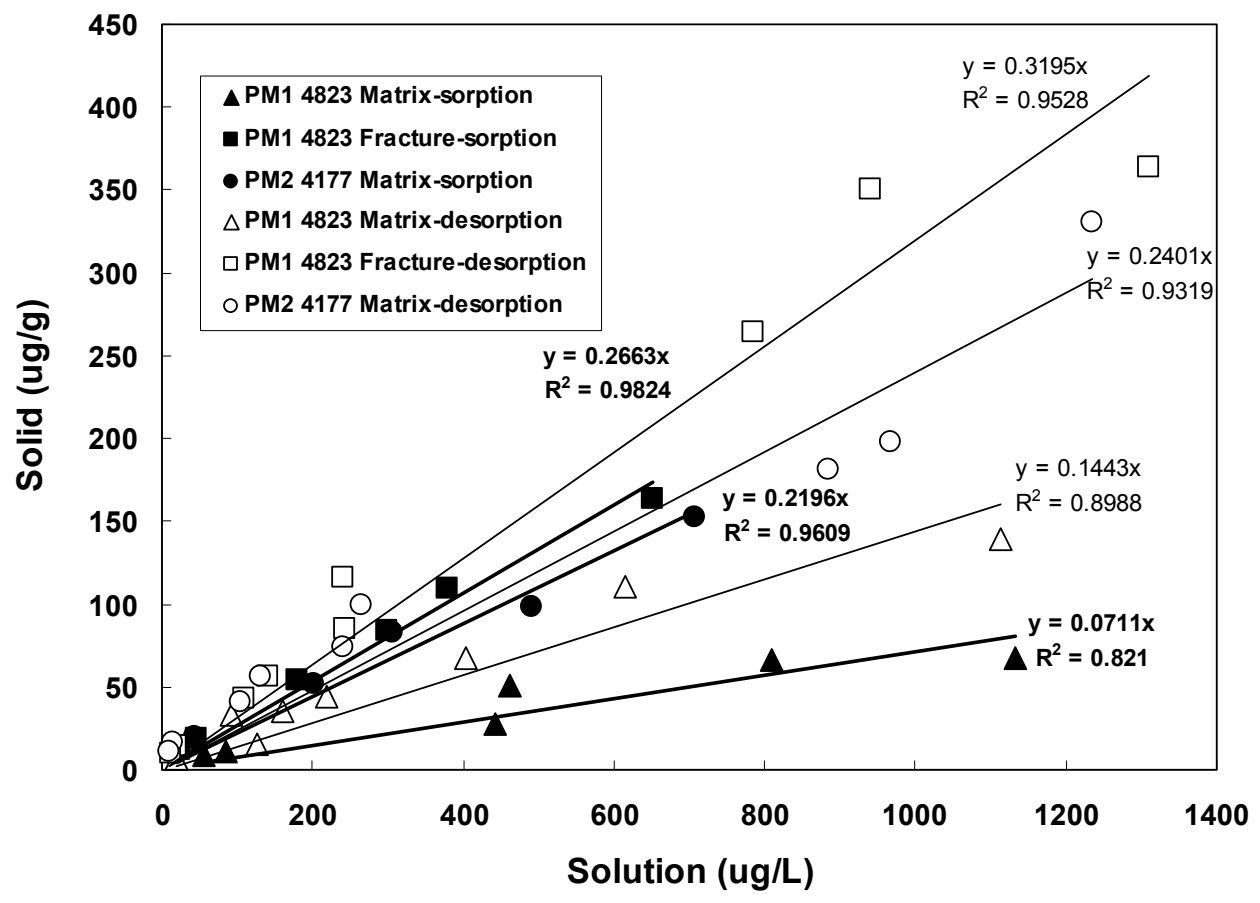

Figure 33. Linear sorption and desorption Cs isotherms for WPM samples. 


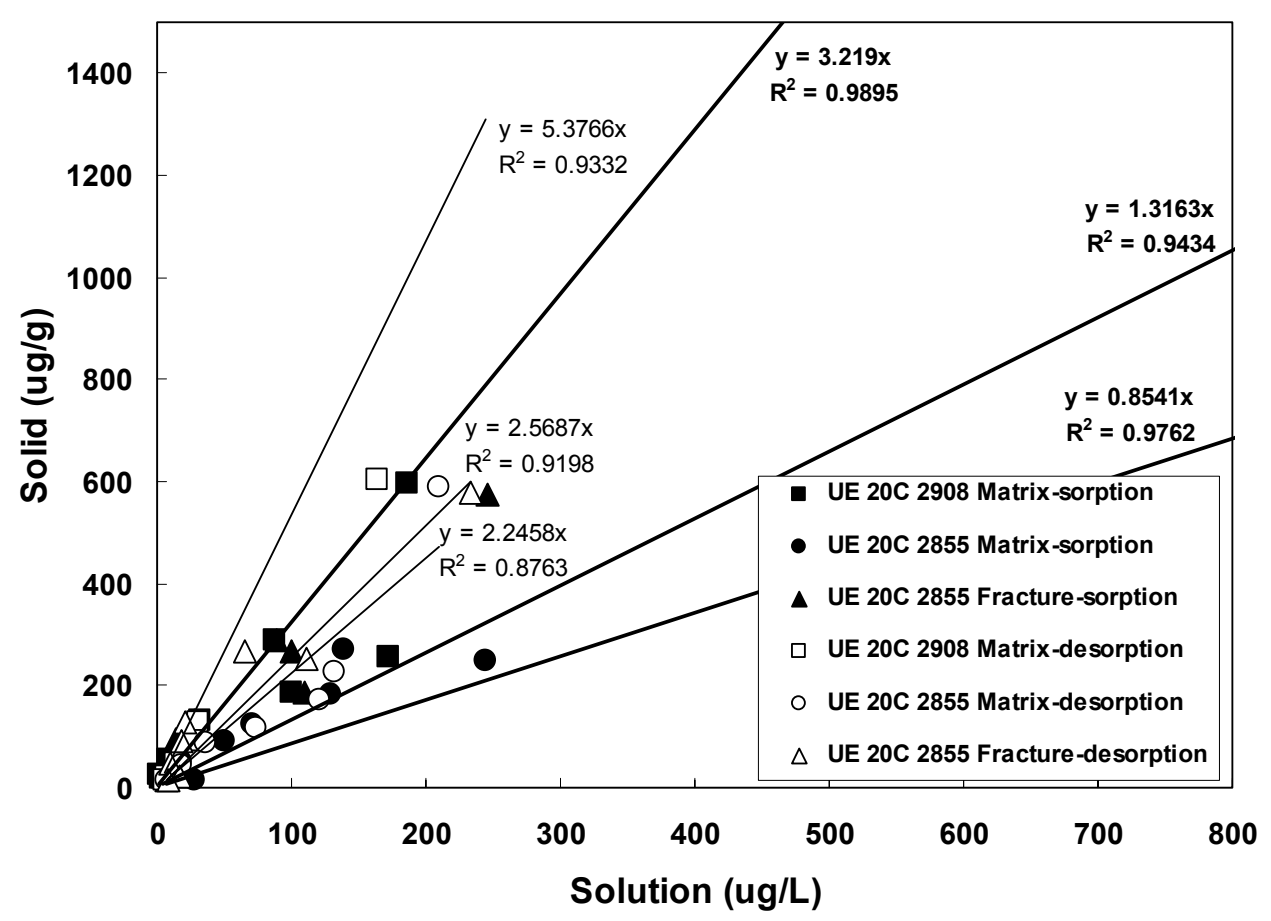

Figure 34. Linear sorption and desorption $\mathrm{Pb}$ isotherms for WPM samples.

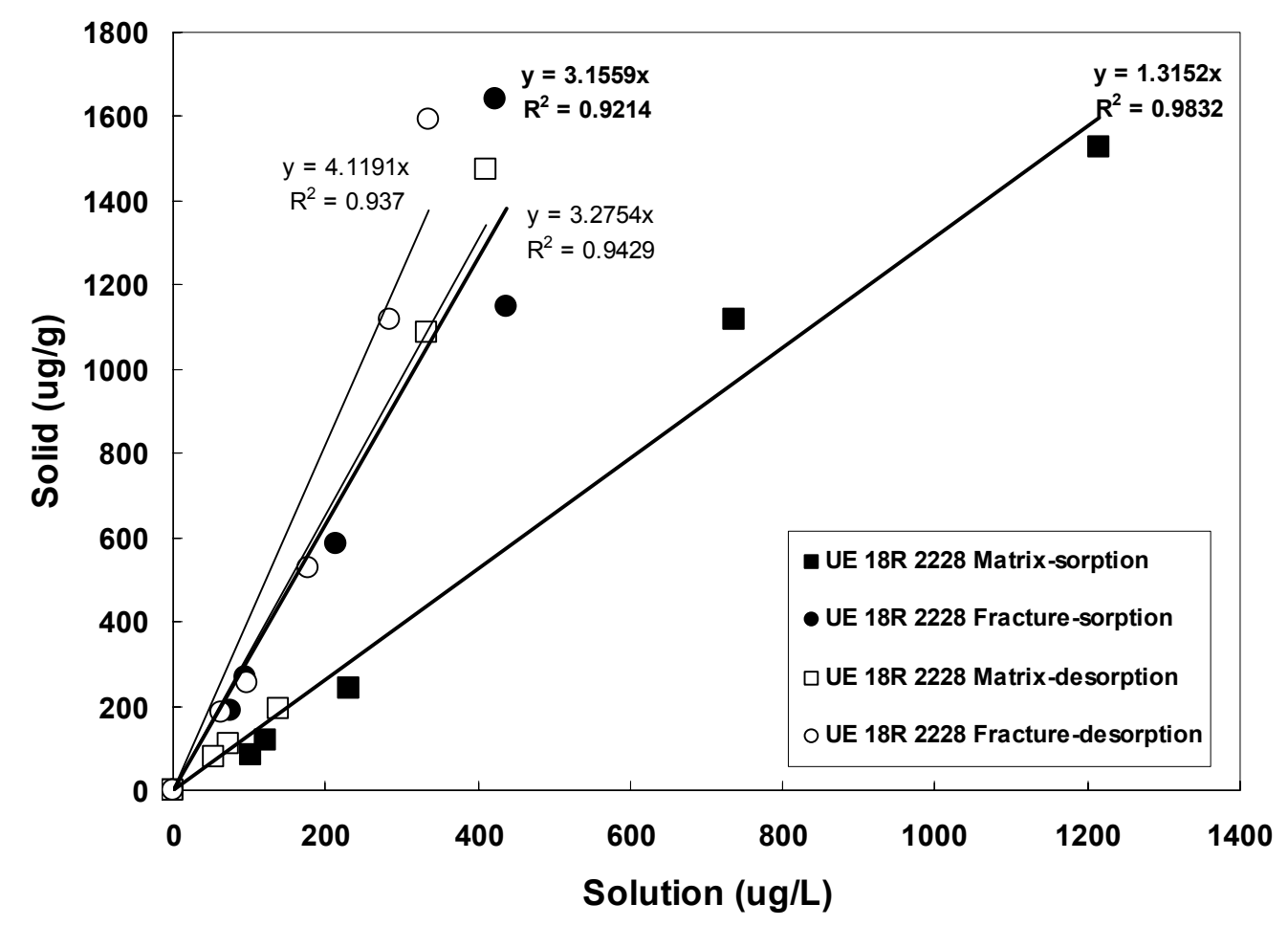

Figure 35. Linear sorption and desorption $\mathrm{Pb}$ isotherms for UE18R 2228 matrix and fracture samples. 


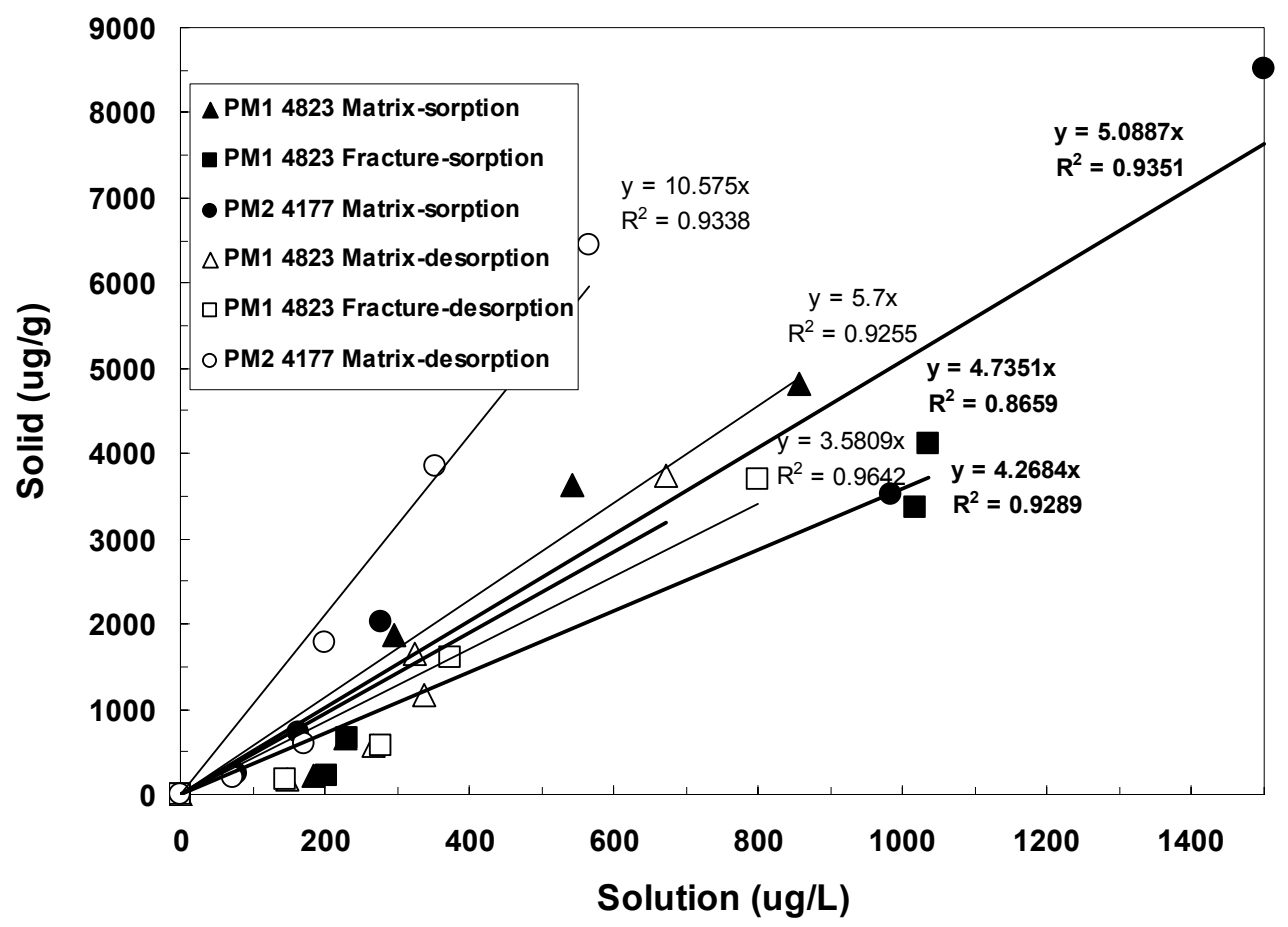

Figure 36. Linear sorption and desorption $\mathrm{Pb}$ isotherms for WPM samples.

Table 3. Linear sorption/desorption isotherms for $\mathrm{Cs}$ and $\mathrm{Pb}$.

\begin{tabular}{llllll}
\hline Core Samples & Metal & $\mathrm{K}_{\mathrm{d}(\mathrm{s})}\left(\mathrm{m}^{3} \mathrm{~g}^{-1}\right)^{*}$ & $\mathrm{R}^{2 \#}$ & $\mathrm{~K}_{\mathrm{d}(\mathrm{des})}\left(\mathrm{m}^{3} \mathrm{~g}^{-1}\right)^{+}$ & $\mathrm{R}^{2 \#}$ \\
\hline UE18R 2228 Fracture & $\mathrm{Cs}$ & $1.44 \times 10^{-4}$ & 0.988 & $1.05 \times 10^{-3}$ & 0.992 \\
UE18R 2228 Matrix & $\mathrm{Cs}$ & $6.67 \times 10^{-5}$ & 0.995 & $6.37 \times 10^{-4}$ & 0.972 \\
UE20C 2908 & $\mathrm{Cs}$ & $1.72 \times 10^{-4}$ & 0.979 & $8.71 \times 10^{-4}$ & 0.987 \\
UE20C 2855 Matrix & $\mathrm{Cs}$ & $1.17 \times 10^{-4}$ & 0.960 & $2.87 \times 10^{-4}$ & 0.950 \\
UE20C 2855 Fracture & $\mathrm{Cs}$ & $1.62 \times 10^{-4}$ & 0.989 & $4.48 \times 10^{-4}$ & 0.994 \\
PM-1 4823 Matrix & $\mathrm{Cs}$ & $7.11 \times 10^{-5}$ & 0.821 & $1.44 \times 10^{-4}$ & 0.899 \\
PM-1 4823 Fracture & $\mathrm{Cs}$ & $2.66 \times 10^{-4}$ & 0.982 & $3.20 \times 10^{-4}$ & 0.953 \\
PM-2 4177 & $\mathrm{Cs}$ & $2.20 \times 10^{-4}$ & 0.961 & $2.40 \times 10^{-4}$ & 0.932 \\
UE18R 2228 Fracture & $\mathrm{Pb}$ & $3.16 \times 10^{-3}$ & 0.921 & $4.12 \times 10^{-3}$ & 0.937 \\
UE18R 2228 Matrix & $\mathrm{Pb}$ & $1.32 \times 10^{-3}$ & 0.983 & $3.28 \times 10^{-3}$ & 0.943 \\
UE20C 2908 & $\mathrm{Pb}$ & $3.22 \times 10^{-3}$ & 0.990 & $5.38 \times 10^{-3}$ & 0.933 \\
UE20C 2855 Matrix & $\mathrm{Pb}$ & $8.54 \times 10^{-4}$ & 0.976 & $2.25 \times 10^{-3}$ & 0.876 \\
UE20C 2855 Fracture & $\mathrm{Pb}$ & $1.32 \times 10^{-3}$ & 0.943 & $2.57 \times 10^{-3}$ & 0.920 \\
PM-1 4823 Matrix & $\mathrm{Pb}$ & $4.74 \times 10^{-3}$ & 0.866 & $5.70 \times 10^{-3}$ & 0.926 \\
PM-1 4823 Fracture & $\mathrm{Pb}$ & $4.27 \times 10^{-3}$ & 0.929 & $3.58 \times 10^{-3}$ & 0.964 \\
PM-2 4177 & $\mathrm{Pb}$ & $5.09 \times 10^{-3}$ & 0.935 & $10.6 \times 10^{-3}$ & 0.934 \\
\hline
\end{tabular}

* Sorption $\mathrm{K}_{\mathrm{d}}$

${ }^{+}$Desorption $\mathrm{K}_{\mathrm{d}}$

${ }^{\#}$ Correlation coefficient

Distribution coefficients derived from desorption isotherms for $\mathrm{Cs}$ and $\mathrm{Pb}$ were always higher than from sorption isotherms, suggesting a sorption-desorption hysteresis. The hysteresis suggests that sorption of $\mathrm{Cs}$ and $\mathrm{Pb}$ on WPM core samples is not completely reversible. The 
hysteresis of $\mathrm{Cs}$ and $\mathrm{Pb}$ was in good agreement with previous desorption experimental results showing 20 to 30 percent desorption for $\mathrm{Cs}$ and 10 percent for $\mathrm{Pb}$. Based on the sorption/desorption isotherms, most $\mathrm{Pb}$ ions showed high affinities for WPM core samples and once $\mathrm{Pb}$ ions reacted with the sorbents, they would not desorb significantly, as long as the background electrolyte conditions did not change. These results indicate that $\mathrm{Pb}$ sorption was partly irreversible. Although Cs sorption was low compared to $\mathrm{Pb}, \mathrm{Cs}$ desorption also showed high hysteresis, reflecting relatively strong sorption affinity for the WPM core samples for this cation as well.

\section{Diffusion Experiments}

\section{Diffusion of the Nonreactive Tracer Bromide}

The total amount of Br ions diffused through the diffusion slabs of WPM core samples was plotted as a function of time to determine the $D_{\text {eff }}$ for $\mathrm{Br}$. The diffusion of $\mathrm{Br}$ is shown in Figure 37. The breakthrough showed a curve in transient state during the early period, for approximately five to six days, and a straight line in steady state after a certain amount of time has passed. The effective diffusion coefficient of $\mathrm{Br}$ was determined by the slope of Equation (10). Because $\mathrm{Br}$ is a nonreactive tracer, the effective diffusivity of $\mathrm{Br}$ was controlled by physical factors such as porosity and tortuosity. The molecular diffusivity, $D_{m o l}$, of $\mathrm{Br}$ was calculated using the Nernst-Haskell equation. The tortuosity factor for each sample was determined from the calculated $D_{m o l}$ and the measured $D_{\text {eff }}$ using Equation (8). The measured diffusivities of $\mathrm{Br}$ and the calculated tortuosity factors are shown in Table 4 . The diffusion results of $\mathrm{Br}$ with a different scale in the $\mathrm{Y}$-axis are shown in Figure 38 to increase resolution during the early stages of the experiments.

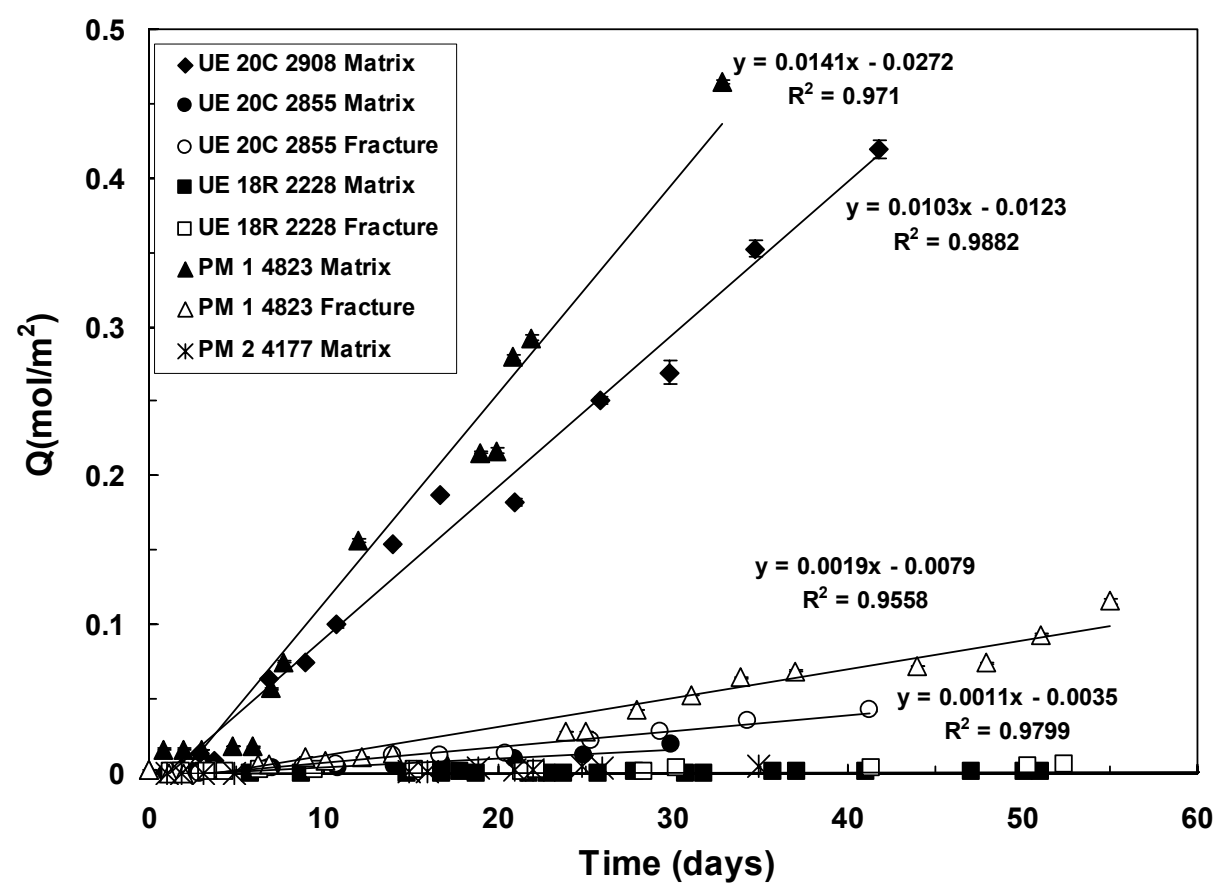

Figure 37. Bromide diffusion in WPM cores; duration of experiment: 60 days. 


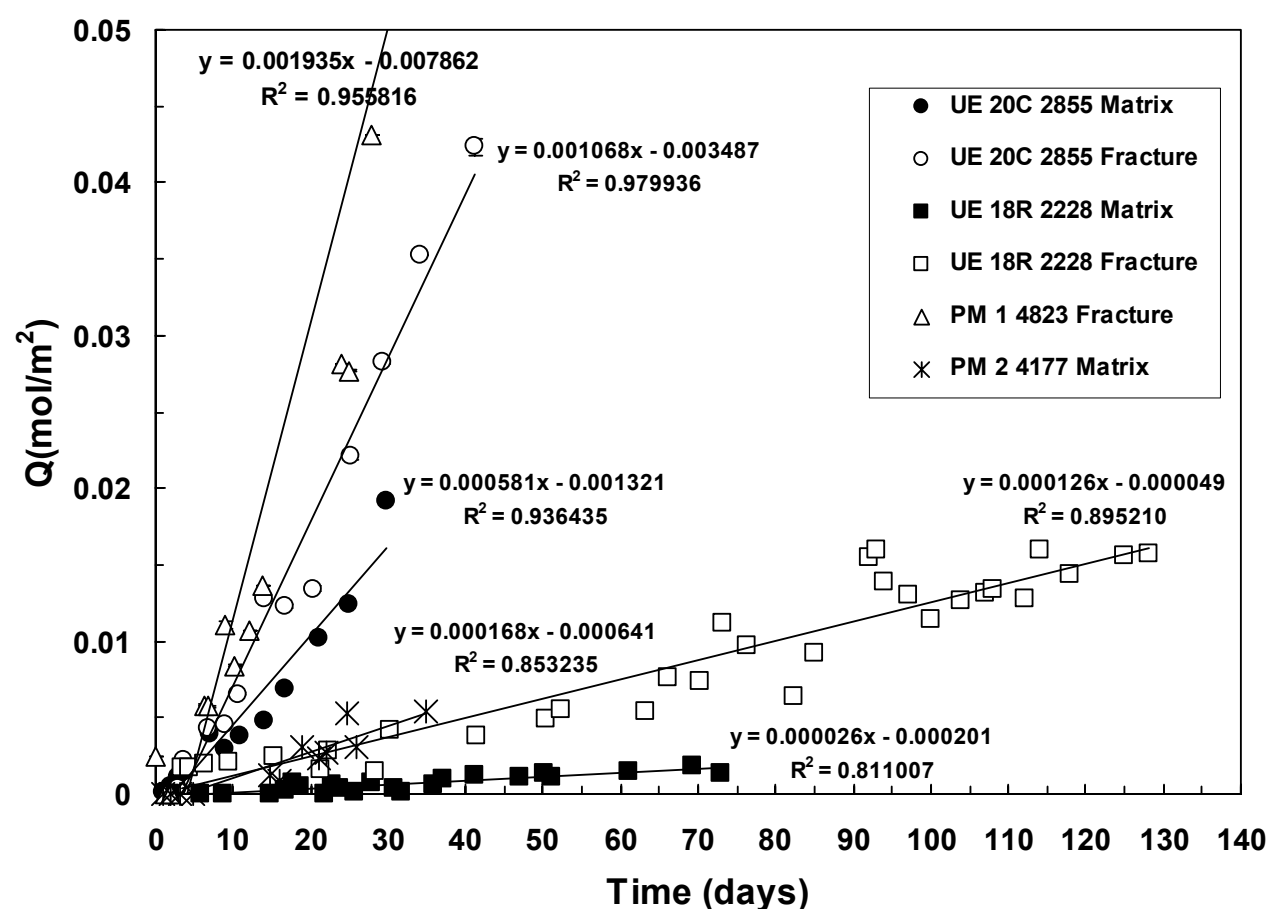

Figure 38. Bromide diffusion in WPM cores; duration of experiment: 140 days.

Bromide concentration in the tracer cell was also measured to check the initial concentration of $\mathrm{Br}$ in the tracer cell and the results are shown in Figure 39. Although the solution was not replaced in the tracer cell, the $\mathrm{Br}$ concentration remained constant throughout the experiment. In Figure 39, the $\mathrm{Br}$ concentration shown is the relative $\mathrm{Br}$ concentration in the tracer cell (concentration of $\mathrm{Br}$ relative to the total initial concentration of $\mathrm{Br}, 0.01 \mathrm{M}$ ). Although there is some fluctuation and noise in the data, Figure 39 shows that the $\mathrm{Br}$ concentration in the tracer cell was essentially constant throughout the diffusion experiments. Constant and relatively high concentration of $\mathrm{Br}$ in the tracer cell satisfied the initial condition for using the time-lag method. The mean value of $\mathrm{Br}$ concentration in the tracer cell was used for $C_{1}$ in Equation (10).

Because the diffusion of $\mathrm{Br}$ through porous materials was controlled by material structure factors such as porosity and tortuosity, the effective diffusion coefficient of the nonreactive tracer was closely related to these factors. Three core samples with high Br effective diffusion coefficients had also high porosity values. UE 20C 2908, PM-1 4823 Matrix, and PM-1 4823 Fracture had relatively high porosity values of $28.8,26.3$, and 28.0 percent, respectively. The measured effective diffusivities of $\mathrm{Br}$ in these three samples were higher than in the other samples (Figure 37 and Table 4). UE18R 2228 Matrix and Fracture samples had the lowest Br effective diffusion coefficients, consistent with the very low porosity of these samples. Comparison of $\mathrm{Br}$ effective diffusivities between matrix and fracture did not provide any consistent correlation, suggesting that the effective diffusivity of $\mathrm{Br}$ is more closely related to solid structure factors than fracture surfaces. 


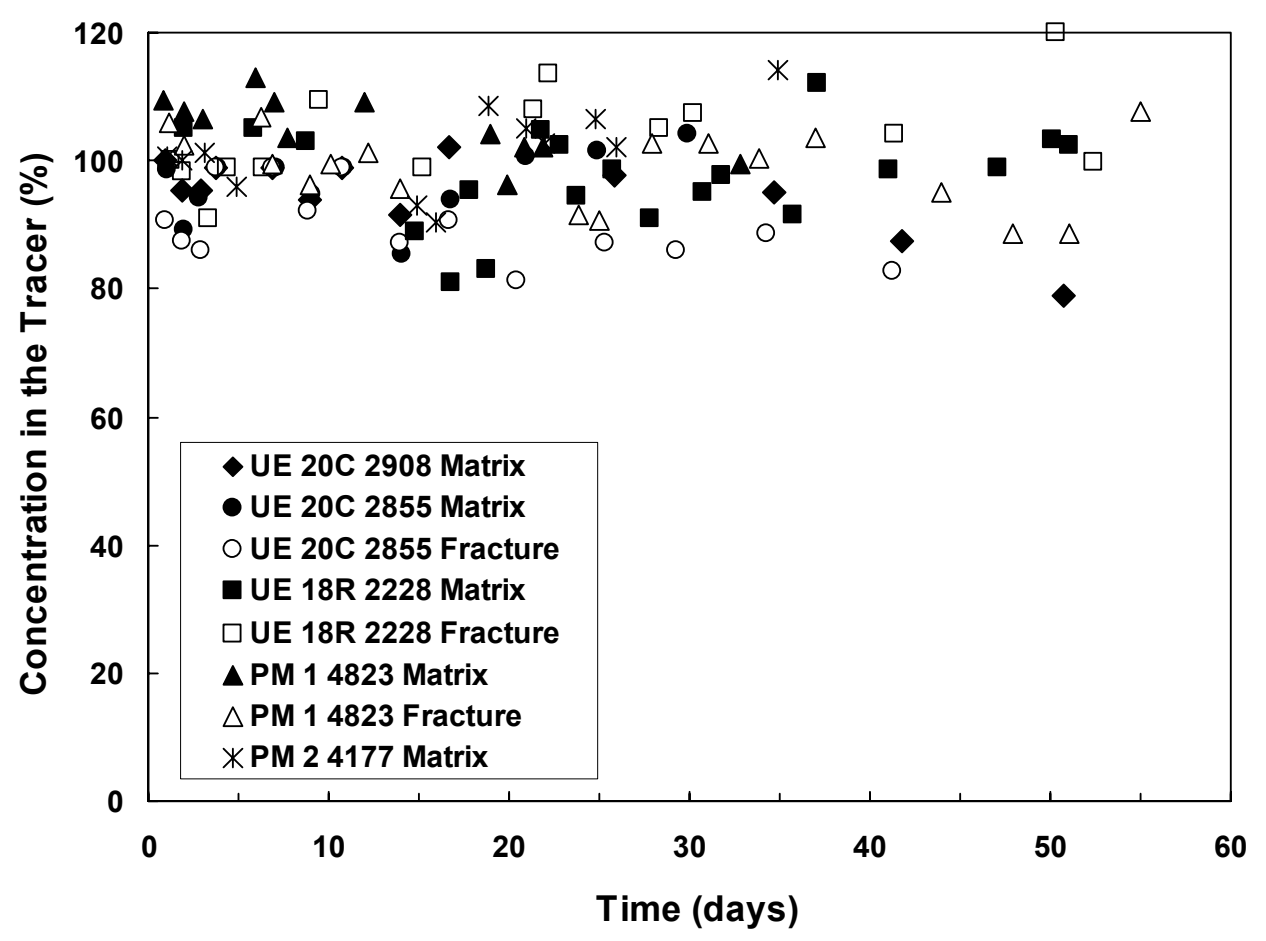

Figure 39. Test of bromide diffusion cell setup.

Table 4. Diffusion coefficients of $\mathrm{Br}$ and calculated tortuosity

\begin{tabular}{llllc}
\hline \multicolumn{1}{c}{ Core samples } & Porosity $(\%)$ & $\mathrm{D}_{\text {mol }}\left(\mathrm{m}^{2} \mathrm{~s}^{-1}\right)$ & $\mathrm{D}_{\text {eff }}\left(\mathrm{m}^{2} \mathrm{~s}^{-1}\right)$ & Tortuosity $(\chi)$ \\
\hline UE18R 2228 Fracture & 3.65 & $1.62 \times 10^{-9}$ & $1.49 \times 10^{-12}$ & 1086 \\
UE18R 2228 Matrix & 2.32 & $1.62 \times 10^{-9}$ & $3.59 \times 10^{-13}$ & 4526 \\
UE20C 2908 & 28.8 & $1.62 \times 10^{-9}$ & $1.75 \times 10^{-10}$ & 9.27 \\
UE20C 2855 Matrix & 15.0 & $1.62 \times 10^{-9}$ & $6.95 \times 10^{-11}$ & 23.37 \\
UE20C 2855 Fracture & 14.8 & $1.62 \times 10^{-9}$ & $7.86 \times 10^{-11}$ & 20.66 \\
PM-1 4823 Matrix & 26.3 & $1.62 \times 10^{-9}$ & $1.82 \times 10^{-10}$ & 8.94 \\
PM-1 4823 Fracture & 28.0 & $1.62 \times 10^{-9}$ & $8.46 \times 10^{-11}$ & 19.21 \\
PM-2 4177 & 13.0 & $1.62 \times 10^{-9}$ & $2.08 \times 10^{-12}$ & 780.5 \\
\hline
\end{tabular}

Diffusion of the Reactive Tracers Cesium, Lead, and Strontium

The diffusion of the three reactive metals of interest, $\mathrm{Pb}, \mathrm{Cs}$, and $\mathrm{Sr}$ was also evaluated in the diffusion cells as a function of time. The metal solution in the tracer cell was replaced by new solution with the same metal concentration as the initial solution every 24 hours. The concentration of metals in the tracer cell was monitored before and after solution replacement and showed no significant decrease in metal concentration. The decrease of $\mathrm{Sr}$ and $\mathrm{Cs}$ concentrations in the tracer cell was within 90 percent of the initial concentration during 24 hours. The decrease of $\mathrm{Pb}$ concentration was about 60 to 70 percent in the early stages in 24 hours. 
The concentration of $\mathrm{Cs}, \mathrm{Sr}$, and $\mathrm{Pb}$ in the measurement cell are shown in Figures 40 to 44. In all core samples, $\mathrm{Sr}$ and $\mathrm{Cs}$ breakthrough was observed, while $\mathrm{Pb}$ breakthrough was not observed in any sample. As expected, based on the previously discussed equilibrium sorption experiments, because of minor Sr sorption affinity for the WPM core samples, Sr showed early breakthrough, indicating higher diffusion coefficients compared to Cs. In the same core sample, Sr could diffuse faster than $\mathrm{Cs}$, because $\mathrm{Cs}$ ions diffusing into the intraparticle pores were retarded by sorption. The molecular diffusion coefficients for $\mathrm{Sr}$ and $\mathrm{Cs}$ were calculated using Equation (2). Apparent diffusivities and linear distribution coefficients were determined from the slope and the intercept of breakthrough curves using Equation (10). Diffusion coefficients for $\mathrm{Sr}$ and calculated retardation factors using the obtained $K_{\mathrm{d}}$ are shown in Table 5.

Table 5. Diffusion coefficients of $\mathrm{Sr}$ and calculated transport parameters.

\begin{tabular}{llll}
\hline Core samples & $\mathrm{D}_{\text {app }}\left(\mathrm{m}^{2} \mathrm{~s}^{-1}\right)$ & $\mathrm{K}_{\mathrm{d}}\left(\mathrm{m}^{3} \mathrm{~g}^{-1}\right)^{*}$ & $\mathrm{R}^{+}$ \\
\hline UE18R 2228 Fracture & $\mathrm{NC}$ & $\mathrm{NC}$ & $\mathrm{NC}$ \\
UE18R 2228 Matrix & $\mathrm{NC}$ & $\mathrm{NC}$ & $\mathrm{NC}$ \\
UE20C 2908 & $1.72 \times 10^{-10}$ & $2.71 \times 10^{-7}$ & $3.25(\mathbf{1 . 0 2})$ \\
UE20C 2855 Matrix & $5.03 \times 10^{-11}$ & $2.90 \times 10^{-7}$ & $6.65(\mathbf{1 . 3 8})$ \\
UE20C 2855 Fracture & $6.71 \times 10^{-11}$ & $4.69 \times 10^{-8}$ & $1.81(\mathbf{1 . 1 7})$ \\
PM-1 4823 Matrix & $7.26 \times 10^{-11}$ & $5.66 \times 10^{-7}$ & $6.79(\mathbf{2 . 5 1})$ \\
$\mathrm{PM}-1$ 4823 Fracture & $1.91 \times 10^{-10}$ & $2.64 \times 10^{-6}$ & $33.8(\mathbf{0 . 4 4})$ \\
$\mathrm{PM}-2$ 4177 & $\mathrm{NC}$ & $\mathrm{NC}$ & $\mathrm{NC}$ \\
\hline $\mathrm{D}_{\text {mol }}(\mathrm{Sr})=1.29 \times 10^{-9} \mathrm{~m}^{2} / \mathrm{s}$ & \\
${ }^{+}$Calculated linear distribution coefficients based on the diffusion experiments. \\
Calculated retardation factors based on the diffusion experiments. \\
Calculated retardation factors based on Equation (4) are shown in bold in parentheses. \\
NC indicates "not calculated."
\end{tabular}

Because the UE18R 2228 core samples had very low porosity, no breakthrough was observed for any of the three metal ions, consistent with the previously determined low $\mathrm{Br}$ effective diffusivity compared to the other core samples. Due to difficulties in preparation, the PM-2 4177 sample was not used for diffusion experiments. Based on the results of diffusion experiments, fracture surfaces were not expected to have any effects on the diffusion of metals. There was no significant correlation between diffusivity and the presence of fracture surfaces. Instead, diffusivity seemed to be closely related with the solid structure, as expressed by porosity. The UE20c 2908 and PM-1 4823 Matrix core samples resulted in faster $\mathrm{Br}$ and $\mathrm{Sr}$ diffusivities compared to the other samples with lower porosity values. Although fracture surfaces might react with metal ions more effectively, the thickness of fracture surfaces was so low compared to the rest of the bulk medium that diffusivity in the porous materials was expected to be more closely related with the solid structure, such as porosity or the presence of micro-fissures existing inside the bulk medium. 


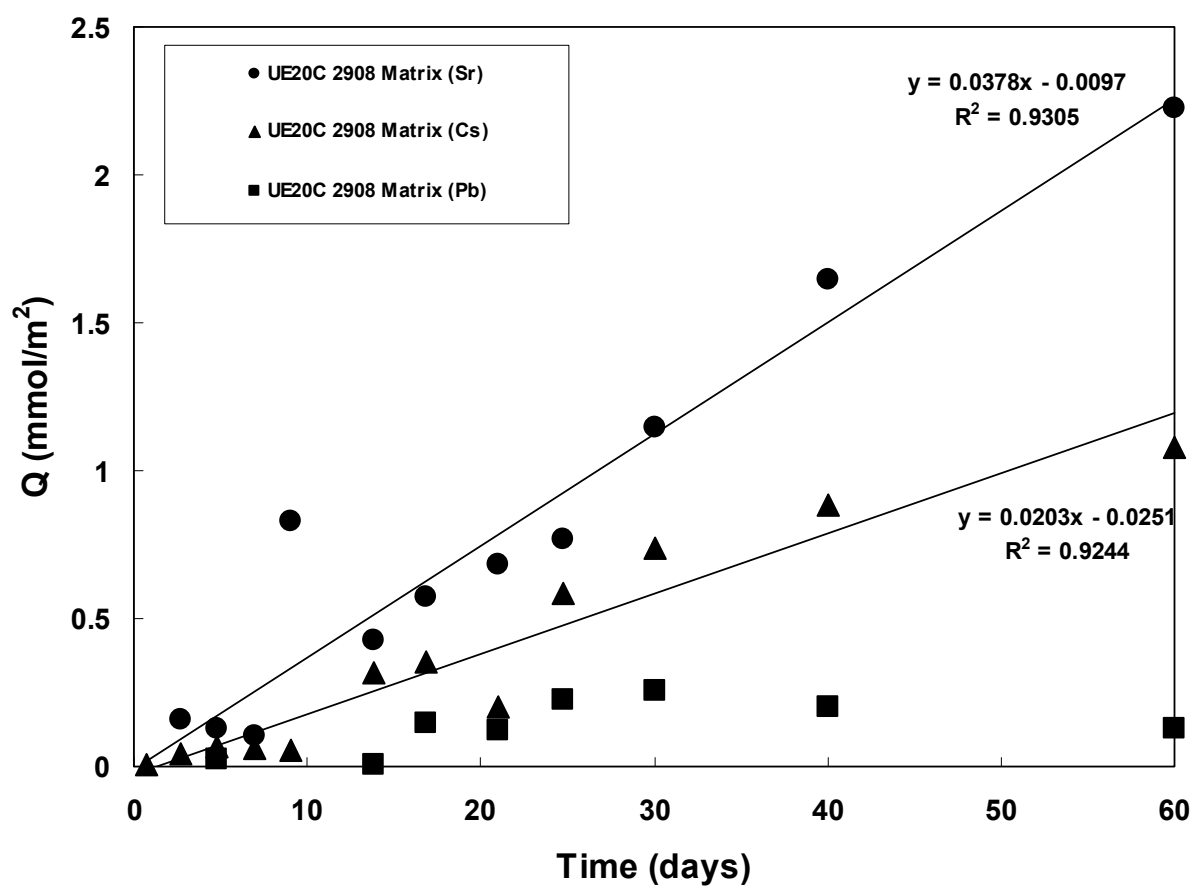

Figure 40. Flux of $\mathrm{Sr}, \mathrm{Cs}$, and $\mathrm{Pb}$ through UE20c 2908 matrix core as a function of time.

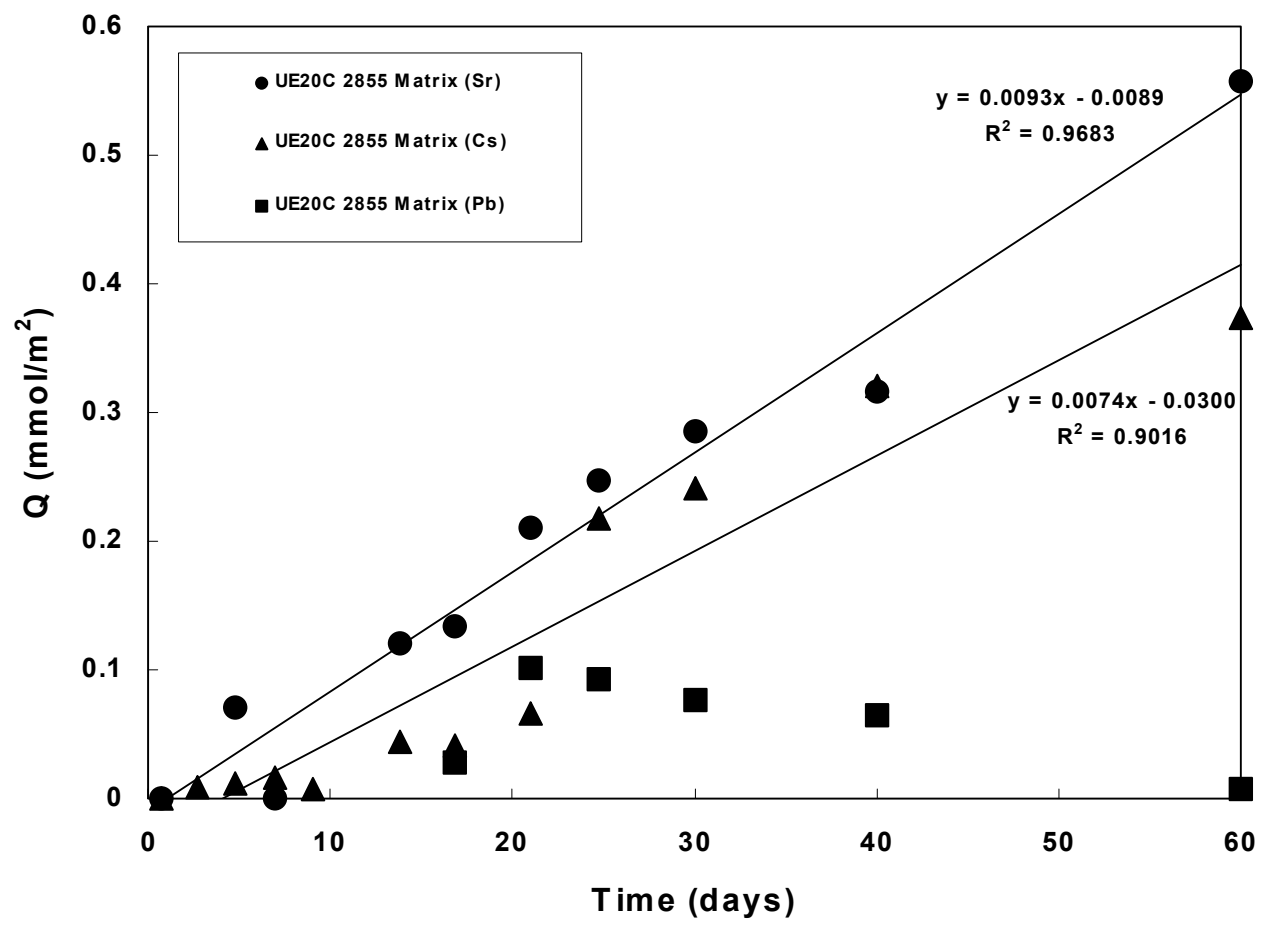

Figure 41. Flux of $\mathrm{Sr}, \mathrm{Cs}$, and $\mathrm{Pb}$ through UE20c 2855 matrix core as a function of time. 


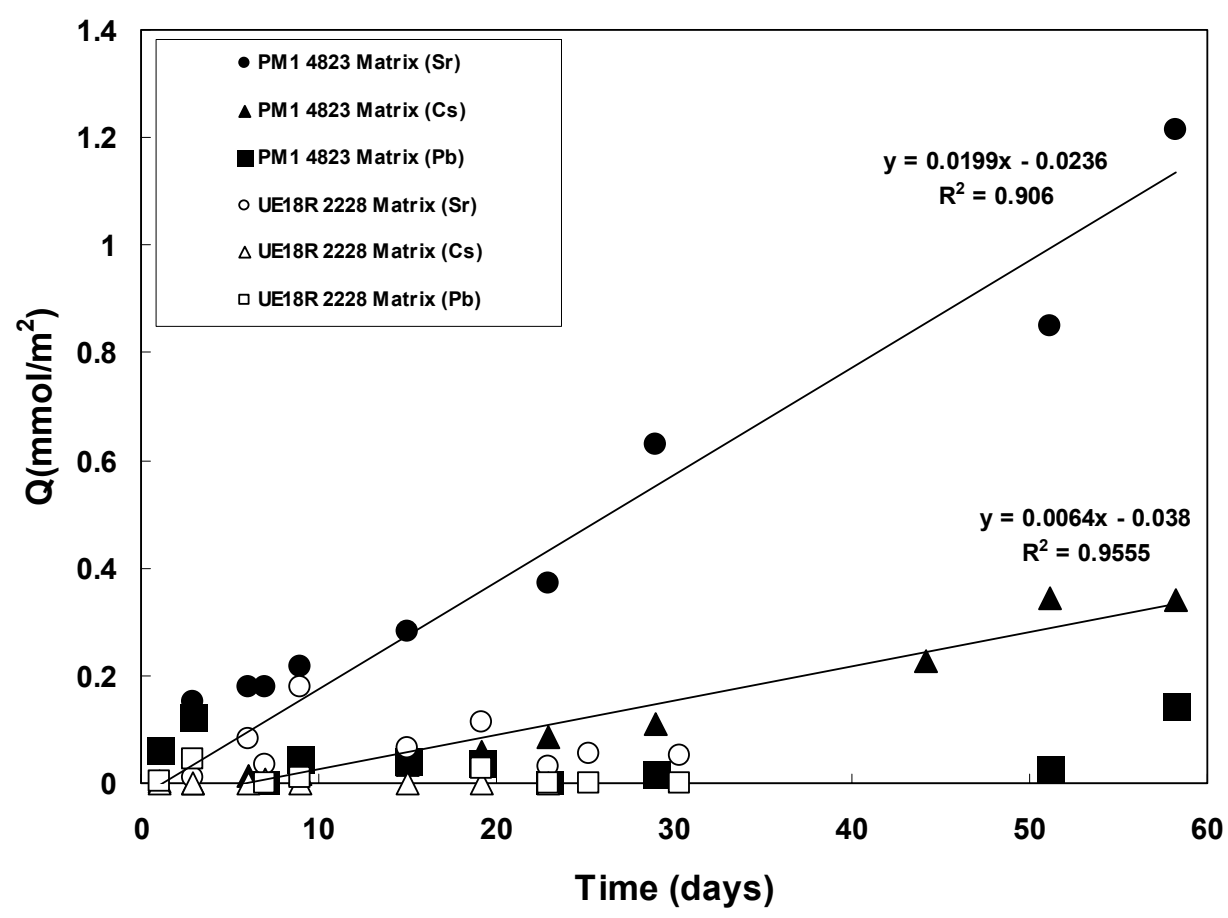

Figure 42. Flux of $\mathrm{Sr}, \mathrm{Cs}$, and $\mathrm{Pb}$ through $\mathrm{PM}-14823$ and UE18R 2228 matrix core as a function of time.

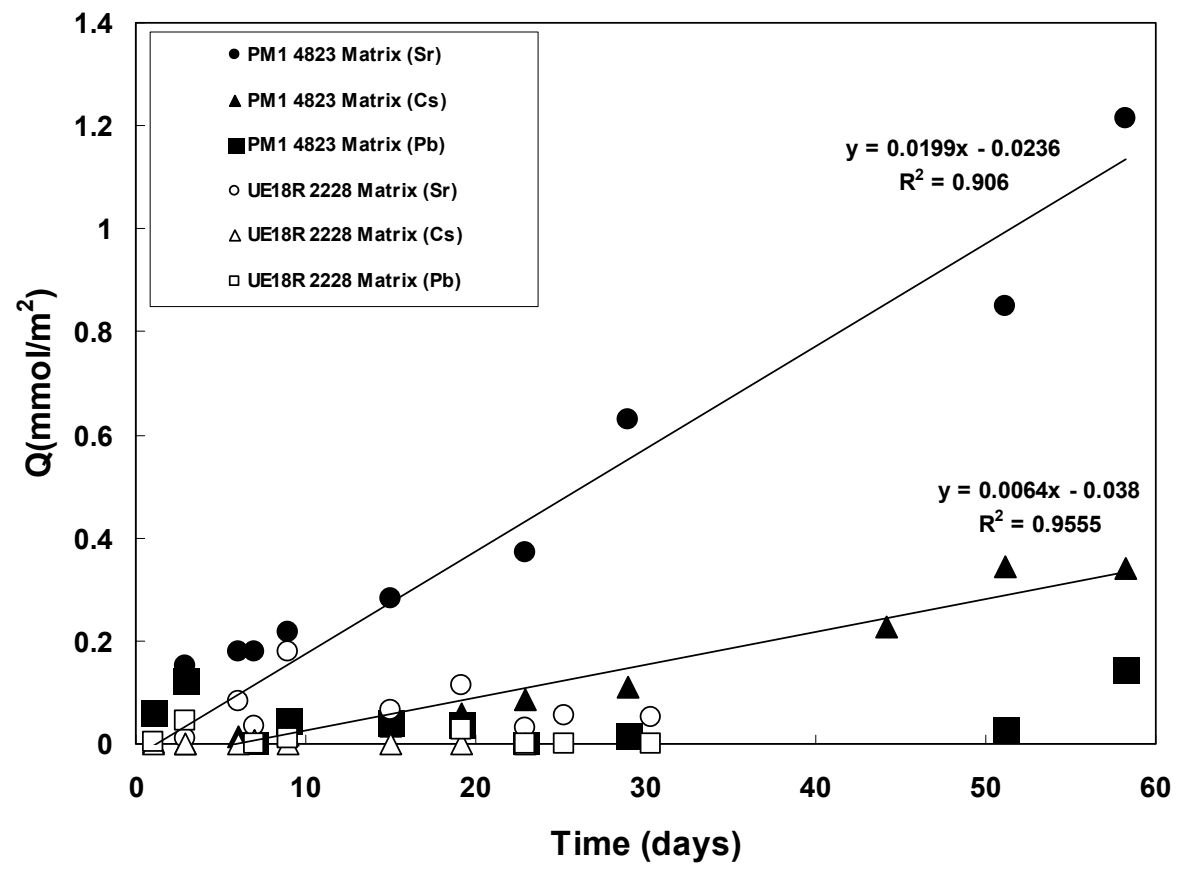

Figure 43. Flux of $\mathrm{Sr}, \mathrm{Cs}$, and $\mathrm{Pb}$ through $\mathrm{PM}-14823$ and UE18R 2228 matrix core as a function of time. 


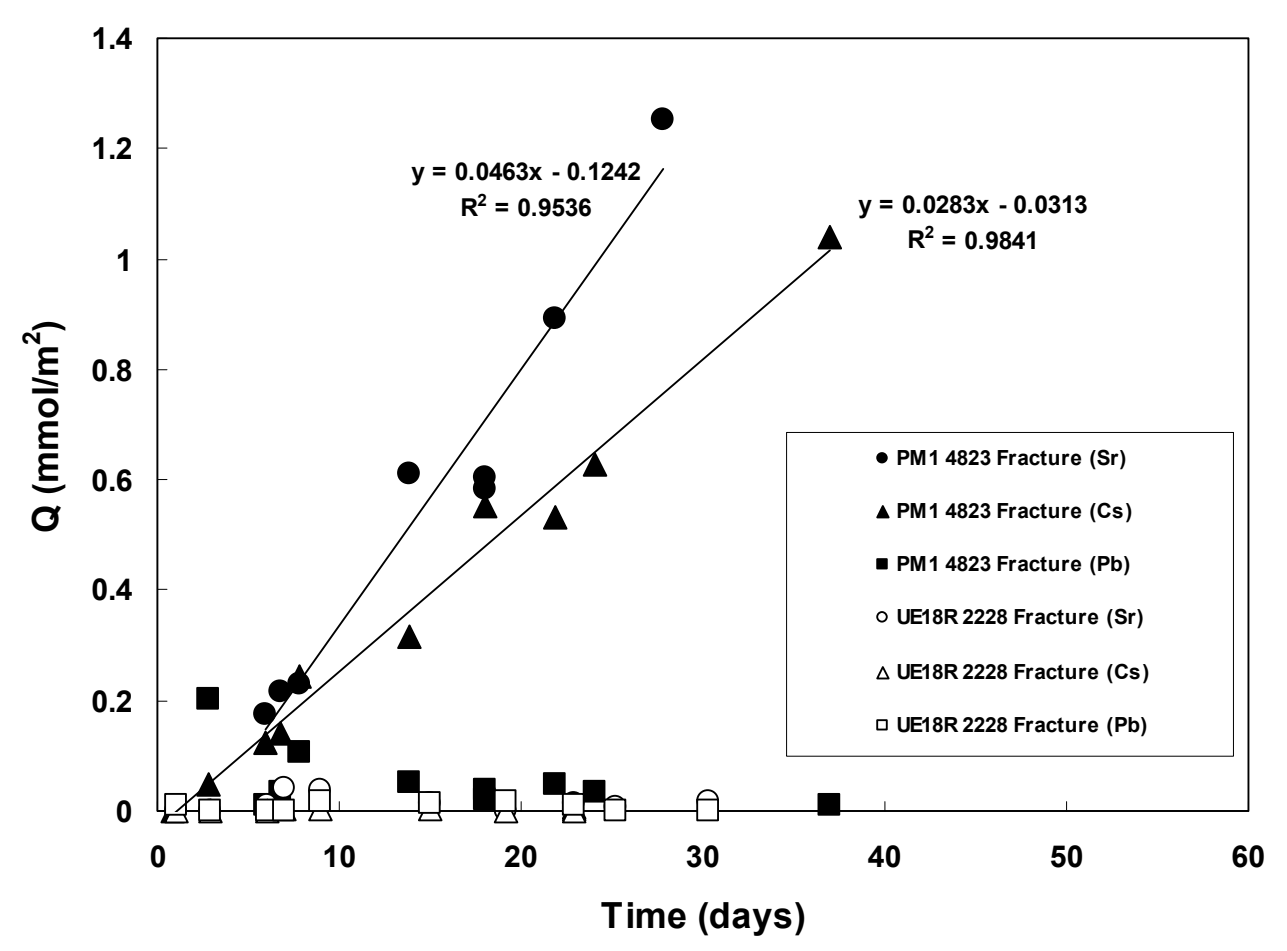

Figure 44. Flux of Sr, Cs, and Pb through PM-1 4823 and UE18R 2228 fracture core as a function of time.

Because of small retardation, Sr showed relatively high apparent diffusivity. The calculated retardation factor of $\mathrm{Sr}$ from the diffusion experiments was less than 10, except for the PM-1 4823 Fracture core. In fact, the apparent diffusivity of Sr in the PM-1 4823 Fracture core sample was higher than the Br effective diffusivity, suggesting that there were possible leaks or flow channels between the tracer and measurement cells. Leaking from the tracer cell to the measurement cell was found when the diffusion experiments were completed. This problem led to errors in the calculation of apparent diffusivities and retardation factors of Sr and Cs. Most of the calculated $K_{\mathrm{d}} \mathrm{S}$ were low, suggesting negligible Sr sorption affinity for the WPM materials. Because of the high uncertainty in developing Sr sorption isotherms, $K_{\mathrm{d}}$ estimates using $\mathrm{Sr}$ sorption isotherms are not presented.

Diffusion coefficients of $\mathrm{Cs}$ and transport parameters obtained from diffusion experiments are shown in Table 6 and compared with those calculated based on the sorption isotherms. The apparent diffusivity of Cs measured from diffusion cells was low compared to that of Sr, consistent with the higher $K_{\mathrm{d}}$ and retardation values of Cs. Because Cs reacted with sorption sites at both surfaces and inside of core samples, the apparent diffusivity of Cs was lower than that of $\mathrm{Br}$ and $\mathrm{Sr}$. There was also no significant difference of diffusivities between fracture and matrix samples. Since there was no breakthrough of metals in both UE18R 2228 and the PM-2 4177 Matrix samples, Cs diffusivities were calculated based on the sorption isotherms and derived retardation factors using Equation (8). 
Table 6. Diffusion coefficients of Cs and calculated transport parameters.

\begin{tabular}{llll}
\hline Core samples & $\mathrm{D}_{\text {app }}\left(\mathrm{m}^{2} \mathrm{~s}^{-1}\right)^{\#}$ & $\mathrm{~K}_{\mathrm{d}}\left(\mathrm{m}^{3} \mathrm{~g}^{-1}\right)^{*}$ & $\mathrm{R}^{+}$ \\
\hline UE18R 2228 Fracture & $\left(5.73 \times 10^{-16}\right)$ & $\left(3.96 \times 10^{-5}\right)$ & $(3166)$ \\
UE18R 2228 Matrix & $\left(1.34 \times 10^{-16}\right)$ & $\left(3.39 \times 10^{-5}\right)$ & $(3185)$ \\
UE20C 2908 & $1.17 \times 10^{-10}$ & $1.13 \times 10^{-6}\left(1.54 \times 10^{-4}\right)$ & $10.39(\mathbf{1 . 4 9 6})(1279)$ \\
UE20C 2855 Matrix & $4.98 \times 10^{-11}$ & $1.38 \times 10^{-6}\left(9.92 \times 10^{-5}\right)$ & $27.89(\mathbf{1 . 3 9 5})(1935)$ \\
UE20C 2855 Fracture & $4.34 \times 10^{-11}$ & $5.39 \times 10^{-7}\left(1.43 \times 10^{-4}\right)$ & $10.30(\mathbf{1 . 8 1 1})(2475)$ \\
PM-1 4823 Matrix & $3.74 \times 10^{-11}$ & $1.62 \times 10^{-6}\left(5.86 \times 10^{-5}\right)$ & $17.51(\mathbf{4 . 8 6 6})(1180)$ \\
PM-1 4823 Fracture & $1.48 \times 10^{-10}$ & $7.43 \times 10^{-7}\left(2.05 \times 10^{-4}\right)$ & $10.24(\mathbf{0 . 5 7 2})(2097)$ \\
PM-2 4177 & $\left(1.33 \times 10^{-15}\right)$ & $\left(1.52 \times 10^{-4}\right)$ & $(1893)$ \\
\hline
\end{tabular}

$\operatorname{Dmol}(\mathrm{Cs})=1.97 \times 10-9 \mathrm{~m} 2 / \mathrm{s}$

\# Calculated apparent diffusivities based on the diffusion experiments. Cs apparent diffusivities calculated using sorption $\mathrm{K}_{\mathrm{d}}$ and Equation (8) are shown in the parentheses.

* Calculated linear distribution coefficients based on the diffusion experiments. Corrected $\mathrm{K}_{\mathrm{d}} \mathrm{s}$ based on sorption isotherms are shown in the parentheseis.

+ Calculated retardation factors based on the diffusion experiments. Calculated retardation factors based on the corrected $\mathrm{K}_{\mathrm{d}}$ are shown in parentheses. Calculated retardation factors based on Equation (4) are shown in bold in parentheses.

The $D_{m o l}$ of Cs was calculated using the Nernst-Haskell equation. The initially determined tortuosity factor by $\mathrm{Br}$ diffusion experiments for the same diffusion cores and the calculated molecular diffusivity were used to determine the effective diffusivity. The calculated retardation factor, $R$, based on the bulk density, porosity, and linear distribution coefficient $\left(K_{\mathrm{d}}\right)$, was used to calculate the apparent diffusivity. The distribution coefficient $\left(K_{\mathrm{d}}\right)$ derived from the batch sorption isotherms was used to determine $R$ (Table 3 ). The distribution coefficients obtained from batch experiments, however, are usually higher than those obtained from diffusion experiments. The difference of specific surface area of crushed and intact rocks contributes to the discrepancy between distribution coefficients (Tachi et al., 1998). Assuming that the mineral composition of surfaces in crushed and intact rocks is similar, the distribution coefficients for the intact rock can be determined by the distribution coefficients obtained from batch experiments by adjusting for the difference between specific surface area of crushed and intact rocks using the following equation:

$$
K_{d(\text { diffusion })}=K_{d(\text { batch })} \frac{S A_{\text {int act }}}{S A_{\text {crushed }}}
$$

where $K_{d(d i f f u s i o n)}$ is the corrected distribution coefficient for intact rock $\left(\mathrm{m}^{3} \mathrm{~g}^{-1}\right), K_{d(\text { batch }}$ is the distribution coefficient from batch sorption experiments $\left(\mathrm{m}^{3} \mathrm{~g}^{-1}\right), S A_{\text {intact }}$ and $S A_{\text {crushed }}$ are the specific surface areas for intact and crushed samples $\left(\mathrm{m}^{2} \mathrm{~g}^{-1}\right)$, respectively (Tachi et al., 1998). The corrected distribution coefficients were used to calculate apparent diffusivity and retardation factors. The calculated retardation factors and apparent diffusion coefficients of Cs based on the corrected distribution coefficients are shown in parentheses in Table 6.

Because of the high $K_{\mathrm{d}}$ and $R$ values, the calculated apparent diffusivities of Cs based on sorption isotherms were low. Calculated $K_{\mathrm{d}}$ and $R$ based on sorption isotherms usually were two orders of magnitude higher than $K_{\mathrm{d}}$ and $R$ estimated from diffusion cell experiments. Although an adjustment was made for the different surface areas for $K_{\mathrm{d}} \mathrm{s}$ from equilibrium and diffusion experiments, the differences were still significant. These differences were attributed to the 
presence of micropores in the sorption samples and the unknown microstructures existing in the inside of cores. Because the correction method mentioned above did not provide an adequate correction factor for differences originating from the presence of micropores and microstructures, the calculated $K_{\mathrm{d}}$ values using batch sorption isotherms were higher than $K_{\mathrm{d}} \mathrm{S}$ estimated from diffusion experiments.

No breakthrough of $\mathrm{Pb}$ was observed in any core sample. Lead concentrations in the measurement cells, even after 100 days, were negligible, consistent with strong sorption affinity for the WPM core samples as pointed out in the previously discussed sorption/desorption experiments. In the absence of a breakthrough, the time-lag method could not be used to estimate diffusion coefficients for $\mathrm{Pb}$. Moridis (1998) already mentioned this disadvantage or erroneous calculation of diffusion coefficients when using the time-lag method in the case of strongly sorbing solutes. Therefore, diffusion coefficients for $\mathrm{Pb}$ were also calculated using Equation (8) based on the previously determined sorption isotherm parameters. The corrected distribution coefficients were used to determine the retardation factor and apparent diffusivity of $\mathrm{Pb}$. The calculated retardation factor and apparent diffusion coefficients of $\mathrm{Pb}$ are shown in Table 7. Because of the high $K_{\mathrm{d}}$ and $R, \mathrm{~Pb}$ showed very low apparent diffusivity, consistent with very strong sorption on WPM core samples. The very low apparent diffusivities of $\mathrm{Pb}$ ions are in good agreement with the previously discussed high sorption affinity and low desorption of $\mathrm{Pb}$.

Table 7. Diffusion coefficients of $\mathrm{Pb}$ and calculated transport parameters.

\begin{tabular}{llll}
\hline Core samples & $\mathrm{D}_{\text {app }}\left(\mathrm{m}^{2} \mathrm{~s}^{-1}\right)^{\#}$ & $\mathrm{~K}_{\mathrm{d}}\left(\mathrm{m}^{3} \mathrm{~g}^{-1}\right)^{*}$ & $\mathrm{R}^{+}$ \\
\hline UE18R 2228 Fracture & $1.88 \times 10^{-17}$ & $8.68 \times 10^{-4}$ & 69451 \\
UE18R 2228 Matrix & $4.98 \times 10^{-18}$ & $6.71 \times 10^{-4}$ & 63014 \\
UE20C 2908 & $6.40 \times 10^{-15}$ & $2.88 \times 10^{-3}$ & 23933 \\
UE20C 2855 Matrix & $4.59 \times 10^{-15}$ & $7.24 \times 10^{-4}$ & 14118 \\
UE20C 2855 Fracture & $3.41 \times 10^{-15}$ & $1.17 \times 10^{-3}$ & 20163 \\
PM-1 4823 Matrix & $2.02 \times 10^{-15}$ & $3.91 \times 10^{-3}$ & 78633 \\
PM-1 4823 Fracture & $5.53 \times 10^{-16}$ & $3.29 \times 10^{-3}$ & 33649 \\
PM-2 4177 & $4.16 \times 10^{-17}$ & $3.52 \times 10^{-3}$ & 43778 \\
\hline $\mathrm{D}_{\text {mol }}(\mathrm{Pb})=1.42 \times 10^{-9} \mathrm{~m}^{2} \mathrm{~s}^{-1}$ & & \\
${ }^{*}$ Calculated apparent diffusivities of Pb using sorption $\mathrm{K}_{\mathrm{d}}$ and Equation $(8)$. & & \\
${ }^{*}$ Corrected $\mathrm{K}_{\mathrm{d}} \mathrm{s}$ based on sorption isotherms using Equation (11). & & \\
${ }^{+}$Calculated retardation factors based on the corrected $\mathrm{K}_{\mathrm{d} .}$. & &
\end{tabular}

As described earlier for $\mathrm{Sr}$ and $\mathrm{Cs}, \mathrm{Pb}$ diffusivities did not differ significantly between fracture and matrix core samples. Although there were some effects of fracture surfaces on metal diffusion or migration through the core, because of the relatively small thickness of fracture surfaces compared to the bulk of the core samples, no significant differences between core samples with and without fracture surfaces could be observed. Different chemical reactions of metals at fracture surfaces, therefore, were attempted to be examined by a more quantitative and surface sensitive method. Specifically, XPS was used to help us distinguish between different sorption mechanisms on matrix and fractures surfaces and for different metal ions, as will be discussed below.

Given the differences in $K_{\mathrm{d}} \mathrm{s}$ and retardation factors obtained from batch equilibrium and diffusion experiments, one might reasonably ask the question - which set of data would be more 
appropriate to use in transport modeling of radionuclides and other inorganic ions? The results from the diffusion experiments would definitely be more appropriately applied to matrix diffusion. One must always keep in mind, however, that any fractures in the direction of the flow could significantly accelerate transport. The question always arises as to how representative experiments of the laboratory scale are to field-scale transport modeling; what degree of variability exists between samples and how many measurements would be required to produce a statistically significant result. Retardation along transmissive fractures would certainly be a function of flow conditions. As long as groundwater velocity is low enough, $K_{\mathrm{d}} \mathrm{s}$ from sorption isotherms would be applicable, provided the mineralogical composition of the samples is similar and the $K_{\mathrm{d}}$ data are scaled with respect to available surface area, another elusive quantity at the field scale.

\section{XPS Experiments}

The objective of the XPS experiments was to compare the macroscopic sorption and diffusion experiments to the spectroscopic information obtained from the characterization of these surfaces before and after sorption and diffusion. The major advantage of the XPS experiments compared to the macroscopic experiments is that specific information on chemical composition and chemical state of a surface can be obtained. Information about surface composition and chemical state, of course, is critical in any surface study. In addition, using XPS, information about specific areas of a sample can be obtained, depending on the spot size of analysis used.

For this work, XPS data were collected on powders and core samples (or pieces of rock) before the sorption and diffusion experiments and after. Two types of general information were collected and will be discussed below: binding energies (BE) of elements present and information on elemental abundance. The information on $\mathrm{BE}$ is representative of the chemical state of the element and can provide valuable information regarding oxidation state and coordination environment. The elemental composition, besides being useful information by itself in terms of interpreting macroscopic sorption experiments, can be used to estimate the surface coverage of sorbents and to distinguish between different types of sorption, including adsorption and surface precipitation.

For every sample, a broad survey spectrum was collected, in the 0 to $1100 \mathrm{eV}$ energy range, using a high-sensitivity but low-resolution data-collection mode ( $1 \mathrm{eV} / \mathrm{step})$. The survey scan was then followed by narrower scans, typically 20 to $30 \mathrm{eV}$, with lower sensitivity but higher resolution $(0.065 \mathrm{eV} / \mathrm{step})$ for the elements of interest. These elements typically included the major cations anticipated or observed in the sample, including silicon ( $\mathrm{Si}$ ), aluminum (Al), sodium $(\mathrm{Na})$, potassium $(\mathrm{K})$, calcium $(\mathrm{Ca})$, magnesium $(\mathrm{Mg})$, iron $(\mathrm{Fe})$, manganese $(\mathrm{Mn})$, and the anion oxygen $(\mathrm{O})$. In addition, narrow scans of the sorbates of interest, strontium (Sr), cesium $(\mathrm{Cs})$, and lead $(\mathrm{Pb})$ were also included when analyzing sorption samples. A typical survey scan of a core sample, with major photoelectron peaks labeled, is shown in Figure 45. Narrow scans for individual elements are shown in the following section. 


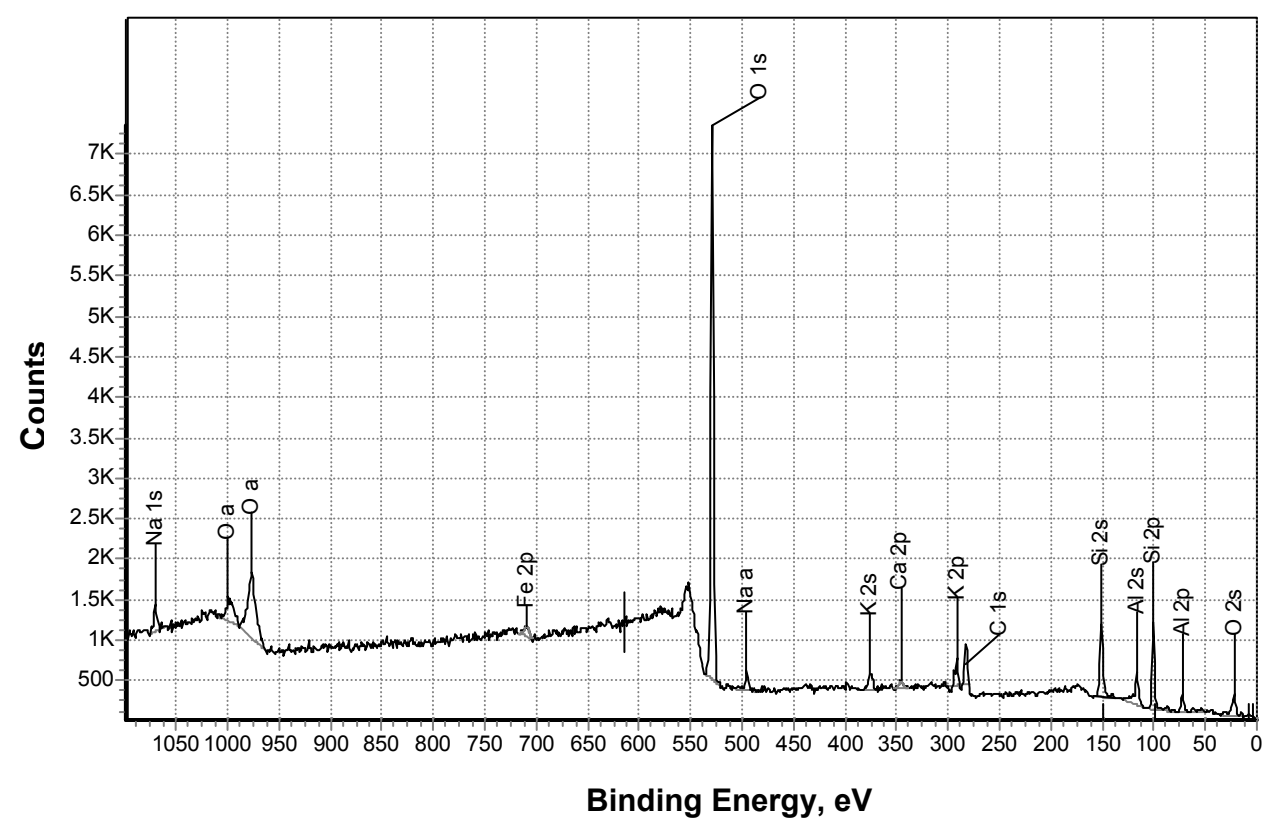

Figure 45. Typical XPS survey scan of a WPM sample.

\section{Binding Energies}

The BE and corresponding chemical shift for all elements collected in narrow scan mode and for all samples analyzed are listed in Table 8 for both powder and core samples. The results are grouped together by sample and element. By comparing the measured BE to the BEs reported in the literature, one can draw conclusions about the chemical state and coordination environment of the element. The charge referencing for all narrow scans was made by the adventitious carbon method assuming the energy of the $\mathrm{C}$ 1s line to be $284.6 \mathrm{eV}$.

A representative XPS spectrum of the A1 2p peak is shown in Figure 46. Average chemical shifts for most samples ranged between 1.25 and $1.35 \mathrm{eV}$, the only exception being PM-2 4177, with a chemical shift of $1.54 \mathrm{eV}$. These chemical shifts correspond to BEs ranging from 74.24 to $74.37 \mathrm{eV}$. These numbers are in perfect agreement with the quantitative mineralogy of these samples. For example, the BE for Al is $72.9 \mathrm{eV}$, substantially lower than the measured BEs, whereas Al oxides and aluminosilicates correspond to a BE of 74 to 75 . Specifically, the BE of albite, a very common feldspar and substantial component of these samples is $74.3 \mathrm{eV}$, in excellent agreement with the measured BE. The only samples with a higher BE, two spots on the PM-2 4177 core with BEs 74.48 and $74.61 \mathrm{eV}$, respectively, corresponded to the sample with the highest kaolinite component where the $\mathrm{Al} 2 \mathrm{p} \mathrm{BE}$ is $74.6 \mathrm{eV}$. It is, therefore, highly likely that kaolinite crystals were analyzed.

A representative XPS spectrum of the Si 2p peak is shown in Figure 47. Average chemical shifts for these samples ranged from 3.51 to $3.83 \mathrm{eV}$, with several clustered around $3.8 \mathrm{eV}$, corresponding to Si 2p BEs from 102.51 to $102.83 \mathrm{eV}$. These values are in agreement with BEs for silicates, which range between 102 and $103 \mathrm{eV}$, but they are too low for silica, with a Si $2 p$ $\mathrm{BE}$ of $103.5 \mathrm{eV}$. On the other hand, the Si 2p BEs for albite, mica, and kaolinite are 102.6, 102.4, and 103.0, respectively. The values measured, therefore, agree very well with a combination of mostly feldspars and other silicates and a smaller fraction of silica, again, in good agreement with the results of quantitative mineralogy performed on these samples. 
Table 8. Chemical shifts and binding energies $(\mathrm{eV})$ of major elements in core and powder samples.

\begin{tabular}{|c|c|c|c|c|c|c|c|c|c|c|c|c|c|c|c|c|c|c|c|c|}
\hline \multirow[b]{2}{*}{ SAMPLE } & \multicolumn{20}{|c|}{ XPS Line } \\
\hline & $\begin{array}{l}\mathrm{Al} 2 \mathrm{p} \\
\text { Chem. } \\
\text { Shift }\end{array}$ & $\begin{array}{l}\text { Adj. } \\
\text { BE }\end{array}$ & $\begin{array}{l}\text { Si } 2 p \\
\text { Chem. } \\
\text { Shift }\end{array}$ & $\begin{array}{l}\text { Adj. } \\
\text { BE }\end{array}$ & $\begin{array}{l}\text { O 1s } \\
\text { Chem. } \\
\text { Shift }\end{array}$ & $\begin{array}{l}\text { Adj. } \\
\text { BE }\end{array}$ & $\begin{array}{l}\text { Na 1s } \\
\text { Chem. } \\
\text { Shift }\end{array}$ & Adj. BE & $\begin{array}{l}\text { K } 2 p 3 \\
\text { Chem. } \\
\text { E Shift }\end{array}$ & $\begin{array}{l}\text { Adj. } \\
\text { BE }\end{array}$ & $\begin{array}{l}\text { Ca 2p3 } \\
\text { Chem. } \\
\text { Shift }\end{array}$ & $\begin{array}{l}\text { Adj. } \\
\text { BE }\end{array}$ & $\begin{array}{l}\text { Fe 2p3 } \\
\text { Chem. } \\
\text { Shift }\end{array}$ & $\begin{array}{l}\text { Adj. } \\
\text { BE }\end{array}$ & $\begin{array}{l}\mathrm{Sr} 3 \mathrm{~d} 5 \\
\text { Chem. } \\
\text { Shift }\end{array}$ & $\begin{array}{l}\text { Adj. } \\
\text { BE }\end{array}$ & $\begin{array}{l}\text { Cs } 3 \mathrm{~d} 5 \\
\text { Chem. } \\
\text { Shift }\end{array}$ & $\begin{array}{l}\text { Adj. } \\
\text { BE }\end{array}$ & $\begin{array}{l}\mathrm{Pb} 4 \mathrm{f} 7 \\
\text { Chem. } \\
\text { Shift }\end{array}$ & $\begin{array}{l}\text { Adj. } \\
\text { BE }\end{array}$ \\
\hline \multicolumn{21}{|l|}{ PM-1 4823 Matrix } \\
\hline Powder & 1.40 & 74.40 & 3.82 & 102.82 & 0.12 & 532.12 & 0.47 & 1072.47 & -0.53 & 293.47 & & & 1.95 & 711.95 & & & -0.91 & 725.09 & & \\
\hline Powder & 1.36 & 74.36 & 3.79 & 102.79 & 0.08 & 532.08 & 0.44 & 1072.44 & -0.48 & 293.52 & & & 1.96 & 711.96 & & & & & 1.24 & 139.24 \\
\hline Core (Spot \#1) & 1.36 & 74.36 & 3.86 & 102.86 & 0.12 & 532.12 & 0.26 & 1072.26 & -0.51 & 293.49 & 1.07 & 348.07 & 2.00 & 712.00 & & & & & & \\
\hline Core (Spot \#2) & 1.37 & 74.37 & 3.85 & 102.85 & 0.02 & 532.02 & 0.26 & 1072.26 & -0.69 & 293.31 & 0.49 & 347.49 & 2.51 & 712.51 & & & & & & \\
\hline \multicolumn{21}{|c|}{ PM-1 4823 Fracture } \\
\hline Powder & 1.16 & 74.16 & 3.44 & 102.44 & -0.22 & 531.78 & 0.10 & 1072.10 & -0.78 & 293.22 & & & 1.53 & 711.53 & & & -0.73 & 725.27 & & \\
\hline Powder & 1.19 & 74.19 & 3.66 & 102.66 & -0.06 & 531.94 & 0.19 & 1072.19 & -0.55 & 293.45 & & & 2.05 & 712.05 & & & & & 1.01 & 139.01 \\
\hline Core (Spot \#1) & 1.45 & 74.45 & 3.86 & 102.86 & -0.11 & 531.89 & -0.05 & 1071.95 & -0.64 & 293.36 & & & 1.67 & 711.67 & & & & & & \\
\hline Core (Spot \#2) & 1.19 & 74.19 & 3.64 & 102.64 & -0.37 & 531.63 & -0.28 & 1071.72 & -0.81 & 293.19 & 0.83 & 347.83 & 1.50 & 711.50 & & & & & & \\
\hline \multicolumn{21}{|l|}{ PM-2 4177} \\
\hline Powder & & & 3.76 & 102.76 & -0.23 & 531.77 & & & & & & & & & & & -1.50 & 724.50 & & \\
\hline Powder & & & 3.70 & 102.70 & -0.24 & 531.76 & & & & & & & & & & & & & 0.90 & 138.90 \\
\hline Core (Spot \#1) & 1.61 & 74.61 & 3.98 & 102.98 & 0.12 & 532.12 & 0.36 & 1072.36 & -0.42 & 293.58 & 0.36 & 347.36 & -0.63 & 709.37 & & & & & & \\
\hline Core (Spot \#2) & 1.48 & 74.48 & 3.89 & 102.89 & 0.01 & 532.01 & 0.24 & 1072.24 & -0.77 & 293.23 & 0.43 & 347.43 & -1.15 & 708.85 & & & & & & \\
\hline \multicolumn{21}{|c|}{ UE18R 2228 Matrix } \\
\hline Powder & 1.50 & 74.50 & 3.85 & 102.85 & 0.28 & 532.28 & 0.87 & 1072.87 & -0.51 & 293.49 & & & 0.59 & 710.59 & & & -0.89 & 725.11 & & \\
\hline Powder & 1.24 & 74.24 & 3.74 & 102.74 & 0.08 & 532.08 & 0.42 & 1072.42 & -0.71 & 293.29 & 2.35 & 349.35 & & & & & & & 1.04 & 139.04 \\
\hline Powder & 1.25 & 74.25 & 3.84 & 102.84 & 0.13 & 532.13 & 0.34 & 1072.34 & -0.82 & 293.18 & 3.18 & 350.18 & 2.71 & 712.71 & 1.57 & 134.57 & & & & \\
\hline \multicolumn{21}{|c|}{ UE18R 2228 Fracture } \\
\hline Powder & 1.53 & 74.53 & 3.83 & 102.83 & 0.22 & 532.22 & 0.65 & 1072.65 & -0.55 & 293.45 & & & & & & & -0.89 & 725.11 & & \\
\hline Powder & 1.08 & 74.08 & 3.57 & 102.57 & -0.10 & 531.90 & 0.25 & 1072.25 & -0.87 & 293.13 & 0.87 & 347.87 & & & & & & & 0.91 & 138.91 \\
\hline Powder & 1.36 & 74.36 & 3.74 & 102.74 & 0.08 & 532.08 & 0.42 & 1072.42 & -0.61 & 293.39 & 1.74 & 348.74 & 2.07 & 712.07 & 0.84 & 133.84 & & & & \\
\hline
\end{tabular}


Table 8. Chemical shifts and binding energies (eV) of major elements in core and powder samples (continued).

\begin{tabular}{|c|c|c|c|c|c|c|c|c|c|c|c|c|c|c|c|c|c|c|c|c|}
\hline \multirow{3}{*}{ SAMPLE } & \multicolumn{20}{|c|}{ XPS Line } \\
\hline & Al 2p & & Si 2p & & $\mathrm{O}$ ls & & $\mathrm{Na}$ ls & & K 2p3 & & Ca $2 \mathrm{p} 3$ & & $\mathrm{Fe} 2 \mathrm{p} 3$ & & Sr 3d5 & & Cs $3 \mathrm{~d} 5$ & & $\mathrm{~Pb} 4 \mathrm{f7}$ & \\
\hline & $\begin{array}{l}\text { Chem. } \\
\text { Shift }\end{array}$ & $\begin{array}{l}\text { Adj. } \\
\text { BE }\end{array}$ & $\begin{array}{l}\text { Chem. } \\
\text { Shift }\end{array}$ & $\begin{array}{l}\text { Adj. } \\
\mathrm{BE}\end{array}$ & $\begin{array}{l}\text { Chem. } \\
\text { Shift }\end{array}$ & $\begin{array}{l}\text { Adj. } \\
\text { BE }\end{array}$ & $\begin{array}{l}\text { Chem. } \\
\text { Shift }\end{array}$ & Adj. BF & $\begin{array}{l}\text { Chem. } \\
\text { 3E Shift }\end{array}$ & $\begin{array}{l}\text { Adj. } \\
\text { BE }\end{array}$ & $\begin{array}{l}\text { Chem. } \\
\text { Shift }\end{array}$ & $\begin{array}{l}\text { Adj. } \\
\text { BE }\end{array}$ & $\begin{array}{l}\text { Chem. } \\
\text { Shift }\end{array}$ & $\begin{array}{l}\text { Adj. } \\
\text { BE }\end{array}$ & $\begin{array}{l}\text { Chem. } \\
\text { Shift }\end{array}$ & $\begin{array}{l}\text { Adj. } \\
\text { BE }\end{array}$ & $\begin{array}{l}\text { Chem. } \\
\text { Shift }\end{array}$ & $\begin{array}{l}\text { Adj. } \\
\mathrm{BE}\end{array}$ & $\begin{array}{l}\text { Chem. } \\
\text { Shift }\end{array}$ & $\begin{array}{l}\text { Adj. } \\
\text { BE }\end{array}$ \\
\hline \multicolumn{21}{|c|}{ UE20c 2855 Matrix } \\
\hline Powder & 1.23 & 74.23 & 3.70 & 102.70 & 0.08 & 532.08 & 0.34 & 1072.34 & -0.75 & 293.25 & & & 0.49 & 710.49 & & & & & 0.90 & 138.90 \\
\hline Powder & 1.67 & 74.67 & 4.09 & 103.09 & 0.44 & 532.44 & 0.73 & 1072.73 & -0.28 & 293.72 & & & & & & & -0.94 & 725.06 & & \\
\hline Core (Spot\#1) & 0.95 & 73.95 & 3.15 & 102.15 & -0.24 & 531.76 & 0.01 & 1072.01 & -0.93 & 293.07 & 0.25 & 347.25 & & & & & & & 0.59 & 138.59 \\
\hline Core (Spot \#2) & 1.07 & 74.07 & 3.28 & 102.28 & -0.12 & 531.88 & & & & & & & & & & & & & 0.64 & 138.64 \\
\hline Core (Spot \#3) & 1.19 & 74.19 & 3.36 & 102.36 & 0.14 & 532.14 & & & & & & & & & & & & & 1.29 & 139.29 \\
\hline \multicolumn{21}{|c|}{ UE20c 2855 Fracture } \\
\hline Powder & 1.49 & 74.49 & 3.90 & 102.90 & 0.29 & 532.29 & 0.81 & 1072.81 & -0.50 & 293.50 & & & & & & & -0.96 & 725.04 & & \\
\hline Powder & 1.26 & 74.26 & 3.72 & 102.72 & 0.08 & 532.08 & 0.54 & 1072.54 & -0.66 & 293.34 & 1.66 & 348.66 & & & & & & & 0.81 & 138.81 \\
\hline \multicolumn{21}{|l|}{ UE20c 2908} \\
\hline Powder & 0.78 & 73.78 & 3.15 & 102.15 & -0.40 & 531.60 & -0.06 & 1071.94 & -1.22 & 292.78 & 1.00 & 348.00 & 1.05 & 711.05 & & & & & 0.68 & 138.68 \\
\hline Powder & 1.23 & 74.23 & 3.63 & 102.63 & -0.03 & 531.97 & 0.43 & 1072.43 & -0.80 & 293.20 & & & 1.24 & 711.24 & & & -1.09 & 724.91 & & \\
\hline Core (Spot \#1) & 1.51 & 74.51 & 3.81 & 102.81 & 0.43 & 532.43 & 0.97 & 1072.97 & -0.59 & 293.41 & 0.50 & 347.50 & & & & & & & 1.45 & 139.45 \\
\hline Core (Spot \#2) & 1.44 & 74.44 & 3.44 & 102.44 & 0.17 & 532.17 & & & & & & & & & & & & & 1.49 & 139.49 \\
\hline
\end{tabular}




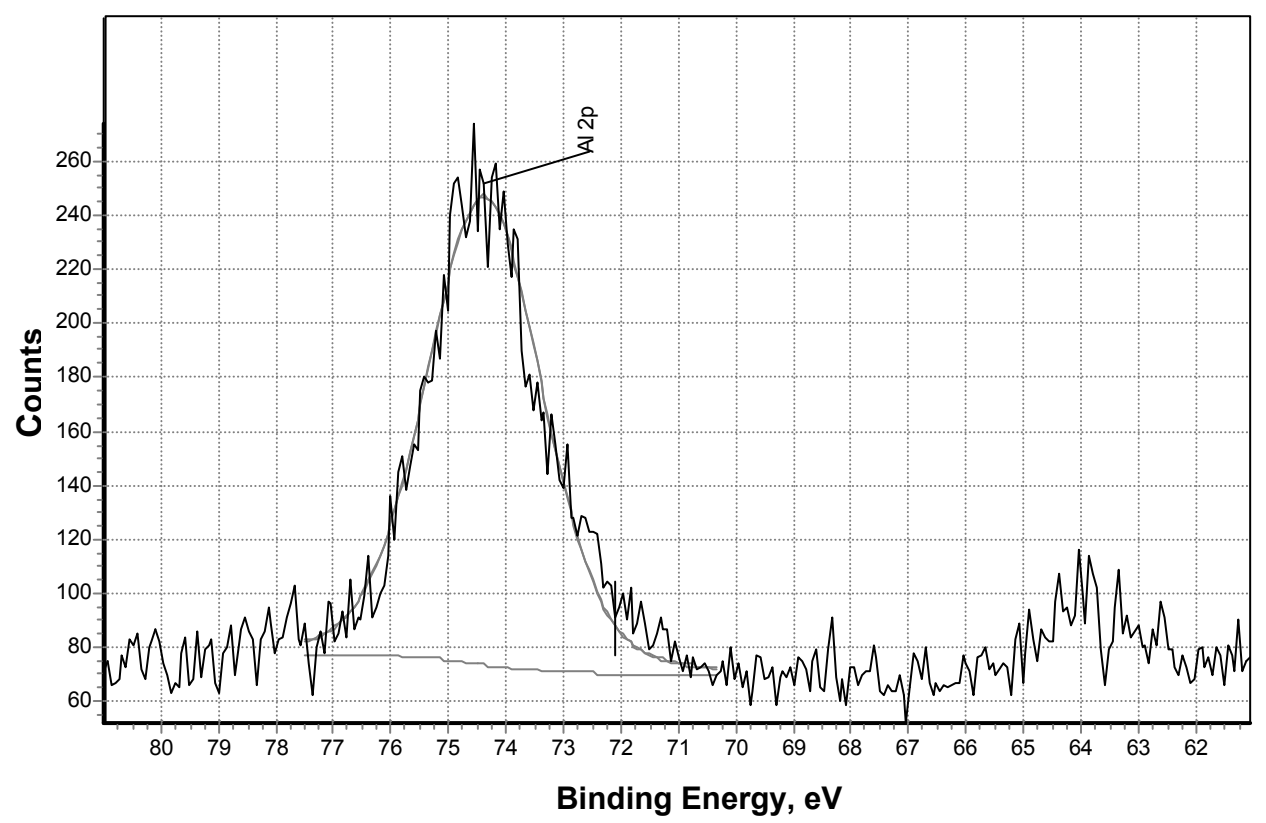

Figure 46. Typical Al 2p x-ray photoelectron spectrum in a WPM sample.

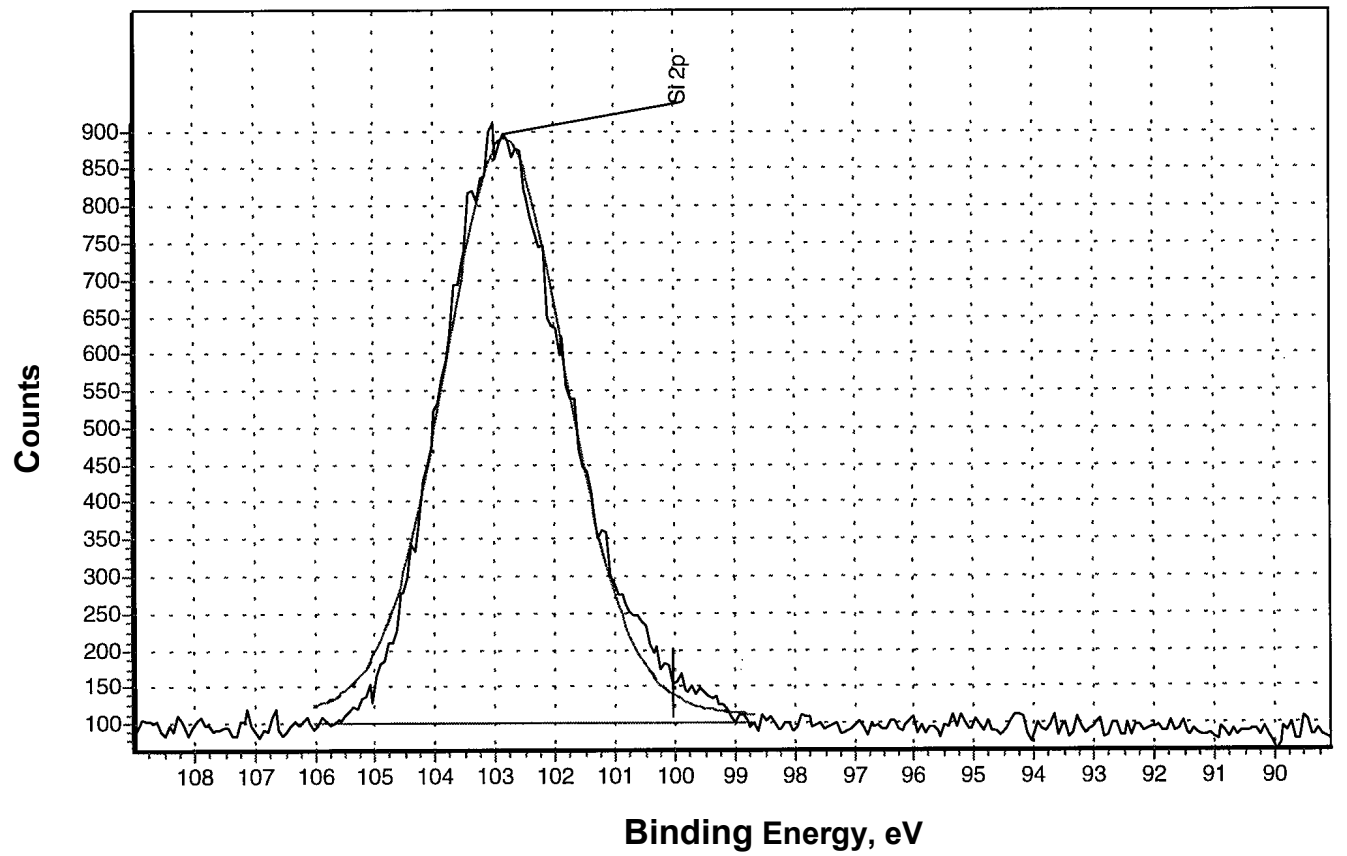

Figure 47. Typical Si 2p x-ray photoelectron spectrum in a WPM sample.

A representative XPS spectrum of the $\mathrm{O} 1 \mathrm{~s}$ peak is shown in Figure 48. The $\mathrm{O} 1 \mathrm{~s}$ chemical shifts for all samples were very small, resulting essentially to a BE of $532 \mathrm{eV}$, an average value for several different oxygen-containing compounds. The measured value, however, would be too high for metal oxides, which usually have BEs between 528 and $531 \mathrm{eV}$, and too low for silica, with a BE 532 to $533 \mathrm{eV}$. These results, therefore, are again consistent with $\mathrm{O}$ in a combination of aluminosilicates and quartz, as expected, based on the mineralogical analysis. 


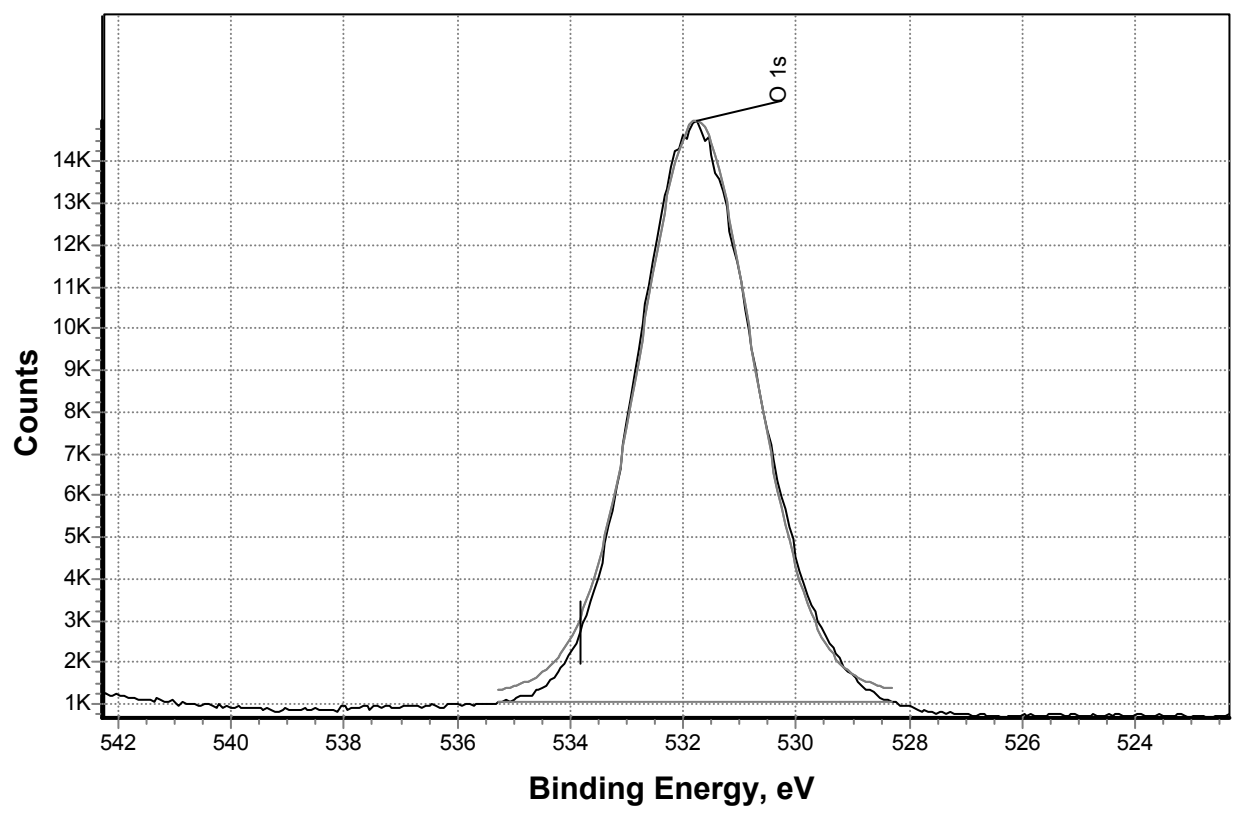

Figure 48. Typical O 1s x-ray photoelectron spectrum in a WPM sample.

The next set of major cations, in concentrations lower than the primary components $\mathrm{Al}$, $\mathrm{Si}$, and $\mathrm{O}$, included the cations of $\mathrm{Na}, \mathrm{K}$, and $\mathrm{Ca}$. Sodium and $\mathrm{K}$ were essentially present in every sample, whereas $\mathrm{Ca}$ was not, although narrow scans for the three cations were not collected for every sample. A representative XPS spectrum of the $\mathrm{Na} 1 \mathrm{~s}$ peak is shown in Figure 49. Average chemical shifts for these samples ranged mostly between 0.3 and $0.7 \mathrm{eV}$, resulting in BEs mostly between 1072.3 and $1072.7 \mathrm{eV}$, with the exception of sample PM-1 4823 fracture, where the BEs were consistently close to 1072.0. These results are certainly consistent with the presence of feldspars and other aluminosilicates. For example, the reported $\mathrm{BE}$ of $\mathrm{Na}$ in albite is $1072.2 \mathrm{eV}$ and values of $\mathrm{Na} 1 \mathrm{~s}$ BEs in molecular sieves range from 1071.8 to $1072.6 \mathrm{eV}$. The BEs for sodium carbonate and sodium bicarbonate appear to be lower, around $1071.5 \mathrm{eV}$.

A representative XPS spectrum of the $\mathrm{K} 2 \mathrm{p}$ peak is shown in Figure 50, where the spin orbit splitting of the $2 p$ level into $2 p_{1 / 2}$ and $2 p_{3 / 2}$ can be easily observed. The split orbit splitting was easily observed in all samples and the observed energy split was in good agreement with values reported in the literature. The chemical shift of the $\mathrm{K} 2 \mathrm{p}$ line was fairly consistent across the different samples, suggesting similar coordination environments in the different cores. The average chemical shifts ranged between -0.55 and $-0.80 \mathrm{eV}$, resulting in BEs between 293.45 and $293.2 \mathrm{eV}$. These BEs are common for a number of potassium salts, although no values for feldspars have been reported. The BE in the only aluminosilicate listed was $293.0 \mathrm{eV}$.

The concentration of $\mathrm{Ca}$ in the core samples was substantially lower than the rest of the cations and not present in all samples. In addition, the chemical shifts observed were scattered across a wider range compared to other cations, indicating that $\mathrm{Ca}$ was probably incorporated in different compounds, for example feldspars and carbonates. It is also likely that the larger scatter is partly a result of the lower abundance of $\mathrm{Ca}$ compared to other cations and the resulting more difficult definition of the peaks. BE shifts ranged from 0.25 to $3.18 \mathrm{eV}$ with corresponding BEs between 347.25 and 350.18. The highest BE was observed for sample UE18R 2228 matrix, while the lowest BE was observed for sample UE20c 2855 matrix. A representative XPS spectrum of the $\mathrm{Ca} 2 \mathrm{p}$ peak is shown in Figure 51. The BE values measured appear to be too high for calcite. The higher BE values measured would be consistent with aluminosilicates and calcium salts. 


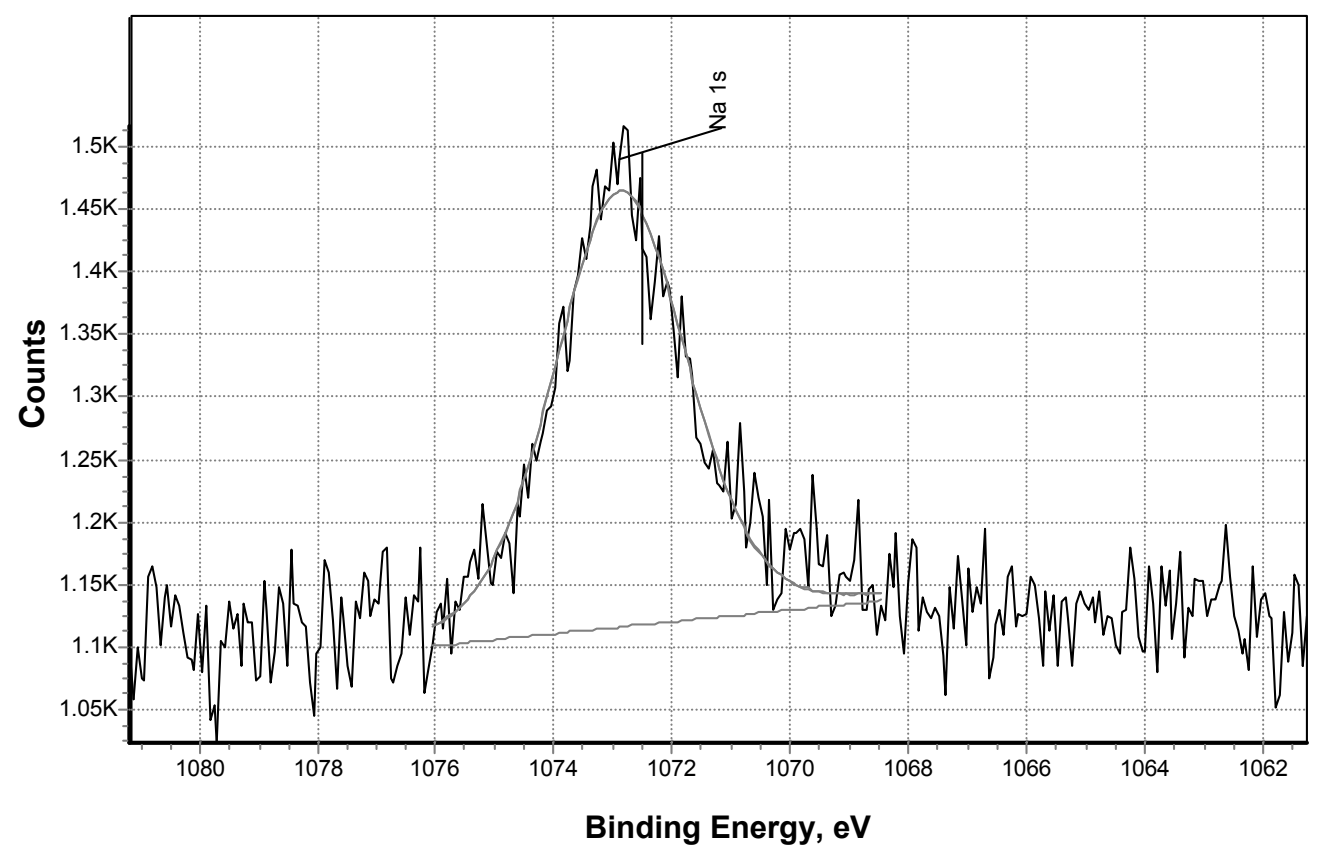

Figure 49. Typical Na 1s x-ray photoelectron spectrum in a WPM sample.

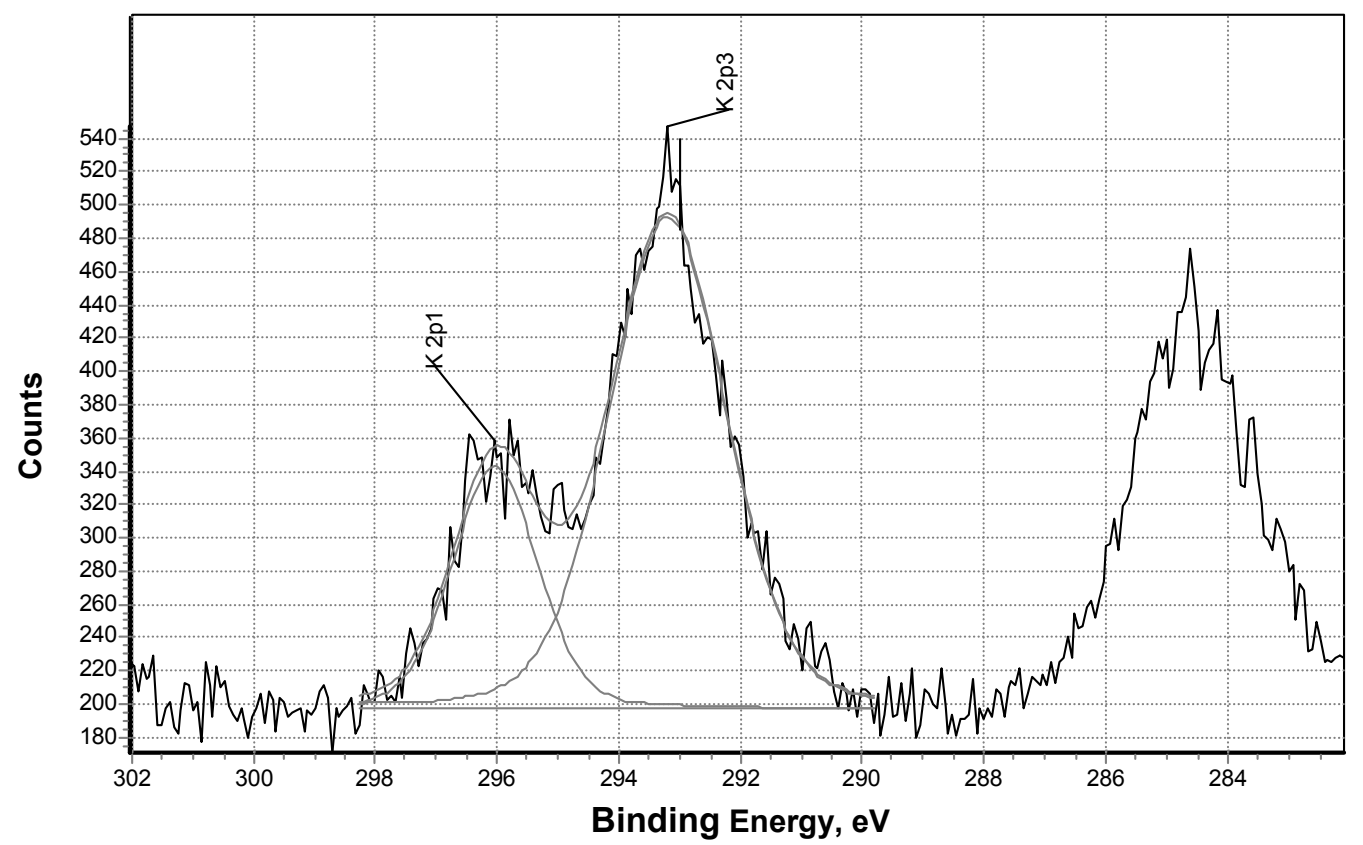

Figure 50. Typical K 2p x-ray photoelectron spectrum in a WPM sample. 


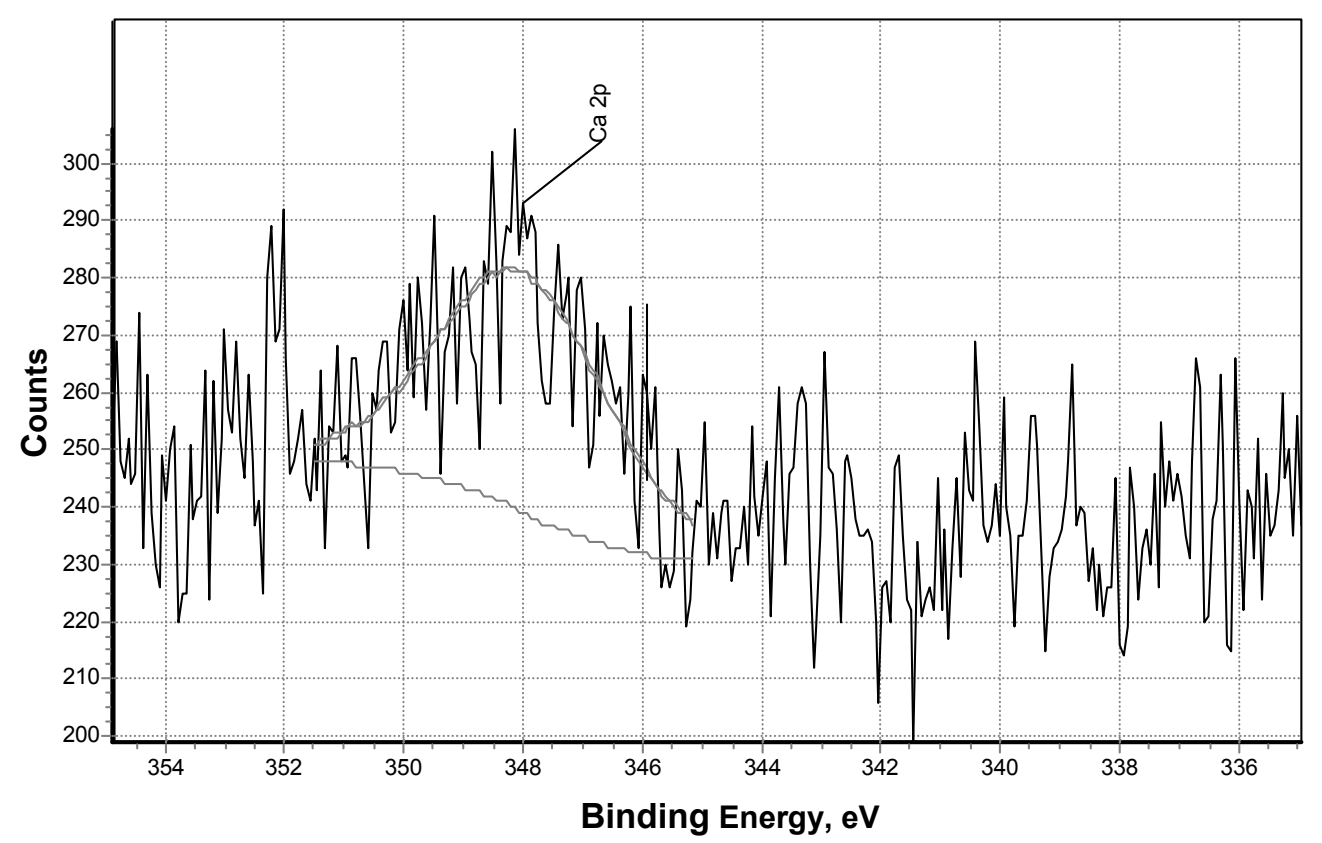

Figure 51. Typical Ca 2p x-ray photoelectron spectrum in a WPM sample.

Not all samples had measurable amounts of Fe and in some samples, Fe was not measured. In samples where Fe was present and measured, the chemical shifts and BEs varied over a considerable range. This result is not unexpected, given that there may be multiple sources of Fe where Fe could be found in the +2 or +3 oxidation state. These sources include hematite and mica in samples UE18R 2228, UE20c 2855, and PM-2 4177, and smectite in all samples. In addition, Fe oxides could be present on fracture coatings that are not necessarily identified by XRD. A representative XPS spectrum of the Fe $2 p$ peak is shown in Figure 52. The Fe 2p3 chemical shift ranged from -1.15 to $2.51 \mathrm{eV}$ in these samples. Some uncertainty may have been introduced by the relatively low concentration of $\mathrm{Fe}$ in some of these samples that makes peak definition more difficult. The resulting BEs ranged from 708.9 to 712.5 . For comparison purposes, the reported Fe 2p BEs for hematite, ferrihydrite, and ferrous oxide are 710.9, 711.8, and 709.4, respectively. These results suggest that although in the majority of cases, Fe must be present in the form of iron oxide coatings (similar to ferrihydrite) or hematite, divalent Fe must also be present in some cases, perhaps in mica or smectites.

A small quantity of Sr was detected on two powder samples examined and a representative spectrum of the $\mathrm{Sr} 3 \mathrm{~d}$ photoelectric peak is shown in Figure 53. The BEs of this peak in the two samples were 134.57 and $133.84 \mathrm{eV}$, respectively. The reported BE for Sr metal is $134.3 \mathrm{eV}$. Unfortunately, there are not as many values reported for different Sr environments, so that assigning of the peaks becomes more challenging. It appears though, that these values are too low for strontium oxide $(135.3 \mathrm{eV})$ and too high for strontium carbonate $(133.2 \mathrm{eV})$. These results, therefore, are not consistent with the formation of either a strontium carbonate precipitate, or the formation of a simple $\mathrm{Sr}-\mathrm{O}$ bond, similar to the one in strontium oxide. This latter scenario would imply the formation of Sr inner-sphere complexes on these surfaces, against substantial evidence from spectroscopic studies that suggest that $\mathrm{Sr}$ forms outer-sphere complexes only. The measured BEs, therefore, could be consistent with the presence of Sr as outer-sphere complexes or Sr incorporated into the solid as part of the mineral structure. 


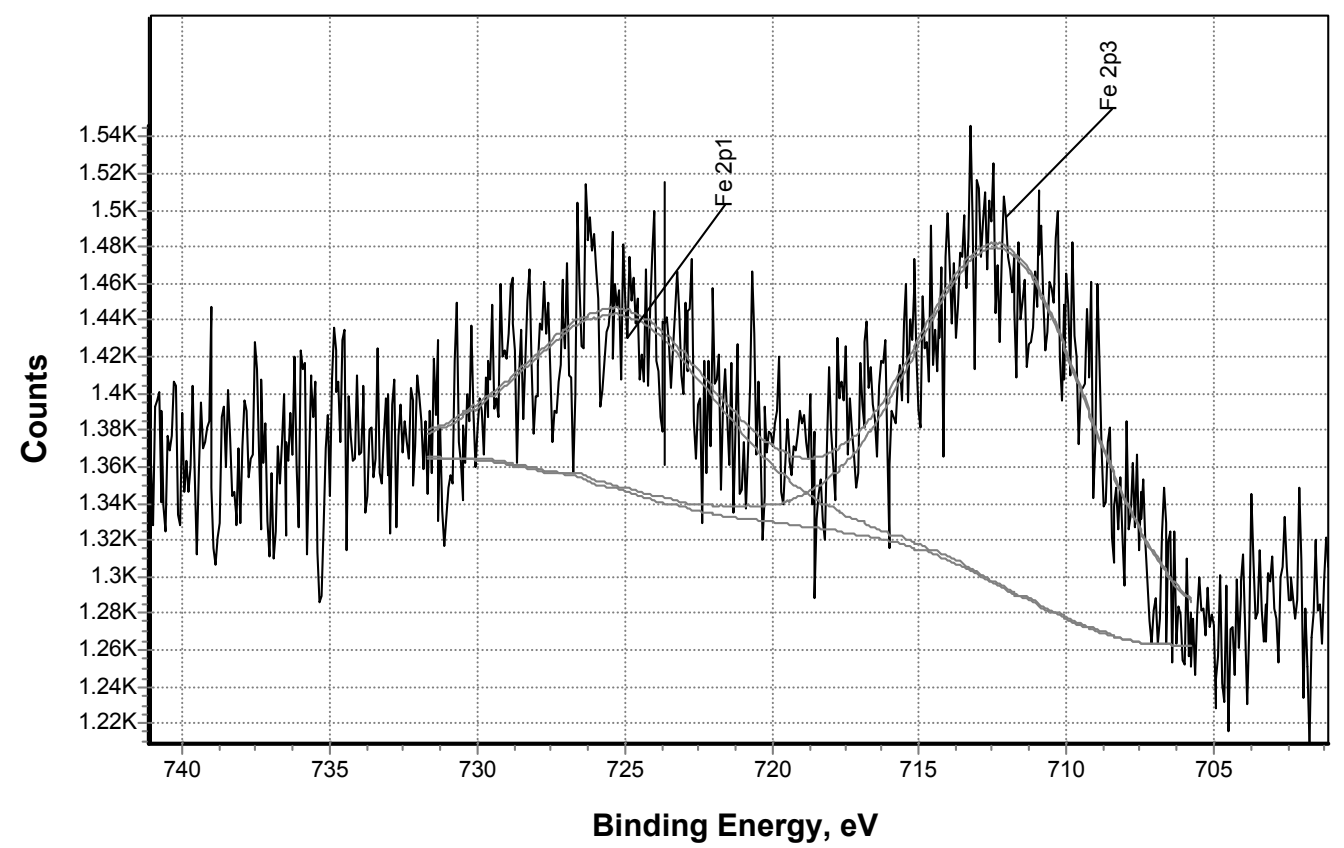

Figure 52. Typical Fe 2p x-ray photoelectron spectrum in a WPM sample.

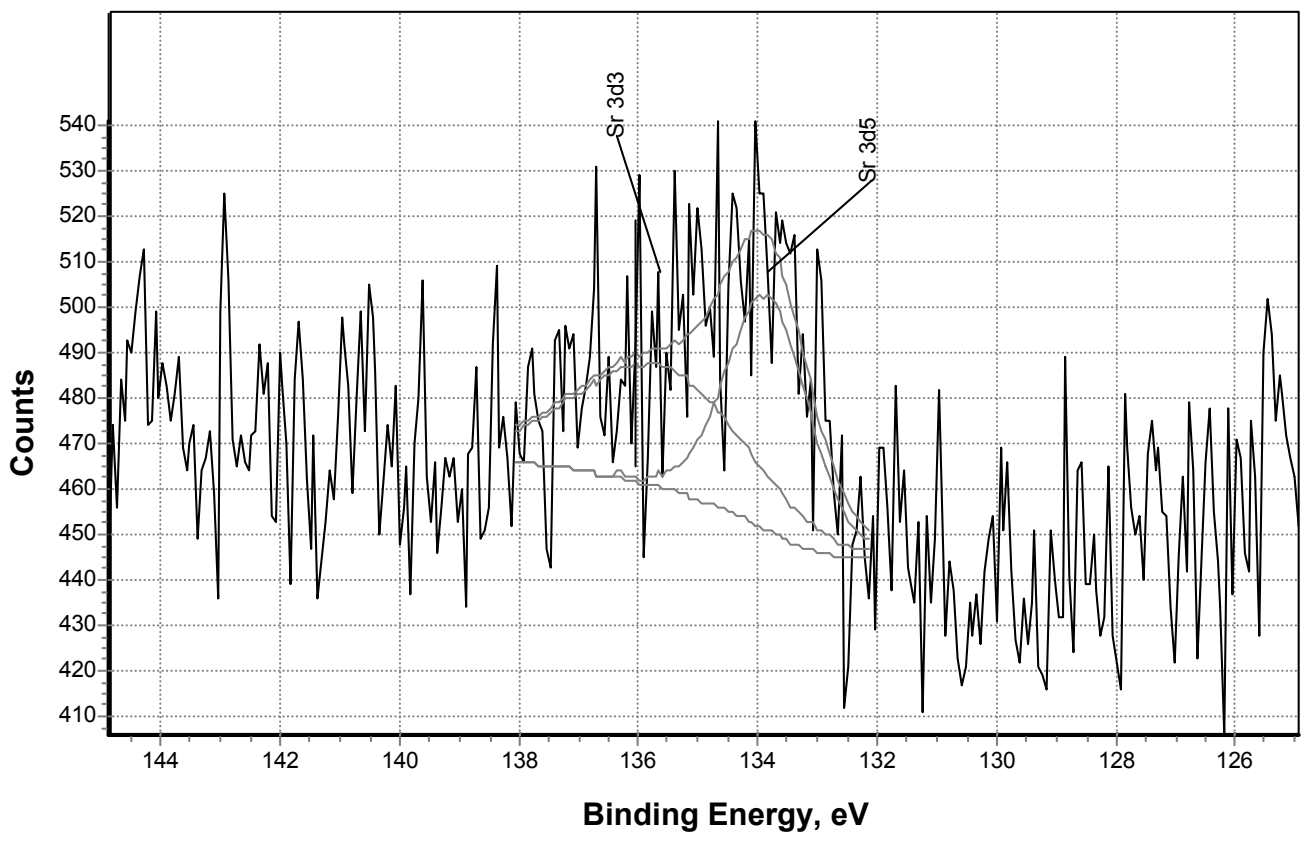

Figure 53. Typical Sr 3d x-ray photoelectron spectrum in a WPM sample.

Cesium was detected on all powders exposed to that ion. A representative spectrum of the Cs $3 \mathrm{~d}$ photoelectric peak is shown in Figure 54. The measured chemical shifts, with the exception of one sample, were approximately $-1 \mathrm{eV}$, resulting in BEs between 724.5 and 725.3 $\mathrm{eV}$. The reported BE for Cs is 726.0 or $726.4 \mathrm{eV}$. The measured values are therefore definitely lower than that and, most likely, correspond to a different chemical state. As for Sr, relatively few studies have been conducted that would help identify the chemical state in the sorption samples. The Cs $3 \mathrm{~d}$ BE in cesium hydroxide, however, is reported as $724.5 \mathrm{eV}$, at the low end of 
the spectrum of measured values. The measured BE for these sorption complexes, therefore, appears to be reasonable.

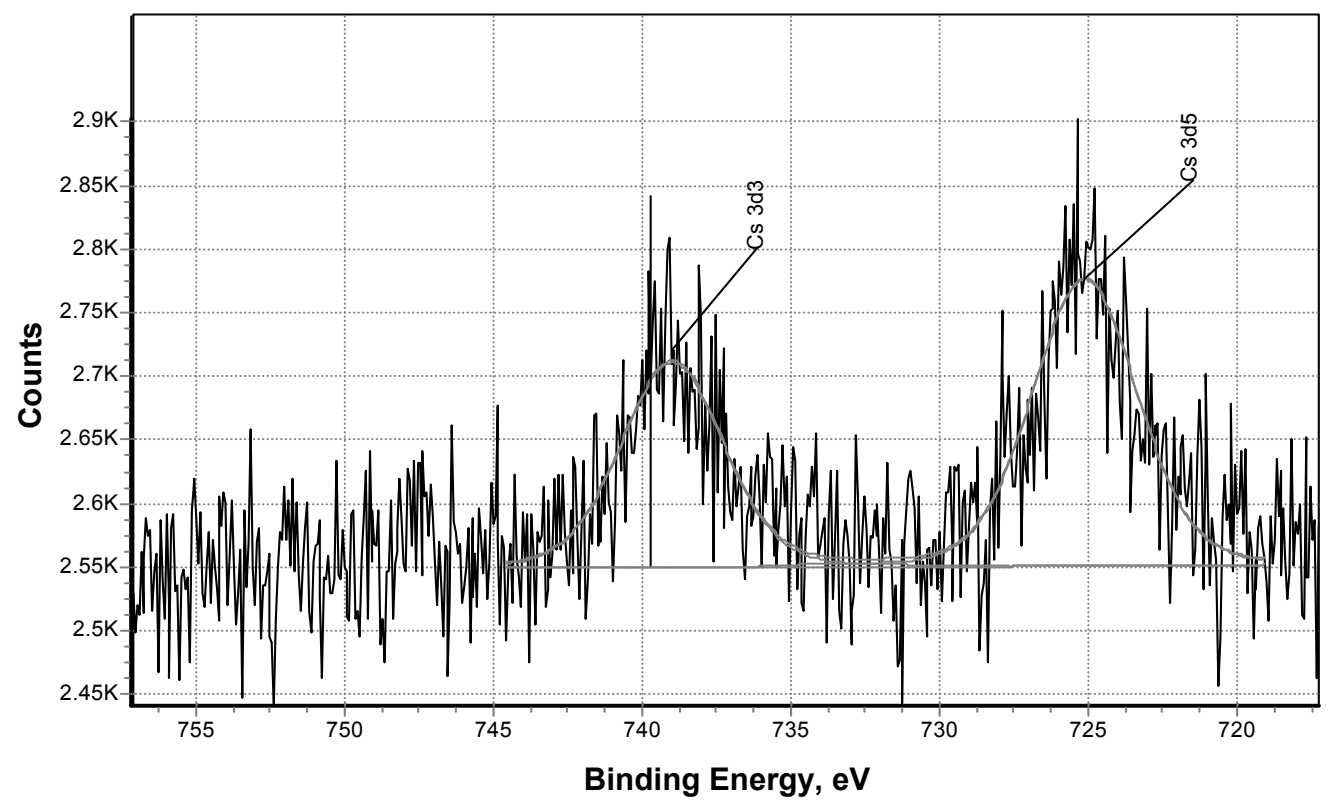

Figure 54. Typical Cs 3d x-ray photoelectron spectrum in a WPM sample.

A representative spectrum of the $\mathrm{Pb} 4 \mathrm{f}$ photoelectric peak is shown in Figure 55. In all powder and core samples that were exposed to $\mathrm{Pb}$ solutions, the $\mathrm{Pb} 4 \mathrm{f}$ peak could be detected. The measured BEs varied a fair amount between the different samples and ranged from 138.6 to $139.5 \mathrm{eV}$. These BEs appear to preclude the presence of $\mathrm{Pb}$ in a metallic form (BE $136.9 \mathrm{eV})$. The measured BEs, instead would be consistent with the $\mathrm{Pb}$ chemical state in lead oxide (138.9 $\mathrm{eV})$, possibly lead hydroxide $(138.4 \mathrm{eV})$, or even lead nitrate $(139.3 \mathrm{eV})$. Given the high potential of $\mathrm{Pb}$ for hydrolysis and the possibility of formation of different types of $\mathrm{Pb}$ complexes, the measured chemical shifts appear to be reasonable.

\section{Surface Composition}

The composition of the powder and core samples was also determined using the XPS. The advantage of the XPS in elemental composition determination over other techniques, such as EDX, is that only the first few atomic layers contribute to the signal, thus allowing us to study the composition of the surfaces involved in sorption reactions. Sample analysis was conducted for both powder and core samples, both before and after the sorption reactions. In some cases, only the most abundant elements were included in the analysis, namely $\mathrm{Al}$, Si, and $\mathrm{O}$. In most cases, however, all major cations and $\mathrm{O}$ were included in the elemental composition table. The composition table is prepared automatically by the ESCAVB software by including the peaks of interest. 


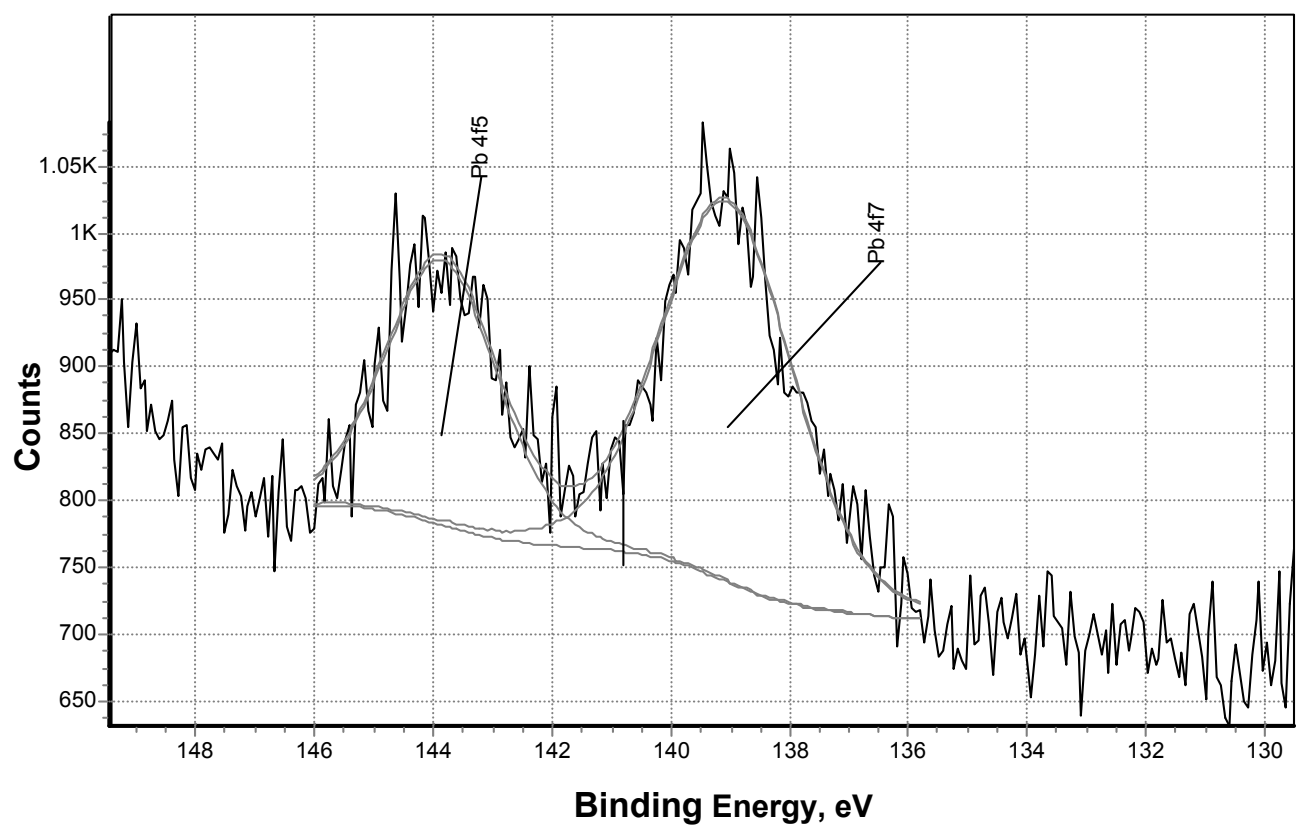

Figure 55. Typical $\mathrm{Pb} 4 \mathrm{f} \mathrm{x}$-ray photoelectron spectrum in a WPM sample.

The calculations of surface composition are listed in Table 9. In addition to the major cations and $\mathrm{O}$, elemental composition includes the $\mathrm{Cs}, \mathrm{Sr}$, and $\mathrm{Pb}$ adsorbates, where present. Although, strictly speaking, at least $\mathrm{Cs}$ and $\mathrm{Pb}$ were not present in the original samples and therefore it would not be appropriate to include them in the core composition, the total concentration of these elements is so small (less than 0.5 percent), that the calculated percentage would not be affected by the inclusion of these elements.

The surface composition of the samples is reported as a percentage of atomic composition, based on the number of atoms present, as opposed to percentage composition by weight, as is sometimes done. It should be emphasized that all analyses are semi-quantitative, performed without use of reference standards. The software, however, accounts for different efficiencies of photoelectrons having different binding energies. An analytical error of approximately 10 to 20 percent is typically expected.

The general trends in atomic composition will be summarized below. Oxygen, Si, and Al were, as expected, the most abundant elements at the surface. Sodium and K were present at lower concentrations and in every sample. Calcium and Fe were not detectable in all samples. The concentrations of $\mathrm{Na}$ and $\mathrm{K}$ were comparable and substantially higher than the $\mathrm{Ca}$ concentration. In some samples, $\mathrm{Na}$ was more abundant than $\mathrm{K}$, whereas in others, the opposite was true. The highest Na concentration was 4.75 percent in a core sample of PM-2 4177 and the highest $\mathrm{K}$ concentration was 4.43 percent in a powder sample of UE20c 2855 matrix. Finally, the highest $\mathrm{Ca}$ concentration was 0.66 percent in a core of the PM-1 4823 fracture sample and the highest Fe concentration was 1.03 percent in a core of PM-1 4823 matrix. 
Table 9. Atomic composition of core and powder samples.

\begin{tabular}{|c|c|c|c|c|c|c|c|c|}
\hline SAMPLE & & & & & & & & \\
\hline PM-1 4823 Matrix & Powder & & Powder & & Core & & Core & \\
\hline & Cs $3 \mathrm{~d} 5$ & 0.28 & $\mathrm{~Pb} 4 \mathrm{f} 7$ & 0.05 & & & & \\
\hline & $\mathrm{Al} 2 \mathrm{p}$ & 7.13 & $\mathrm{Al} 2 \mathrm{p}$ & 7.37 & Al 2p & 7.20 & Al 2p & 7.91 \\
\hline & Si $2 p$ & 21.98 & Si $2 p$ & 20.50 & Si $2 p$ & 20.35 & Si $2 p$ & 19.28 \\
\hline & $\mathrm{O} 1 \mathrm{~s}$ & 65.17 & $\mathrm{O} 1 \mathrm{~s}$ & 66.09 & $\mathrm{O} 1 \mathrm{~s}$ & 65.93 & $\mathrm{O} 1 \mathrm{~s}$ & 66.29 \\
\hline & $\mathrm{Na} 1 \mathrm{~s}$ & 1.75 & $\mathrm{Na} 1 \mathrm{~s}$ & 1.73 & $\mathrm{Na} 1 \mathrm{~s}$ & 2.22 & $\mathrm{Na} 1 \mathrm{~s}$ & 1.91 \\
\hline & $\mathrm{K} 2 \mathrm{p} 3$ & 3.03 & K 2p3 & 3.52 & K 2p3 & 2.99 & $\mathrm{~K} 2 \mathrm{p} 3$ & 3.08 \\
\hline & & & & & $\mathrm{Ca} 2 \mathrm{p}$ & 0.39 & $\mathrm{Ca} 2 \mathrm{p}$ & 0.49 \\
\hline & Fe $2 p 3$ & 0.65 & $\mathrm{Fe} 2 \mathrm{p} 3$ & 0.74 & $\mathrm{Fe} 2 \mathrm{p} 3$ & 0.92 & $\mathrm{Fe} 2 \mathrm{p} 3$ & 1.03 \\
\hline PM-1 4823 Fracture & Powder & & Powder & & Core & & Core & \\
\hline & Cs $3 \mathrm{~d} 5$ & 0.38 & $\mathrm{~Pb} 4 \mathrm{f} 7$ & 0.10 & & & & \\
\hline & Al 2p & 7.38 & $\mathrm{Al} 2 \mathrm{p}$ & 7.29 & Al 2p & 7.60 & $\mathrm{Al} 2 \mathrm{p}$ & 7.61 \\
\hline & Si $2 p$ & 20.75 & Si $2 p$ & 21.16 & Si $2 p$ & 19.22 & Si $2 p$ & 18.01 \\
\hline & $\mathrm{O} 1 \mathrm{~s}$ & 65.13 & $\mathrm{O} 1 \mathrm{~s}$ & 65.19 & $\mathrm{O} 1 \mathrm{~s}$ & 67.70 & $\mathrm{O} 1 \mathrm{~s}$ & 67.95 \\
\hline & $\mathrm{Na} 1 \mathrm{~s}$ & 2.11 & $\mathrm{Na} 1 \mathrm{~s}$ & 1.41 & $\mathrm{Na} 1 \mathrm{~s}$ & 1.85 & $\mathrm{Na} 1 \mathrm{~s}$ & 1.87 \\
\hline & $\mathrm{K} 2 \mathrm{p} 3$ & 3.42 & $\mathrm{~K} 2 \mathrm{p} 3$ & 3.76 & K 2p3 & 3.07 & K 2p3 & 3.13 \\
\hline & & & & & & & $\mathrm{Ca} 2 \mathrm{p}$ & 0.66 \\
\hline & Fe $2 \mathrm{p} 3$ & 0.83 & Fe $2 \mathrm{p} 3$ & 1.10 & Fe $2 p 3$ & 0.56 & $\mathrm{Fe} 2 \mathrm{p} 3$ & 0.77 \\
\hline PM-2 4177 & Powder & & Powder & & Core & & Core & \\
\hline & Cs $3 \mathrm{~d} 5$ & 0.19 & $\mathrm{~Pb} 4 \mathrm{f} 7$ & 0.07 & & & & \\
\hline & & & & & $\mathrm{Al} 2 \mathrm{p}$ & 7.34 & $\mathrm{Al} 2 \mathrm{p}$ & 8.22 \\
\hline & Si $2 p$ & 22.90 & Si $2 p$ & 22.54 & Si $2 p$ & 19.81 & Si $2 p$ & 18.46 \\
\hline & $\mathrm{O} 1 \mathrm{~s}$ & 76.91 & $\mathrm{O} 1 \mathrm{~s}$ & 77.39 & $\mathrm{O} 1 \mathrm{~s}$ & 65.57 & $\mathrm{O} 1 \mathrm{~s}$ & 65.06 \\
\hline & & & & & $\mathrm{Na} 1 \mathrm{~s}$ & 4.24 & $\mathrm{Na} 1 \mathrm{~s}$ & 4.75 \\
\hline & & & & & $\mathrm{K} 2 \mathrm{p} 3$ & 2.54 & K 2p3 & 2.45 \\
\hline & & & & & $\mathrm{Ca} 2 \mathrm{p}$ & 0.33 & $\mathrm{Ca} 2 \mathrm{p}$ & 0.23 \\
\hline & & & & & & & $\operatorname{Mg} 2 p$ & 0.61 \\
\hline & & & & & Fe $2 \mathrm{p} 3$ & 0.18 & Fe $2 p 3$ & 0.22 \\
\hline UE18R 2228 Matrix & Powder & & Powder & & Powder & & & \\
\hline & Cs $3 \mathrm{~d} 5$ & 0.25 & $\mathrm{~Pb} 4 \mathrm{f} 7$ & 0.16 & Sr 3d & 0.14 & & \\
\hline & $\mathrm{Al} 2 \mathrm{p}$ & 5.43 & $\mathrm{Al} 2 \mathrm{p}$ & 5.65 & $\mathrm{Al} 2 \mathrm{p}$ & 5.90 & & \\
\hline & Si $2 p$ & 23.67 & Si $2 p$ & 23.84 & Si $2 p$ & 23.27 & & \\
\hline & $\mathrm{O} 1 \mathrm{~s}$ & 64.96 & $\mathrm{O} 1 \mathrm{~s}$ & 63.53 & $\mathrm{O} 1 \mathrm{~s}$ & 64.18 & & \\
\hline & $\mathrm{Na} 1 \mathrm{~s}$ & 3.13 & $\mathrm{Na} 1 \mathrm{~s}$ & 3.56 & $\mathrm{Na} 1 \mathrm{~s}$ & 3.74 & & \\
\hline & $\mathrm{K} 2 \mathrm{p} 3$ & 2.35 & $\mathrm{~K} 2 \mathrm{p} 3$ & 2.83 & $\mathrm{~K} 2 \mathrm{p} 3$ & 2.06 & & \\
\hline & & & $\mathrm{Ca} 2 \mathrm{p}$ & 0.42 & $\mathrm{Ca} 2 \mathrm{p}$ & 0.36 & & \\
\hline & $\mathrm{Fe} 2 \mathrm{p} 3$ & 0.20 & & & $\mathrm{Fe} 2 \mathrm{p} 3$ & 0.35 & & \\
\hline
\end{tabular}


Table 9. Atomic composition of core and powder samples (continued).

\begin{tabular}{|c|c|c|c|c|c|c|c|c|c|c|}
\hline \multicolumn{11}{|l|}{ SAMPLE } \\
\hline \multirow[t]{9}{*}{ UE18R 2228 Fracture } & Powder & & Powder & & Powder & & & & & \\
\hline & Cs $3 d 5$ & 0.21 & $\mathrm{~Pb} 4 \mathrm{f} 7$ & 0.14 & Sr 3d5 & 0.12 & & & & \\
\hline & $\mathrm{Al} 2 \mathrm{p}$ & 6.00 & $\mathrm{Al} 2 \mathrm{p}$ & 6.35 & Al 2p & 5.83 & & & & \\
\hline & Si $2 p$ & 23.76 & Si $2 p$ & 22.87 & Si $2 p$ & 22.47 & & & & \\
\hline & $\mathrm{O} 1 \mathrm{~s}$ & 63.43 & $\mathrm{O} 1 \mathrm{~s}$ & 62.30 & $\mathrm{O} 1 \mathrm{~s}$ & 63.51 & & & & \\
\hline & $\mathrm{Na} 1 \mathrm{~s}$ & 3.37 & $\mathrm{Na} 1 \mathrm{~s}$ & 5.23 & $\mathrm{Na} 1 \mathrm{~s}$ & 4.37 & & & & \\
\hline & K 2 p3 & 3.23 & K 2p3 & 2.91 & K 2p3 & 2.86 & & & & \\
\hline & & & $\mathrm{Ca} 2 \mathrm{p}$ & 0.20 & $\mathrm{Ca} 2 \mathrm{p}$ & 0.60 & & & & \\
\hline & & & & & Fe $2 \mathrm{p} 3$ & 0.24 & & & & \\
\hline \multirow[t]{9}{*}{ UE20c 2855 Matrix } & Core & & Core & & Core & & Powder & & Powder & \\
\hline & $\mathrm{Pb} 4 \mathrm{f} 7$ & 0.22 & $\mathrm{~Pb} 4 \mathrm{f} 7$ & 0.25 & $\mathrm{~Pb} 4 \mathrm{f} 7$ & 0.30 & Cs $3 \mathrm{~d} 5$ & 0.24 & $\mathrm{~Pb} 4 \mathrm{f} 7$ & 0.12 \\
\hline & $\mathrm{Al} 2 \mathrm{p}$ & 3.84 & $\mathrm{Al} \mathrm{2p}$ & 3.59 & $\mathrm{Al} \mathrm{2p}$ & 2.71 & $\mathrm{Al} 2 \mathrm{p}$ & 5.54 & $\mathrm{Al} 2 \mathrm{p}$ & 5.59 \\
\hline & Si $2 p$ & 23.39 & Si $2 p$ & 24.36 & Si 2p & 25.22 & Si $2 p$ & 24.32 & Si $2 p$ & 22.69 \\
\hline & $\mathrm{O} 1 \mathrm{~s}$ & 68.65 & $\mathrm{O} 1 \mathrm{~s}$ & 71.80 & $\mathrm{O} 1 \mathrm{~s}$ & 71.77 & $\mathrm{O} 1 \mathrm{~s}$ & 63.65 & $\mathrm{O} 1 \mathrm{~s}$ & 63.19 \\
\hline & $\mathrm{Na} 1 \mathrm{~s}$ & 1.56 & & & & & $\mathrm{Na} 1 \mathrm{~s}$ & 2.08 & $\mathrm{Na} 1 \mathrm{~s}$ & 3.88 \\
\hline & $\mathrm{K} 2 \mathrm{p} 3$ & 1.74 & & & & & K 2p3 & 4.17 & K 2p3 & 4.43 \\
\hline & $\mathrm{Ca} 2 \mathrm{p}$ & 0.60 & & & & & & & & \\
\hline & & & & & & & & & $\mathrm{Fe} 2 \mathrm{p} 3$ & 0.11 \\
\hline \multirow[t]{8}{*}{ UE20c 2855 Fracture } & Powder & & Powder & & & & & & & \\
\hline & Cs $3 d 5$ & 0.22 & $\mathrm{~Pb} 4 \mathrm{f} 7$ & 0.15 & & & & & & \\
\hline & Al 2p & 5.31 & $\mathrm{Al} 2 \mathrm{p}$ & 6.00 & & & & & & \\
\hline & Si $2 p$ & 24.31 & Si $2 p$ & 23.79 & & & & & & \\
\hline & $\mathrm{O} 1 \mathrm{~s}$ & 63.84 & $\mathrm{O} 1 \mathrm{~s}$ & 63.02 & & & & & & \\
\hline & $\mathrm{Na} 1 \mathrm{~s}$ & 2.14 & $\mathrm{Na} 1 \mathrm{~s}$ & 2.64 & & & & & & \\
\hline & K 2p3 & 4.19 & K 2p3 & 4.25 & & & & & & \\
\hline & & & $\mathrm{Ca} 2 \mathrm{p}$ & 0.15 & & & & & & \\
\hline \multirow[t]{9}{*}{ UE20c 2908} & Core & & Core & & Powder & & Powder & & & \\
\hline & $\mathrm{Pb} 4 \mathrm{f} 7$ & 0.38 & $\mathrm{~Pb} 4 \mathrm{f} 7$ & 0.52 & Cs $3 \mathrm{~d} 5$ & 0.25 & $\mathrm{~Pb} 4 \mathrm{f} 7$ & 0.10 & & \\
\hline & $\mathrm{Al} 2 \mathrm{p}$ & 3.78 & $\mathrm{Al} 2 \mathrm{p}$ & 4.09 & $\mathrm{Al} 2 \mathrm{p}$ & 5.74 & $\mathrm{Al} 2 \mathrm{p}$ & 5.92 & & \\
\hline & $\operatorname{Si} 2 p$ & 23.16 & Si $2 p$ & 23.81 & $\operatorname{Si} 2 p$ & 22.95 & $\operatorname{Si} 2 p$ & 23.01 & & \\
\hline & $\mathrm{O} 1 \mathrm{~s}$ & 69.60 & $\mathrm{O} 1 \mathrm{~s}$ & 71.59 & $\mathrm{O} 1 \mathrm{~s}$ & 64.29 & $\mathrm{O} 1 \mathrm{~s}$ & 63.35 & & \\
\hline & $\mathrm{Na} 1 \mathrm{~s}$ & 1.31 & & & $\mathrm{Na} 1 \mathrm{~s}$ & 3.25 & $\mathrm{Na} 1 \mathrm{~s}$ & 3.25 & & \\
\hline & $\mathrm{K} 2 \mathrm{p} 3$ & 1.53 & & & K 2p3 & 3.31 & K 2p3 & 3.82 & & \\
\hline & $\mathrm{Ca} 2 \mathrm{p}$ & 0.23 & & & & & $\mathrm{Ca} 2 \mathrm{p}$ & 0.37 & & \\
\hline & & & & & $\mathrm{Fe} 2 \mathrm{p} 3$ & 0.22 & $\mathrm{Fe} 2 \mathrm{p} 3$ & 0.18 & & \\
\hline
\end{tabular}

The atomic percentages of $\mathrm{O}, \mathrm{Si}$, and $\mathrm{Al}$ averaged around 65, 22, and 6 percent, respectively, accounting for approximately 93 percent of the sample. The highest $O$ percentage was approximately 69, the highest Si percentage was approximately 24 , and the highest $\mathrm{Al}$ percentage was approximately 8 . These numbers are entirely consistent with the reported mineralogy of the samples that consisted mainly of feldspars and quartz. In the case of quartz, 
the expected composition would be 33 percent Si and 67 percent O, with no Al. In the case of feldspars, taking the mineral albite as an example with the formula $\mathrm{NaAlSi}_{3} \mathrm{O}_{8}$, the expected percentages would be $\mathrm{O}$ 62, Si 23, and $\mathrm{Al}$ and $\mathrm{Na} 8$ each. If half of $\mathrm{Na}$ were substituted by $\mathrm{K}$, the expected composition would have been $\mathrm{O}$ 62, Si 23, Al 8, Na 4, and $\mathrm{K} 4$. Assuming a mixture of 33 percent quartz and 67 percent feldspar would result in an approximate composition of 64 percent $\mathrm{O}, 26$ percent $\mathrm{Si}, 5$ percent $\mathrm{Al}, 3$ percent $\mathrm{Na}$, and 3 percent $\mathrm{K}$. This composition is indeed remarkably close to the obtained results and reassuring in terms of confidence in the XPS analytical results and the method used to estimate surface coverages of the sorbents by $\mathrm{Cs}, \mathrm{Pb}$, and $\mathrm{Sr}$, as discussed below.

\section{Estimation of Sorbent Surface Coverage by Cesium, Lead, and Strontium}

As mentioned previously, one of the major advantages of the XPS technique is its ability to analyze the composition of a surface and, specifically, to determine the composition of the first few atomic monolayers of that surface. This is obviously a great advantage for the study of interfaces, including the study of sorption reactions, as these reactions are controlled by the interaction of dissolved ions with the uppermost layers of atoms on exposed surfaces. Based on macroscopic sorption experiments, one can determine the total uptake of a metal ion by a solid. This information, alone, however, cannot provide any insight into the sorption mechanism of ions of interest on mineral surfaces. For example, based on macroscopic information, one can determine the total amount of a metal sorbed onto a surface, but one cannot distinguish between sorption and surface precipitation. This is because the potential for formation of a precipitate in bulk solution cannot be used to predict the formation of a surface precipitate (Sposito, 1986). Such a distinction is particularly important when trying to distinguish between surface precipitation on one hand and diffusion followed by sorption on the other.

Using XPS, one can estimate the surface coverage of adsorbents, thereby obtaining a direct measurement of the distribution of metal ions at the surface of adsorbents. In this study, this was achieved by analyzing powder and core samples after they had been exposed to a metal ion solution. Because the formation of a surface precipitate is expected to result in multi-layer coverage of the surface and because the XPS signal coming from the uppermost layers is particularly amplified, a result suggesting multi-layer coverage would clearly suggest formation of surface precipitates.

For this study, both powders and core samples were analyzed by XPS and the measured surface coverage estimate was compared to the estimated surface coverage based on macroscopic sorption experiments. The comparison between powder and core samples and the three different metal cations was expected to provide information that could be used to distinguish between different sorption mechanisms. For the powder samples, experiments were conducted as usual. Following equilibration, the samples were centrifuged, most of the supernatant was removed, and the remaining wet paste was freeze-dried using a Labconco freeze dryer. Freeze-drying was used to disturb the coordination environment of the sorbed metal ions as little as possible during the drying process. For the core samples, similarly, the core was removed from the diffusion cell at the end of the diffusion experiment and the wet cell was freeze-dried. The samples were loaded onto aluminum sample holders and pumped down for at least one day in the prep chamber before they were introduced in the analytical chamber for surface analysis.

The comparison of surface coverage as estimated by total metal uptake and measured by XPS involved a number of calculations and assumptions that will be briefly summarized here. The surface coverage based on total metal uptake was estimated by comparing the total amount 
of metal sorbed to the total number of surface sites available. The total amount of metal sorbed was estimated by the total initial metal concentration, the fractional metal uptake (percentage), and was converted to total number of atoms sorbed using Avogadro's number. The total number of sites was estimated from the solid concentration, the specific surface area of the solid, and an estimate of the surface site density of the sample. The highest uncertainty in these calculations stems from the estimate of the surface site density. A value of five sites $/ \mathrm{nm}^{2}$ was used for these calculations. This is an average value obtained from the literature and is only an estimate.

Obviously, this value would be a function of the mineral and is probably not constant even for a single solid. For different types of surface studies, researchers have used values ranging from three to 10 sites $/ \mathrm{nm}^{2}$. The value chosen, five sites $/ \mathrm{nm}^{2}$, was considered a reasonable average. Obviously, the calculated numbers depend on the choice for this parameter.

The estimation of surface coverage by XPS involved a number of assumptions. The adsorbed layer thickness was estimated by comparing the photoelectric peak of the metal of interest to the photoelectric peak of the most abundant cation on the surface, Si. Specifically, the adsorbed layer thickness was calculated based on Equation (13), a generalization of the equation used by Papelis (1995) to calculate surface coverages of adsorbents.

$$
x=-\lambda_{\alpha} \cos \theta \ln \left(1-\frac{A_{x}}{A_{x}+A_{S i}}\right)
$$

where $\mathrm{x}$ is the adsorbed layer thickness $(\AA), \lambda_{\alpha}$ is the attenuation length $(\AA), \theta$ is the angle between the sample normal and the detector, and $A_{x}$ and $A_{S i}$ are the normalized areas of the metal ion of interest and Si, respectively. As explained in more detail in Papelis (1995), the angle between the sample normal and the detector was assumed to be zero and the attenuation length was assumed to be $15 \AA$. The normalized area is calculated by the ESCAVB software and is a function of peak area, the number of scans collected, the peak photoionization cross section, a sensitivity exponent, and the position of the photoelectric peak. The percent monolayer coverage is then estimated by comparing the adsorbed layer thickness to an assumed monolayer thickness of $1.5 \AA$. For example, a calculated adsorbed layer thickness of $0.5 \AA$ would be interpreted as 33 percent monolayer coverage.

The comparison of percent monolayer coverage of all powders by lead as determined by total uptake and XPS is shown in Table 10. With the exception of the UE18R 2228 samples, the agreement between coverage based on total uptake and coverage based on XPS measurements is very good. Although the coverage based on total uptake appears to be approximately twice as high compared to the XPS estimates, one must keep in mind the assumptions that were used for these calculations. For example, if the assumed site density were doubled to $10 \mathrm{sites} / \mathrm{nm}^{2}$, the two sets of numbers would be almost identical. Furthermore, the ratio between these two sets of estimates is almost constant (with the exception of UE18R 2228), suggesting that the estimation method is fairly robust.

It is not exactly clear why there is such a discrepancy between UE18R 2228 and the rest of the samples. One possible explanation, however, hinges on the differences in structure of these solids. As will be remembered, UE18R 2228 was the densely welded tuff sample that had by far the lowest porosity and specific surface area three to five times lower compared to the rest of the samples. It has been shown before (Papelis, 1995), that the structure and porosity of the solid does affect the apparent surface coverage determined by XPS. This fact may be due to the orientation of the sample and counting resulting from several layers in a porous sample 
compared to a nonporous one. Even for the UE18R 2228 samples, however, the coverages estimated by XPS were among the highest of all samples. Finally, the percent monolayer coverages of all samples, as estimated by XPS, ranged from 2.6 to 6.9. These values, all well below 10 percent monolayer coverage, do not support the hypothesis of formation of surface precipitates and are consistent with formation of isolated surface complexes.

Table 10. Comparison of percent monolayer coverage of WPM powders as determined by total lead uptake and XPS.

\begin{tabular}{lcl}
\hline \multicolumn{1}{c}{ Samples } & Total uptake & XPS \\
\hline PM-1 4823 Matrix & 7.4 & 2.6 \\
PM-1 4823 Fracture & 7.2 & 4.7 \\
PM-2 4177 & 6.6 & 3.1 \\
UE18R 2228 Matrix & 31.2 & 6.9 \\
UE18R 2228 Fracture & 36.0 & 6.0 \\
UE20C 2855 Matrix & 9.7 & 5.2 \\
UE20C 2855 Fracture & 11.0 & 6.5 \\
UE20C 2908 & 6.9 & 4.6 \\
\hline
\end{tabular}

The comparison of percent monolayer coverage of all powders by Cs as determined by total uptake and XPS is shown in Table 11. There are differences and similarities compared to the $\mathrm{Pb}$ results. As for $\mathrm{Pb}$, the percent monolayer coverage of UE18R 2228 based on total Cs uptake was substantially higher compared to the estimate by XPS. For the rest of the samples, however, the agreement was much better. Unlike $\mathrm{Pb}$, only for the UE20c 2855 samples was the estimate based on total uptake approximately twice as high as the estimate based on XPS. For the rest of the samples, the estimates were even closer. The differences between $\mathrm{Pb}$ and $\mathrm{Cs}$ could be due to the different type of sorption mechanism in the case of the two metals. Lead tends to hydrolyze substantially more than Cs and to form inner-sphere complexes on oxide and hydroxide surfaces. Cesium, however, is thought to form outer-sphere complexes only. Because of differences in the sorption mechanism, even the estimate of surface site density could very well be different for the two metals. As in the case of $\mathrm{Pb}$, however, the relatively low-percent monolayer coverages (approximately 10 to 20 percent) suggest that a surface precipitation mechanism would be rather unlikely.

Table 11. Comparison of percent monolayer coverage of WPM powders as determined by total cesium uptake and XPS.

\begin{tabular}{lcr}
\hline Samples & Total uptake & XPS \\
\hline PM-1 4823 Matrix & 13.0 & 12.9 \\
PM-1 4823 Fracture & 14.9 & 18.1 \\
PM-2 4177 & 13.2 & 8.1 \\
UE18R 2228 Matrix & 57.8 & 10.3 \\
UE18R 2228 Fracture & 68.4 & 8.7 \\
UE20C 2855 Matrix & 19.7 & 10.0 \\
UE20C 2855 Fracture & 23.2 & 9.1 \\
UE20C 2908 & 15.4 & 10.7 \\
\hline
\end{tabular}


Surface coverage experiments with Sr were conducted with UE18R 2228 samples only, because Sr sorption was minimal, as discussed earlier. The comparison of percent monolayer coverage of UE18R 2228 by Sr as determined by total uptake and XPS is shown in Table 12. Although these numbers have a large degree of uncertainty because of the low Sr concentration, both in terms of sorption uptake and in terms of XPS signal quantification, the results agree very well. In addition, the discrepancy observed for this sample in the case of $\mathrm{Cs}$ and $\mathrm{Pb}$ was not observed in the case of Sr. It should also be kept in mind that based on leaching experiments, $\mathrm{Sr}$ was present in measurable quantities in these samples, so that at least part of the XPS signal could originate from $\mathrm{Sr}$ already present in the sample. This may explain the observed quantification differences between $\mathrm{Sr}$ and the other metal ions, $\mathrm{Cs}$ and $\mathrm{Pb}$.

Table 12. Comparison of percent monolayer coverage of UE18R 2228 powders as determined by total strontium uptake and XPS.

\begin{tabular}{lcl}
\hline Samples & Total uptake & XPS \\
\hline UE18R 2228 Matrix & 4.2 & 4.7 \\
UE18R 2228 Fracture & 2.5 & 4.2 \\
\hline
\end{tabular}

In addition to the powders, core samples following the diffusion experiments were analyzed by XPS to determine the surface coverage of the core by the metals of interest. The percent monolayer coverage of cores UE20c 2908 and UE20c 2855 matrix as determined by XPS is shown in Table 13. Several spots were analyzed on each core to obtain an estimate of sorption variability as a function of surface mineralogy. The spot size varied from 100 to $400 \mu \mathrm{m}$, depending on grain size analyzed. As can be seen from Table 13, only $\mathrm{Pb}$ was detectable on these cores. Neither Cs nor Sr could be detected, despite the numerous scans collected. The surface coverage for $\mathrm{Pb}$, however, exceeded the highest surface coverages obtained on the powders.

Table 13. Percent monolayer coverage of WPM cores by Pb, Cs, and Sr, as determined by XPS.

\begin{tabular}{lcll}
\hline Samples & $\mathrm{Pb}$ & $\mathrm{Cs}$ & $\mathrm{Sr}$ \\
\hline UE20C 2855 Matrix & & & \\
Spot \#1 & 9.3 & $\mathrm{ND}$ & $\mathrm{ND}$ \\
Spot \#2 & 10.1 & $\mathrm{ND}$ & $\mathrm{ND}$ \\
Spot \#3 & 11.9 & $\mathrm{ND}$ & $\mathrm{ND}$ \\
UE20C 2908 & & & \\
Spot \#1 & 16.1 & $\mathrm{ND}$ & $\mathrm{ND}$ \\
Spot \#2 & 21.4 & $\mathrm{ND}$ & $\mathrm{ND}$ \\
\hline
\end{tabular}

ND indicates "not detected."

These results complement and help interpret the diffusion experiments and have significant implications for the migration of radionuclides in the WPM of the NTS. First, the relatively significant variation of sorption as a function of location, especially on UE20c 2908, is an indication of the importance of surface heterogeneity. In addition, the differences in the behavior of the three elements are important. The relatively high percent monolayer surface coverage of $\mathrm{Pb}$, compared to the powder samples, can be explained by the experimental protocol used for the diffusion experiments. Because of the high sorption capacity of the rock for $\mathrm{Pb}$, the tracer solution was replaced daily with $10^{-5} \mathrm{M}$ solution. Higher solution concentration could not be used to prevent $\mathrm{Pb}$ precipitation. The repeat application of fresh $\mathrm{Pb}$ solutions, however, 
resulted in the increased surface coverage, because of the high sorption affinity of $\mathrm{Pb}$ for the rock. The surface coverages measured, however, do not necessarily suggest the formation of a surface precipitate.

It is significant to contrast the sorption of $\mathrm{Pb}$ to the sorption of $\mathrm{Sr}$ and $\mathrm{Cs}$ under these conditions. The absence of any detectable Sr signal is not surprising given the low sorption capacity of these samples for Sr. The essential absence of a Cs signal from the core surfaces, however, is significant and points to the substantially higher sorption affinity of $\mathrm{Pb}$ for these surfaces compared to Cs. These results are in complete agreement with the behavior observed in the diffusion experiments, where a breakthrough of first Sr and then Cs was observed, but not $\mathrm{Pb}$. The XPS experiments help explain this behavior by suggesting that the substantial sorption of $\mathrm{Pb}$ on the external surfaces of the core can account for the extreme retardation and absence of breakthrough. Contrary to that, $\mathrm{Cs}$ and $\mathrm{Sr}$ appear to migrate easily through the core. These results have significant implications for the migration of common radionuclides on the WPM of the NTS.

\section{SUMMARY AND CONCLUSIONS}

Sorption and desorption experiments were conducted with five different cores from the Western Pahute Mesa (WPM) on the NTS. These cores included samples PM-1 4823, PM-2 4177, UE18R 2228, UE20c 2855, and UE20c 2908. Samples PM-1 4823, UE18R 2228, and UE20c 2855 included visible fracture surfaces with coatings, so an attempt was made to separate the part of the core that includes the fracture surface from the rest of the core, resulting in "fracture" and "matrix" samples for the three samples PM-1 4823, UE18R 2228, and UE20c 2855. A total of eight samples were therefore produced, PM-1 4823 Matrix, PM-1 4823 Fracture, PM-2 4177, UE18R 2228 Matrix, UE18R 2228 Fracture, UE20c 2855 Matrix, UE20c 2855 Fracture, and UE20c 2908.

The eight samples were reduced in size and were characterized. Mineralogical characterization was performed by the Los Alamos National Laboratory. In addition, the samples were examined by scanning electron microscopy and energy dispersive X-rays. The specific surface area of the adsorbents was measured by nitrogen adsorption as a function of particle size. The bulk density and porosity of the cores was also determined. Finally, the composition of the surfaces, powders, cores, and pieces of rock, was examined using x-ray photoelectron spectroscopy (XPS), in an attempt to focus specifically on the surfaces, where radionuclides interact with minerals and other aquifer materials.

All these samples are different types of tuff or devitrified lava with similar composition. The majority of the samples consisted of feldspars (50 to 66 percent) and a substantial amount of quartz (28 to 39 percent). Additional minor components included smectite, mica, kaolinite, and hematite. With the exception of sample UE18R 2228, which had a surface area of about $1 \mathrm{~m}^{2} \mathrm{~g}^{-1}$, the rest of the samples had surface areas between 3 and $5 \mathrm{~m}^{2} \mathrm{~g}^{-1}$. The surface area of the samples was correlated to their porosity, which ranged from 2 percent for UE18R 2228 Fracture to 29 percent for UE20c 2908.

Both macroscopic and spectroscopic experiments were conducted with the eight samples. The macroscopic experiments included sorption and desorption experiments and core diffusion experiments with conservative and reactive tracers. Bromide was used as the conservative tracer and $\mathrm{Sr}, \mathrm{Cs}$, and $\mathrm{Pb}$ were the reactive tracers. Based on sorption data with different solid and metal concentrations, linear sorption isotherms were derived for sorption at $\mathrm{pH} 8.3$, representing 
a common NTS groundwater $\mathrm{pH}$. Following sorption, desorption experiments were conducted to determine the reversibility of the sorption reactions. These experiments were conducted as a function of time to better understand kinetic aspects of the desorption processes. Based on the desorption experiments, linear desorption isotherms were also derived.

The sorption experiments can be summarized as follows. Lead was the most reactive metal ion and exhibited considerable $\mathrm{pH}$-dependent behavior. Typical $K_{\mathrm{d}} \mathrm{s}$ for $\mathrm{Pb}$ sorption were 1 to $5 \times 10^{-3} \mathrm{~m}^{3} \mathrm{~g}^{-1}$. The sorption of Cs was much less $\mathrm{pH}$-dependent and was overall substantially reduced compared to $\mathrm{Pb}$. Typical $K_{\mathrm{d}} \mathrm{S}$ for Cs were approximately one order of magnitude less than $\mathrm{Pb} K_{\mathrm{d}} \mathrm{S}\left(1\right.$ to $\left.3 \times 10^{-4} \mathrm{~m}^{3} \mathrm{~g}^{-1}\right)$. Although the results were similar for all samples, sample PM-2 4177 appeared to be slightly more reactive than the other solids, a fact consistent with the mineralogical composition of this solid. Strontium sorption was almost negligible for all solids, especially at the lower concentrations. The minimal Sr sorption was caused, at least partly, by the substantial amount of Sr already present in these cores. Under these conditions, therefore, $\mathrm{Sr}$ would be very mobile. Sorption isotherms, therefore, were not reported for Sr.

The desorption experiments resulted in isotherms that were compared to the sorption isotherms. In all cases, $K_{\mathrm{d}} \mathrm{S}$ obtained from desorption experiments were higher than the $K_{\mathrm{d}} \mathrm{s}$ obtained from sorption experiments. The differences were in several cases relatively small, typically less than a factor of two, but in the case of UE18R 2228, the desorption $K_{\mathrm{d}} \mathrm{S}$ were higher than the sorption $K_{\mathrm{d}} \mathrm{S}$ by almost an order of magnitude. This is an additional manifestation of the differences between the UE18R 2228 welded tuff sample and the rest of the WPM samples. Based on these experiments, sorption of $\mathrm{Pb}$ and $\mathrm{Cs}$ was not completely reversible. These results have significant implications for the migration of radionuclides on the NTS.

Diffusion experiments with the entire core were conducted with a nonreactive tracer, bromide, before experiments with the reactive tracers, $\mathrm{Pb}, \mathrm{Cs}$, and $\mathrm{Sr}$. Based on the bromide diffusion experiments, effective diffusivities and tortuosities were estimated. The effective diffusivities appeared to be directly correlated to sample porosity. The tortuosities, therefore, were inversely related to sample porosity. This behavior has been observed frequently. The lowest tortuosity, 8.94, was observed for sample PM-1 4823 Matrix, while the highest tortuosity, 4526, was observed for the low porosity, densely welded tuff UE18R 2228 sample. The effective diffusivities and corresponding tortuosities measured are within an acceptable range.

Diffusion experiments with the reactive tracers $\mathrm{Pb}, \mathrm{Cs}$, and $\mathrm{Sr}$ were performed simultaneously with all cores. These experiments were interpreted by the time-lag method and resulted in estimation of another set of $K_{\mathrm{d}} \mathrm{S}$ and overall apparent diffusivities. A comparison was attempted between $K_{\mathrm{d}} \mathrm{s}$ determined based on equilibrium sorption experiments with powders and the diffusion experiments with cores. This comparison was possible only in the case of Cs; for $\mathrm{Sr}$, because of limited sorption, no equilibrium $K_{\mathrm{d}} \mathrm{S}$ were determined for the powders, and the high retardation of $\mathrm{Pb}$ prevented any breakthrough in any of the cores. Based on the diffusion experiments, Sr retardation was very limited, in some cases barely above 1, although no breakthrough was observed for the densely welded tuff UE18R 2228 sample. The retardation factors for Cs were substantially higher and ranged from approximately 10 to 30 . The retardation factors that were calculated from the $K_{\mathrm{d}} \mathrm{s}$ derived from the equilibrium experiments with powders were one to two orders of magnitude higher. No retardation factors for $\mathrm{Pb}$ could be calculated from the core-diffusion experiments, because no $\mathrm{Pb}$ breakthrough was observed in any of the samples. These results were consistent with the very high retardation predicted from the 
equilibrium experiments with powders. The predicted retardation for $\mathrm{Pb}$ ranged approximately from 14,000 to 70,000. Under these conditions, $\mathrm{Pb}$ would be immobile.

Both core and powder samples were examined by x-ray photoelectron spectroscopy, before and after sorption and diffusion experiments, to obtain additional information on surface composition and to help distinguish between different sorption mechanisms for the trace elements of interest. The elemental surface composition determined by XPS was consistent with the known sample mineralogy, namely a combination of mostly feldspars and quartz, with limited amount of iron. In addition to the surface composition, XPS allowed us to distinguish between different chemical states of elements. The binding energies (BEs) determined for the major cations and oxygen were consistent with expected BEs in aluminosilicates. The BEs for $\mathrm{Cs}, \mathrm{Pb}$, and $\mathrm{Sr}$ were consistent with the expected coordination environment of these metals under these conditions, although additional studies would be required to establish a better database of BEs as a function of coordination environment for these elements.

The surface coverage of adsorbents by $\mathrm{Cs}, \mathrm{Pb}$, and $\mathrm{Sr}$ was independently determined by XPS measurements following the sorption and diffusion experiments. These surface coverages were compared to estimates from macroscopic uptake experiments. The XPS measurements of surface coverage agreed well with the estimates from sorption experiments, except for the UE18R 2228 sample. The different porosity of this sample, compared to the others, could be a possible reason for the observed difference. Examination of the core diffusion samples could be used to explain the metal-ion-diffusion results with cores. Lead was the only metal that could be easily detected on the external surface of the cores. Lead surface coverage ranged from 9 to 21 percent of a monolayer. These results suggest that even after repeat loadings, $\mathrm{Pb}$ is still removed by sorption rather than surface precipitation. The relatively high surface coverage of $\mathrm{Pb}$, however, explains the high $\mathrm{Pb}$ retardation. Similarly, the fact that neither $\mathrm{Cs}$ nor $\mathrm{Sr}$ could be detected explains the relatively fast breakthrough of these elements.

In summary, sorption, desorption, diffusion, and spectroscopic experiments with five different samples from the WPM and three additional subsamples were used to reduce the uncertainty of modeling interactions of radionuclides with mineral surfaces. These experiments clearly show the difference in degree of interaction between different metal ions with different aquifer materials. Retardation factors were obtained from both equilibrium sorption experiments with powder samples and from diffusion experiments. The retardation in diffusion cores was substantially lower than predicted from equilibrium, batch sorption experiments. Sorption of both $\mathrm{Cs}$ and $\mathrm{Pb}$ was not entirely reversible and the stronger the sorption, the less reversible was the reaction. The spectroscopic experiments allowed distinction between different possible sorption mechanisms and helped explain observations from macroscopic sorption experiments.

In summary, this work demonstrated the significance of aquifer material properties on the observed radionuclide transport behavior and the importance of a combination of studies to reduce transport modeling uncertainties. Specifically, from a modeling perspective point of view, the following general comments are relevant:

- Retardation of radionuclides and other inorganic ions (anions and cations) can be highly dependent on the sorbing phase, even for materials originating from the same general area. Careful characterization of the aquifer materials is therefore necessary to identify the important reactive surfaces. 
- The characterization must include mineralogy, elemental composition, density, porosity, specific surface area, potential coatings, as well as surface characterization by microscopy and spectroscopic techniques. This characterization must be performed at the scale relevant to the study, or if this is not possible, an attempt to extrapolate to the larger, field scale must be outlined. A large enough number of samples must be analyzed to provide a measure of heterogeneity and uncertainty in the results.

- Sorption data have been obtained from batch equilibrium and core diffusion experiments. Although batch equilibrium experiments with crushed rock have been frequently criticized because they destroy the original structure of the rock, they also provide statistically more reliable data and result in more controlled experiments that can be used to evaluate important reactive properties of the material. In addition, sorption experiments with crushed rock can typically provide an upper limit for equilibrium sorption and retardation.

- Diffusion experiments can often provide a more realistic picture of radionuclide migration through rock. The retardation factors obtained from diffusion experiments are frequently lower, compared to batch equilibrium experiments with crushed rock. Comparisons of retardation factors must account for surface area differences. In addition, heterogeneity and reproducibility of the results becomes more of an issue, depending on the structure of specific samples used.

- Spectroscopic and surface-sensitive examination of the surfaces can yield information that cannot be obtained by macroscopic techniques and help distinguish between retardation mechanisms. Sample heterogeneity is an important factor in surface investigations as well. In addition, surface investigations can provide information that cannot be obtained by bulk techniques.

With respect to specific results obtained during this project:

- In general, the chromate cation was much more mobile than either $\mathrm{Cs}$ or $\mathrm{Pb}$. In general, most anions tend to be mobile in most environments. Although at times overly conservative, assuming no retardation of anions might be justifiable.

- Although $\mathrm{Sr}$ is a fairly reactive radionuclide, the retardation may be highly dependent on the natural Sr background in the surrounding rock. In the samples studied, Sr appeared to be highly mobile because of the high Sr concentration in the rock matrix. Under these conditions, assuming a retardation factor of 1 might be a reasonable conservative assumption.

- Lead and any transuranic radionuclide equally or more reactive than $\mathrm{Pb}$ is essentially too reactive to be transported significantly. Under these conditions, these types of radionuclides could be considered to be immobile, unless their transport is facilitated by colloids.

- Distribution coefficients based on sorption and desorption experiments were relatively similar and can be used to bracket an expected sorption behavior. The difference between sorption and desorption properties tends to be a factor of several parameters, including sorbing-phase mineralogy. Either sorption- or desorption-derived retardation factors would provide reasonable estimates of migration potential. 
- With respect to choosing between retardation derived from equilibrium or diffusion experiments, the results from the diffusion experiments would definitely be more appropriately applied to matrix diffusion. One must always keep in mind, however, that any fractures in the direction of the flow could significantly accelerate transport. The question always arises as to how representative experiments of the laboratory scale are to field-scale transport modeling; what degree of variability exists between samples and how many measurements would be required to produce a statistically significant result. Retardation along transmissive fractures would certainly be a function of flow conditions. As long as groundwater velocity is low enough, $K_{\mathrm{d}} \mathrm{s}$ from sorption isotherms would be applicable, provided the mineralogical composition of the samples is similar and the $K_{\mathrm{d}}$ data are scaled with respect to available surface area, another elusive quantity at the field scale.

\section{REFERENCES}

Baes, C.F., Jr. and R.E. Mesmer, 1986. The Hydrolysis of Cations. Krieger, Malabar, FL, 489 pp.

Bargar, J.R., G.E. Brown Jr. and G.A. Parks, 1998. Surface complexation of Pb(II) at oxidewater interfaces: III. XAFS determination of $\mathrm{Pb}(\mathrm{II})$ and $\mathrm{Pb}$ (II)-chloro adsorption complexes on goethite and alumina. Geochim. Cosmochim. Acta. 62, 193-207.

Berner, R.A., 1971. Principles of Chemical Sedimentology. McGraw Hill, New York, 240 pp.

Biino, G.G. and P. Gröning, 1998. Cleavage mechanism and surface chemical characterization of phengitic muscovite and muscovite as constrained by X-ray photoelectron spectroscopy. Phys. Chem. Minerals, 25, 168-181.

Briggs, D. and M.P. Seah, 1990. Practical Surface Analysis, Volume 1, Auger and X-ray Photoelectron Spectroscopy. John Wiley \& Sons, New York, 657 pp.

Brown, N.A., 2000. Modeling the diffusion of reactive and nonreactive solutes in cores from the Cannikin Test Site, Amchitka Island, Alaska. M.S. Thesis, Water Resources Management Program, University of Nevada, Las Vegas.

Brunauer S., P.H. Emmet and E. Teller, 1938. Adsorption of gases in multimolecular layers. $J$. Am. Chem. Soc. 60, 309-319.

Brundle, C.R. and A.D. Baker, 1978. Electron Spectroscopy: Theory, Techniques and Applications, 2. Academic Press, London, 287 pp.

Chisholm-Brause, C.J., A.L. Roe, K.F. Hayes, G.E. Brown, Jr., G.A. Parks and J.O. Leckie, 1989. XANES and EXAFS study of aqueous $\mathrm{Pb}(\mathrm{II})$ adsorbed on oxide surfaces. Physica $B$. $158,674-675$.

Choi,J.-W. and D.W. Oscarson, 1996. Diffusive transport through compacted Na- and Cabentonite. J. Contam. Hydrol. 22, 189-202.

Crank, J., 1975. The Mathematics of Diffusion. $2^{\text {nd }}$ ed. Oxford University Press, London, 414 pp.

Curtis, G.P., M. Reinhard and P.V. Roberts, 1986. Sorption of hydrophobic organic compounds by sediments. In Geochemical Processes at Mineral Surfaces, (edited by J.A. Davis and K.F. Hayes), ACS Symposium Series, No. 323. American Chemical Society, Washington, D.C., $683 \mathrm{pp}$. 
Curtis, G.P., P.V. Roberts and M. Reinhard, 1986. A natural gradient experiment on solute transport in a sand aquifer 4. Sorption of organic solutes and its influence on mobility. Water Resour. Res. 22, 2059-2067.

Drever, J.I., 1997. The Geochemistry of Natural Waters. $3^{\text {rd }}$ edition, Prentice Hall, $436 \mathrm{pp}$.

Farquhar, M.L., D.J. Vaughan, C.R. Hughes, J.M. Charnock and K.E.R. England, 1997. Experimental studies of the interaction of aqueous metal cations with mineral substrates: Lead, cadmium and copper with perthitic feldspar, muscovite and biotite. Geochim. Cosmochim. Acta. 61, 3051-3064.

Fetter, C.W., 1994. Applied Hydrogeology. Prentice Hall, Inc., 691 pp.

Fetter, C.W., 1997. Contaminant Hydrogeology. Prentice Hall, Inc., 458 pp.

Hoag, R.S. and J.S. Price, 1997. The effects of matrix diffusion on solute transport and retardation in undisturbed peat in laboratory columns. J. Contam. Hydrol. 28, 193-205.

Hölttä P., M. Hakanen, A. Hautojärvi, J. Timonen and K. Väätäinen, 1996. The effects of matrix diffusion on radionuclide migration in rock column experiments. J. Contam. Hydrol. 21, 165173.

Hochella, M.F., Jr., 1988. Auger electron and X-ray photoelectron spectroscopies. In Spectroscopic Methods in Mineralogy and Geology (edited by F.C. Hawthorne), Reviews in Mineralogy. 18, 573-637.

Hochella, M.F., Jr., 1990. Atomic structure, microtopography, compound and reactivity of mineral surfaces. In Mineral-Water Interface Geochemistry (edited by M.F. Hochella, Jr. and A.F. White), Reviews in Mineralogy. 23, 87-132.

Jean, G.E. and G.M. Bancroft, 1985. An XPS and SEM study of gold deposition at low temperatures on sulphide mineral surfaces: Concentration of gold by adsorption/reduction. Geochim. Cosmochim Acta. 49, 979-987.

Kelly, M.A., 1986. Electron spectroscopy for chemical analysis. In Encyclopedia of Materials Science and Engineering, (edited by M.B. Bever), No. 2. Pergamon Press, Oxford, 14621467.

Koch S. and H. Flühler, 1993. Non-reactive solute transport with micropore diffusion in aggregated porous media determined by a flow-interruption method. J. Contam. Hydrol. 14, 39-54.

Moridis, G.J., 1998. A set of semianalytical solutions for parameter estimation in diffusion cell experiments. LBNL-41857, Earth Sciences Division, Lawrence Berkeley National Laboratory, Berkeley, CA 94720.

Neretnieks, I., 1980. Diffusion in the rock matrix: An important factor in radionuclide retardation. J. Geophys. Res., 85, 4379-4397.

Papelis, C., 1995. X-ray photoelecton spectroscopic studies of cadmium and selenite adsorption on aluminum oxides. Environ. Sci. Technol. 29, 1099-1108.

Papelis, C. and K.F. Hayes, 1996. Distinguishing between interlayer and external sorption sites of clay minerals using x-ray absorption spectroscopy. Colloids \& Surfaces, A. 107, 89-96. 
Paterson, E. and R. Swaffield, 1994. X-ray photoelectron spectroscopy. In Clay Mineralogy: Spectroscopic and Chemical Determinative Methods (edited by M.J. Wilson). Chapman \& Hall, London, pp 226-259.

Perry, D.L., J.A. Taylor and C.D. Wagner, 1990. X-ray induced photoelectron and Auger spectroscopy. In Instrumental Surface Analysis of Geologic Materials (edited by D.L. Perry), VCH Publishers, New York, 45-86.

Raeburn, S.P., E.S. Ilton and D.R. Veblen, 1997. Quantitative determination of the oxidation state of iron in biotite using X-ray photoelectron spectroscopy: II. In situ analyses. Geochim. Cosmochim Acta. 61, 4531-4537.

Reid, R.C., J.M. Prausnitz and T.K. Sherwood, 1977. The Properties of Gases and Liquids. $3^{\text {rd }}$ Edition. New York, McGraw-Hill, 688 pp.

Robin, M.J.L., R.W. Gillham and D.W. Oscarson, 1987. Diffusion of strontium and chloride in compacted clay-based materials. Soil Sci. Soc. Am. J. 51, 1102-1108.

Scofield, J.H., 1976. Hartree-Slater subshell photoionization cross sections at 1254 and $1487 \mathrm{eV}$. J. Electron Spectr. Rel. Phen. 8, 129-137.

Shackelford, C.D., 1991. Laboratory diffusion testing for waste disposal - A review. J. Contam. Hydrol. 7, 177-217.

Skagius, K. and I. Neretnieks, 1986. Porosities and diffusivities of some nonsorbing species in crystalline rocks. Water Resour. Res. 22, 389-398.

Sloop, D.A., 1998. Equilibrium Studies of Ion Sorption on Zeolitized Tuff from Rainier Mesa, Nye County, Nevada. M.S. Thesis, University of Nevada, Las Vegas.

Sposito, G., 1986. Distinguishing adsorption from surface precipitation. In Geochemical Processes at Mineral Surfaces, (edited by J.A. Davis and K.F. Hayes), ACS Symposium Series, No. 323. American Chemical Society, Washington, D.C., 217-228.

Tachi, Y., T. Shibutani, H. Sato and M. Yui, 1998. Sorption and diffusion behavior of selenium in tuff. J. Contam. Hydrol. 35, 77-89.

Turner, N.H., 1992. Estimates of peak areas and relative atomic amounts from wide-scan XPS spectra. Surf. Interface Anal. 18, 47-51.

Yamaguchi, T., Y. Sakamoto, S. Nakayama and T.T. Vandergraaf, 1997. Effective diffusivity of the uranyl ion in a granite from Inada, Ibaraki, Japan. J. Contam. Hydrol. 26, 109-117.

Wood,W.W., T.F. Kraemer and P.P. Hearn, Jr., 1990. Intragranular diffusion: An important mechanism influencing solute transport in clastic aquifers? Science. 247, 1569-1572. 


\section{DISTRIBUTION}

Jim Aldrich

Los Alamos National Laboratory

P.O. 1663, M/S D-462

Los Alamos, NM 87545

Bob Bangerter

Environmental Restoration Division

Nevada Site Office

National Nuclear Security Administration

U.S. Department of Energy

P.O. Box 98518

Las Vegas, NV 89193-8518

Rick Betteridge, Director

Technology Division

Nevada Site Office

National Nuclear Security Administration

U.S. Department of Energy

P.O. Box 98518

Las Vegas, NV 89193-8518

Melody Bell

Office of Business Affairs

Nevada Site Office

National Nuclear Security Administration

U.S. Department of Energy

P.O. Box 98518

Las Vegas, NV 89193-8518

Jeff Daniels

Lawrence Livermore National Laboratory

P.O. Box 808

M/S J514 CST-7

Livermore, CA 94551

Barbara Deshler

Shaw Environmental, Inc.

7710 W. Cheyenne

Las Vegas, NV 89129

Dave Finnegan

Los Alamos National Laboratory

P.O. Box 1663, M/S J-514, CST-7

Los Alamos, NM 87545
Ward Hawkins

Los Alamos National Laboratory

P.O. Box 1663, M/S F-665

Los Alamos, NM 87545

Bruce Hurley

Hydrology Program Manager

Environment, Safety \& Health Division

Nevada Site Office

National Nuclear Security Administration

U.S. Department of Energy

P.O. Box 98518

Las Vegas, NV 89193-8518

Kenneth Hoar, Director

Environment, Safety \& Health Division

Nevada Site Office

National Nuclear Security Administration

U.S. Department of Energy

P.O. Box 98518

Las Vegas, NV 89193-8518

Marjory Jones

Division of Hydrologic Sciences

Desert Research Institute

2215 Ragio Parkway

Reno, NV 89512-1095

Randy Laczniak

Water Resources Division

U.S. Geological Survey

6770 S. Paradise Rd.

Las Vegas, NV 89119

Dirk Schmidhofer

Stockpile Stewardship Division

Nevada Site Office

National Nuclear Security Administration

U.S. Department of Energy

P.O. Box 98518

Las Vegas, NV 89193-8518

Ken Ortego

Bechtel Nevada

P.O. Box 98521

Las Vegas, NV 89193-8521 
Gayle Pawloski

Lawrence Livermore National Laboratory

P.O. Box 808 L-221

Livermore, CA 94551

Ken Rehfeldt

HSI-GeoTrans

7710 W. Cheyenne

Las Vegas, NV 89129

Tim Rose

Lawrence Livermore National Laboratory

P.O. Box 808, M/S L-231

Livermore, CA 94551

Chuck Russell

Division of Hydrologic Sciences

Desert Research Institute

755 E. Flamingo Road

Las Vegas, NV 89119-7363

David Shafer

Division of Hydrologic Sciences

Desert Research Institute

755 E. Flamingo Road

Las Vegas, NV 89119-7363

Bonnie Thompson

Water Resources Division

U.S. Geological Survey

6770 S. Paradise Rd.

Las Vegas, NV 89119

Rick Waddell

HSI-GeoTrans

9101 Harlan Street, Ste. 210

Westminster, CO 80030

Janet Wille

Shaw Environmental, Inc.

7710 W. Cheyenne

Las Vegas, NV 89129

Nevada State Library and Archives

State Publications

100 North Stewart Street

Carson City, NV 89701-4285

Archives

Getchell Library

University of Nevada, Reno
DeLaMare Library/262

University of Nevada, Reno

Document Section, Library

University of Nevada, Las Vegas

4505 Maryland Parkway

Las Vegas, NV 89154

Shaw Environmental, Inc.

P.O. Box 93838

Bldg. B-1, M/S 439

Las Vegas, NV 89193-3838

ATTN: Toni Miller, M/S 439

Library

Southern Nevada Science Center

Desert Research Institute

755 E. Flaming Road

Las Vegas, NV 89119-7363

Public Reading Facility

Nevada Site Office

National Nuclear Security Administration

U.S. Department of Energy

P.O. Box 98521

Las Vegas, NV 89193-8521

Technical Library

Nevada Site Office

National Nuclear Security Administration

U.S. Department of Energy

P.O. Box 98518

Las Vegas, NV 89193-8518

Office of Scientific and Technical Information

U.S. Department of Energy

P.O. Box 62

Oak Ridge, TN 37831-9939

(electronic copy) 